\title{
A synopsis of the genus Bursaphelenchus Fuchs, 1937 (Aphelenchida: Parasitaphelenchidae) with keys to species
}

\author{
Alexander RYSS ${ }^{1}$, Paulo VIEIRA ${ }^{2, *}$, Manuel MotA ${ }^{2}$ and Oleg KULINICH ${ }^{3}$ \\ ${ }^{1}$ Zoological Institute RAS, Universitetskaya Naberezhnaya 1, St Petersburg 199034, Russia \\ ${ }^{2}$ NemaLab-ICAM, Departamento de Biologia, Universidade de Évora, 7002-554 Évora, Portugal \\ ${ }^{3}$ Institute of Parasitology RAS, Leninskii Prospect 33, Moscow 117071, Russia
}

Received: 12 February 2004; revised: 19 April 2005

Accepted for publication: 20 April 2005

\begin{abstract}
Summary - The 75 valid species of the genus Bursaphelenchus are listed together with their synonyms. Diagnostic characters and their states are discussed and illustrated. Tabular and traditional text keys are provided for the genus. Two new subspecies are proposed to distinguish populations of B. piniperdae and B. poligraphi, as described by Rühm (1956), from the original descriptions of these species published by Fuchs (1937). Known records of Bursaphelenchus species with their associated natural vectors, plants and plant families are given. Dendrograms of species relationships (UPGMA, standard distance: mean character difference) based on combined taxonomic characters and also on spicule characters only, are provided. Discussion as to whether the species groups are natural or artificial (and therefore purely diagnostic) is based on their relationships in the dendrogram and the vector and associated plant ranges of the species. Of the six species groups distinguished, two appear to represent natural assemblages, these being the xylophilus-group (with ten species) and the hunti-group (seven species), of which two, B. cocophilus and B. dongguanensis, form the cocophilus-cluster which is separated on the dendrogram from the main clusters. The remaining four species groups appear to be artificial and purely diagnostic in function, namely the aberrans-group (four species); the eidmanni-group (six species); the borealis-group (five species), and the piniperdae-group (43 species). Two new subspecies, both in the piniperdae-group, viz. B. piniperdae ruehmpiniperdae n. subsp. and B. poligraphi ruehmpoligraphi n. subsp., are proposed and diagnosed from B. piniperdae piniperdae and B. poligraphi poligraphi the respective type subspecies. Bursaphelenchus dongguanensis is regarded as being a valid member of the genus and its transfer to Parasitaphelenchus is rejected.
\end{abstract}

Keywords - associated plants, dendrogram, key, morphology, new subspecies, taxonomy, vectors.

The genus Bursaphelenchus Fuchs, 1937 was established by Fuchs (1937) and includes nematodes that are associated with insects and dead or dying, mainly coniferous, trees and which have an ectophoretic stage. The type species is B. piniperdae Fuchs, 1937. Most species are fungal feeders and are either transmitted to dead or dying trees during oviposition by insect vectors, or to healthy trees during maturation feeding of their insect vectors. The majority of vectors are beetles, mostly from the Scolytidae, Cerambycidae, Curculionidae and Buprestidae (see Appendix). Until recently, only one species of the genus, Bursaphelenchus cocophilus (Cobb, 1919) Baujard, 1989, was recorded outside of the northern hemisphere. However, with the record of B. leoni Baujard, 1980 in South Africa (Braasch et al., 1998), and more recently a Bursaphelenchus sp. from dying pine (Pinus halepensis Miller) in Australia (Ridley et al., 2001), the known range of the genus has significantly increased. Of the total number of known species, approximately $70 \%$ are associated with conifers, mainly Pinus spp. (Vieira $e t$ al., 2003; Braasch, 2004a).

In western Europe the species composition, distribution and associated plants of Bursaphelenchus have been studied especially thoroughly in Austria, Germany, Greece, Italy (Braasch et al., 2000; Braasch, 2001, 2004a), Finland (Tomminen et al., 1989), Cyprus (Braasch \& Philis, 2002), Portugal (Penas et al., 2004) and Spain (Abelleira et al., 2003). In Eastern Europe, the longest species lists have been published for Georgia (Kurashvili et al., 1980) and Russia (Korentchenko, 1980; Braasch, 2001).

In Asia, first in Japan (Mamiya \& Kiyohara, 1972) and later in China (Cheng, 1983), Taiwan (Tzean \& Jan, 1985)

\footnotetext{
*Corresponding author, e-mail: pvieira@uevora.pt
} 
and Korea (Yi et al., 1989), special attention was paid to this group after the detection of the pathogenicity of the pine wood nematode, B. xylophilus (Steiner \& Buhrer, 1934) Nickle, 1970, in pine trees in Japan (Kiyohara \& Tokushige, 1971). More recently, new species and reports have increased our knowledge of Bursaphelenchus species diversity within this broad area (Dan \& Yu, 2003; Kanzaki \& Futai, 2003; Tomiczek et al., 2003; Braasch, 2004b; Palmisano et al., 2004).

Bursaphelenchus xylophilus is considered to be indigenous to North America (Robbins, 1982; Rutherford et al., 1990). On the American continent several other Bursaphelenchus species have been recorded, a number being described as new to science (Steiner, 1932; Massey, 1974; Thong \& Webster, 1983; Giblin-Davis et al., 1993). In the Caribbean and Latin American regions several species have also been found (Loof, 1964; Perez \& Plumas, 1999), although the major focus has been on the red ring nematode, B. cocophilus (Cobb, 1919; Dean, 1979; Araújo et al., 1998; Harrison \& Jones, 2003).

According to Braasch (2001), the American continent has a species list that differs almost completely from those of Europe and Asia, the following species being common to all three regions: B. xylophilus (apparently introduced from America where it is the native species), B. fraudulentus Rühm, 1956 and B. mucronatus Mamiya \& Enda, 1979. The Bursaphelenchus species of Europe and Asia may be divided into three assemblages; two groups being represented by species found in only one continent and the third with species widely distributed in both continents. Detailed data on species distribution, associated plants and vectors are given in Table 2 and Appendix.

Recent studies have suggested that some Bursaphelenchus species may, under particular circumstances, be pathogenic to young pines (Mamiya, 1999; Braasch et al., 2000; Michalopoulos-Skarmoutsos et al., 2004). However, within the genus, only B. cocophilus and B. xylophilus are officially recognised as agricultural and forestry pests of world importance.

Bursaphelenchus cocophilus, otherwise known as the red ring nematode, uses the palm weevil, Rhynchophorus palmarum L., as host and vector. The nematode is responsible for the devastating red ring disease of coconut palm (Cocos nucifera L.), oil palm (Elaeis guineensis Jacquin), and other palms (Dean, 1979; Griffith \& Koshy, 1990). In Venezuela, over a period of more than 10 years, 35\% of oil palms died from red ring disease and, in Tobago, more than $80 \%$ losses were reported in coconut planta- tions (Esser \& Meredith, 1987; Brammer \& Crow, 2001). This species, which is restricted to the American continent, is recorded from a huge area having a tropical climate, including Central and South America and many of the Caribbean islands. It is morphologically distinct from other species of Bursaphelenchus and was previously placed in its own genus - Rhadinaphelenchus J.B. Goodey, 1960. Taking into consideration the large area where coconut palms are grown, this species is regarded as one of the most important nematode pests in the tropics (Griffith \& Koshy, 1990; Brammer \& Crow, 2001).

Bursaphelenchus xylophilus, also known as the pine wood nematode (PWN) and the causal agent of pine wilt disease, is associated with cerambycid beetles, particularly Monochamus spp. It is a pest of many commercially important forestry trees, including pine, spruce, fir, larch and other conifers, thus playing an important role in world and national economies. In 2000, approximately 580000 ha of pine forest in Japan were estimated to be infested by this species, an area corresponding to $28 \%$ of the total area of pine forest (Mamiya, 2004). The damage caused, and rapid spread in Japan and in other Asian countries (Mamiya, 1984, 2004; Yang, 2004), as well the recent detection of PWN in Portugal (Mota et al., 1999) has increased concern that the disease may be disseminated to regions where it is currently absent. For this reason, a number of political measures have been taken, including an EU directive (77/93 updated as 2000/29/EC) aimed at preventing the introduction and spread of this pathogen in Europe by implementing special phytosanitary measures for solid wood packaging materials exported from countries where the nematode has been recorded.

Because of the commercial implications, accurate diagnosis of B. xylophilus is critical. Identification requires a high level of expertise as it is morphologically difficult to distinguish from other, similar species of Bursaphelenchus (Bolla \& Wood, 2004; Braasch, 2004a). In this scenario, special attention is given to those species belonging to the pine wood nematode species complex (PWNSC), a complex of morphologically similar species, such as B. xylophilus and B. mucronatus, which may be capable of genetic exchange, either directly or via intermediate forms (Rutherford et al., 1990). In addition, several other species of Bursaphelenchus are morphologically similar to B. xylophilus and share a combination of characters, including the distinctive angular shape of spicules, presence of four lateral lines and the large vulval flap in females (Braasch, 2001). Taxonomically these species may be considered as the xylophilus-group, a group that in- 
cludes the following nematodes: B. xylophilus; B. abruptus Giblin-Davis, Mundo-Ocampo, Baldwin, Norden \& Batra, 1993; B. conicaudatus Kanzaki, Tsuda \& Futai, 2000; B. fraudulentus; B. kolymensis Korentchenko, 1980; and B. mucronatus (see Braasch, 2001; Kanzaki \& Futai, 2003).

With increasing globalisation and the breaking down of geographical boundaries, new biological invasions by non-indigenous species have become a global environmental problem. According to the Convention on Biological Diversity (CBD), accurate identification to diagnose dangerous invasive species at an early stage is the most important initial phase of programmes for monitoring and control of the environment. Precise data on the distribution of accurately identified world pests, including the PWNSC and B. cocophilus, is therefore necessary to counteract such potent threats.

Morphology remains the standard method for routine identification of nematode species. In the case of Bursaphelenchus, several characteristics have been used, including male spicule shape, presence or absence of a vulval flap and its size, female tail shape, etc. Light microscopical observations have been supplemented by the use of scanning electron microscopy (SEM) (Brzeski \& Baujard, 1997; Braasch, 1998, 2000; Penas et al., 2004). Other techniques, such as sex pheromone analysis, have also been used for species separation (Riga \& Webster, 1992), although precise identification and diagnosis of the species belonging to the pine wood nematode species complex remains a difficult task.

Due to the limitations and constraints of morphological observations, molecular methods have recently become a valuable tool for separating Bursaphelenchus species (Tarès et al., 1993; Hoyer et al., 1998; Mota et al., 1999; Liao et al., 2001; Kanzaki \& Futai, 2002b; Abad, 2004; Iwahori et al., 2004). Of major interest is: i) the molecular characterisation of the nematode rDNA, and in particular the ITS regions (ITS-1 and ITS-2), which appear to be highly conserved within a species (Hoyer et al., 1998; Liao et al., 2001); ii) satellite DNA as a speciesspecific probe (Tarès et al., 1993; Abad, 2004); and iii) homologous DNA probes (Tarès et al., 1992). Intraspecific variability using RAPD-PCR techniques (Braasch et al., 1995; Zhang et al., 2002) and DNA base sequences (18S, 5.8S, ITS1 and ITS2 of rDNA, and mithochondrial cytochrome oxidase subunit I (COI) gene) (Beckenbach et al., 1999; Kanzaki \& Futai, 2002b; Iwahori et al., 2004) has proved very useful for evaluating genetic distances and for assisting the development of phylogenies and pathway analysis of world populations of the pine wood nematode.

The objectives of this paper are: $i$ ) to compile a list of valid species and their synonyms; $i$ ) to create a catalogue of the best morphological characters previously used by taxonomists of the genus; iii) to use these data to construct text and tabular keys to the genus (the tabular key may be later used to develop a computer-aided identification system of the genus); $i v$ ) to perform a critical comparison of the original descriptions of the species; $v$ ) to review the published records of each species, in order to analyse possible links of nematode species with specific taxa of associated insect vectors and host plants; and vi) to construct a dendrogram of the phenetic similarities of the species based on the tabular key to the genus and then to attempt to verify the clusters so formed by linking with published records of their vector taxa and associated plants.

\section{Material and methods}

In this paper, data from the original descriptions of the species were used in addition to other taxonomical studies on the genus plus recent morphological investigations of various species. Material from the collections of the University of Évora (Évora), Institute of Parasitology RAS (Moscow) and the Zoological Institute RAS (St Petersburg), as well as the collection of Drs Ana Catarina Penas and Maria Antónia Bravo, National Agricultural Station (Oeiras, Portugal) were also used.

As male morphology is most relevant for species identification, two columns have been added to the tabular key to give an idea of how many specimens were assessed for the characters used (see Table 1). These columns are: $\mathrm{N} \_$lit $=$the number of males studied from literature sources (drawings, photographs, specific measurements and descriptions of every character listed in the table); and N_coll $=$ the number of specimens studied from various collections.

The following species were studied from mounted material in various slide collections (Table 1): B. borealis Korentchenko, 1980, B. eroshenkii Kolossova, 1998, B. glochis Brzeski \& Baujard, 1997, B. hylobianum (Korentchenko, 1980) Hunt, 1993, B. kolymensis, B. тисronatus, B. pinophilus Brzeski \& Baujard, 1997, B. tusciae Ambrogioni \& Palmisano, 1998 and B. xylophilus. Aphelenchoides ritzemabosi (Schwartz, 1911) Steiner \& Buhrer, 1932 was used as an outgroup. 
The taxonomic analysis and keys are mainly based on a detailed study of literature data supplemented by available collection material. In the catalogue of the diagnostic characters used in the tabular key, references to the main publications are cited when a character was proposed as being of species diagnostic value or was used in keys, differential diagnoses, or in the taxonomic descriptions. A uniform nomenclature of the character states for each character was necessary as different authors have either used various terms for the same character state, or one name to cover different character states (see section on the characters for the tabular key). Line drawings of the diagnostic characters and their states (Figs 2-23) are provided to illustrate accurately each of the character states used in the keys and thereby avoid any ambiguity stemming from subjective interpretation of the descriptive terms employed. The drawings were prepared from original material, slides in our collections, or adapted from published taxonomic descriptions.

A summarised range of the character variability in published descriptions of the species was accepted herein as the range of the character for this species (e.g., a suite of alternative forms for qualitative characters and the minimum and maximum values for quantitative characters). If information on a particular character was absent in the published descriptions and could not be inferred from the illustrations, the species was regarded as indeterminate for this character and was marked by a '?' symbol in the tabular key.

A minimum level of difference between similar species of at least three characters was established for any species to be considered as valid. This criterion was used to appraise the taxonomic status of all currently described Bursaphelenchus species. All published species descriptions and illustrations were considered to be reliable unless proof to the contrary existed.

The number of valid species in this overview is greater than in previous reviews of the genus, an increase due partly to the criteria used and partly because of additional valid species revealed by a detailed study of the previously insufficiently known species proposed in the Chinese, Georgian, German and Russian literature.

Detailed study of character variability in a larger set of species may necessitate revision of the taxonomic status of the nominal taxa proposed herein. However, the purpose of this analysis is to attempt to evaluate the diagnostic data for all Bursaphelenchus species and to define groups of similar species in order to aid further taxonomic research using morphological and molecular methods.
In the species list that follows, references to the pertinent literature, including page numbers, taxonomic information, notes, etc., are cited in square brackets and in a smaller point. This should facilitate referral to the original source.

Genus Bursaphelenchus Fuchs, 1937 [p. 366] $=$ Aphelenchoides (Bursaphelenchus) Fuchs, 1937 (Rühm, 1956)

[p. 218, type-species Bursaphelenchus piniperdae Fuchs, 1937]

= Devibursaphelenchus Kakulia, 1967

[pp. 441-442, type-species Devibursaphelenchus typographi

Kakulia, 1967 = Bursaphelenchus typographi] $=$ Huntaphelenchoides Nickle, 1970

[p. 379, Figs 16, 46, 66, 87, type-species

Bursaphelenchus fungivorus Franklin \& Hooper, 1962] = Omemeea Massey, 1971a

[p. 289, type-species Omemeea maxbassiensis Massey, 1971 = Bursaphelenchus maxbassiensis] = Teragramia Massey, 1974

[p. 213, type-species Teragramia willi Massey, 1974 = Bursaphelenchus willi]

= Ipsaphelenchus Lieutier \& Laumond, 1978

[p. 192, type-species Ipsaphelenchus silvestris Lieutier \&

Laumond, 1978 = Bursaphelenchus silvestris]

$=$ Rhadinaphelenchus J.B. Goodey, 1960b

[pp. 99, 102, type-species Aphelenchus cocophilus

Cobb, 1919 = Bursaphelenchus cocophilus]

\section{DiAGNOSIS}

Based on Nickle (1970), Yin et al. (1988), Hunt (1993) and Braasch (2001).

Adult

Parasitaphelenchidae. Mature female vermiform. Male tail strongly curved ventrally, tip with terminal bursa-like flap of cuticle, tail tip evenly tapering, not spicate. Body length 0.3-1.7 mm. Cuticle annuli fine, $1 \mu \mathrm{m}$ wide or less. Oral disc absent, lips cup-like, lateral lips narrower than others. Stylet less than $30 \mu \mathrm{m}$ long, slender with narrow lumen, basal knobs weak. Anus and rectum functional.

\section{Male}

Spicules separate, hook-like, sometimes linear, but never strongly curved. Spicule rostrum usually prominent and separated from condylus (Figs 1, 2A, D-F), but sometimes fused with condylus to form compact capitulum 
(Fig. 2B). Two or more pairs of caudal papillae present, one adanal and one to four pairs postanal. Gubernaculum absent.

\section{Female}

Tail subconoid, evenly tapering; tip usually smooth, sometimes with simple mucro, but never spicate or with four tubercles; anterior vulval flap present or absent. Postuterine sac present, usually 3-6 vulval body diam. long; $\mathrm{V}=64-92 ; \mathrm{c}^{\prime}=7$ or less.

\section{Dispersal juvenile (insect associate)}

Ectophoretic, with single exception of B. hylobianum, the juveniles of which were found in the haemocoel of the curculionid host (Coleoptera: Curculionidae).

\section{RELATIONSHIPS}

The main diagnostic feature of the Parasitaphelenchidae is the presence of a bursa-like flap of cuticle surrounding the terminal region of the male tail. The family currently contains two valid genera: Bursaphelenchus Fuchs 1937; and Parasitaphelenchus Fuchs, 1930. Bursaphelenchus may be distinguished from Parasitaphelenchus in that the insect-associated juvenile (dispersal juvenile, J3/J4) is usually ectophoretic $v s$ the endoparasitic fourth-stage juvenile being located in the insect haemocoel in Parasitaphelenchus; the spicules are separate in Bursaphelenchus vs usually partially fused in Parasitaphelenchus; and the male tail of Bursaphelenchus is strongly recurved $v s$ more or less straight in Parasitaphelenchus.

Bursaphelenchus differs from the morphologically closest Aphelenchoididae genera (Aphelenchoides Fischer, 1894; Laimaphelenchus Fuchs, 1937; Megadorus J.B. Goodey, 1960; Ruehmapahelenchus J.B. Goodey, 1963; Schistonchus Cobb, 1927 (Fuchs, 1937); Sheraphelenchus Nickle, 1970; Tylaphelenchus Rühm, 1956; Anomyctus Allen, 1940) in the presence of a small bursa-like flap of cuticle on the tip of the male tail $v s$ males lacking a bursalike flap. Bursaphelenchus differs from the genera of the family Ektaphelenchidae (Ektaphelenchus Fuchs, 1937; Cryptaphelenchus Fuchs, 1937; Cryptaphelenchoides J.B. Goodey, 1960; Ektaphelenchoides Baujard, 1984) in having a functional anus and rectum in the female and in having a narrow stylet lumen $v$ s females lacking a functional anus and rectum and stylet usually with a wide lumen.

\section{TYPE SPECIES}

Bursaphelenchus piniperdae piniperdae ${ }^{1)}$ Fuchs, 1937 (by original designation) [pp. 366-370, Figs 66-69] nec Aphelenchoides (Bursaphelenchus) piniperdae apud Rühm, 1956 [pp. 218, 229-230, Fig. 61]

= Aphelenchoides piniperdae (Fuchs, 1937) T. Goodey, 1951 [p. 166]

\section{OTHER SPECIES}

B. aberrans Fang, Zhuo \& Zhao, 2002b [pp. 791-794, Fig. 1, Table 1]

B. abietinus Braasch \& Schmutzenhofer, 2000 [pp. 2-5, Figs 1-3, Table 1]

B. abruptus Giblin-Davis, Mundo-Ocampo, Baldwin, Norden \& Batra, 1993 [pp. 161-172, Figs 1-6]

B. baujardi Walia, Negi, Bajaj \& Kalia, 2003 [pp. 3-5, Fig. 1]

B. bestiolus Massey, 1974 [p. 182, Fig. 121]

B. borealis Korentchenko, 1980 [pp. 1768-1772, Figs 1, 2]

B. chitwoodi Rühm, 1956 (J.B. Goodey, 1960a) [p. 116]

$=$ Aphelenchoides (Bursaphelenchus) chitwoodi Rühm, 1956 [pp. 219, 231, Fig. 62]

B. cocophilus (Cobb, 1919) Baujard, 1989 [p. 324]

= Aphelenchus cocophilus Cobb, 1919 [pp. 203-210]

= Aphelenchus (Chitinoaphelenchus) cocophilus (Cobb, 1919) Micoletzky, 1922 [pp. 586-587]

= Aphelenchoides cocophilus (Cobb, 1919) T. Goodey, 1933 [pp. 217-219. Figs 91, 92]

$=$ Chitinoaphelenchus cocophilus (Cobb, 1919) Chitwood in Corbett, 1959 [pp. 83-86]

$=$ Rhadinaphelenchus cocophilus (Cobb, 1919) J.B. Goodey, 1960b [pp. 98-101, Fig. 1]

B. conicaudatus Kanzaki, Tsuda \& Futai, 2000 [pp. 165168, Fig. 1, Table 1]

B. corneolus Massey, 1966 [p. 428, Fig. 10]

B. crenati Rühm, 1956 (J.B. Goodey, 1960a) [p. 116]

= Aphelenchoides (Bursaphelenchus) crenati Rühm, 1956 [pp. 219, 227-228, Fig. 59]

B. cryphali (Fuchs, 1930) J.B. Goodey, 1960a [p. 116]

= Parasitaphelenchus cryphali Fuchs, 1930 [pp. 635-636, Figs 172, 173]

= Aphelenchoides cryphali (Fuchs, 1930) Fuchs, 1937 [p. 331]

$=$ Shistonchus cryphali (Fuchs, 1930) Skrjabin, Shikhobalova, Sobolev, Paramonov \& Sudarikov, 1954 [p. 310]

$=$ Aphelenchoides (Bursaphelenchus) cryphali (Fuchs, 1930) Rühm, 1956 [pp. 220, 234-235, Fig. 65] 
species inquirenda apud Tarjan \& Baeza-Aragon, 1982 [p. 127]

B. digitulus Loof, 1964 [pp. 203, 235-237, Fig. 14]

B. dongguanensis Fang, Zhao \& Zhuo, 2002a [pp. 109-111; Fig. 1] $]^{2)}$

$=$ Parasitaphelenchus dongguanensis (Fang, Zhao \& Zhuo, 2002) Kaisa, 2005 [pp. 3-5, Figs 1-9, Table 1]

B. eggersi Rühm, 1956 (J.B. Goodey, 1960a) [p. 116]

= Aphelenchoides (Bursaphelenchus) eggersi Rühm, 1956 [pp. 219, 231-233, Fig. 63]

B. eidmanni Rühm, 1956 (J.B. Goodey, 1960a) [p. 116]

= Aphelenchoides (Bursaphelenchus) eidmanni Rühm, 1956 [pp. 220, 238-239, Fig. 69]

B. elytrus Massey, 1971b [pp. 167-168, Fig. 5 (a-e)]

B. eremus Rühm, 1956 (J.B. Goodey, 1960a) [p. 116]

$=$ Aphelenchoides (Bursaphelenchus) eremus Rühm, 1956 [pp. 219, 225-226, Fig. 57]

B. eroshenkii Kolossova, 1998 [pp. 161-164, Figs 1, 2]

B. erosus Kurashvili, Kakulia \& Devdariani, 1980 [pp. 88-89, Fig. 18]

B. eucarpus Rühm, 1956 (J.B. Goodey, 1960a) [p. 116]

= Aphelenchoides (Bursaphelenchus) eucarpus Rühm, 1956 [pp. 219, 226-227, Fig. 58]

B. fraudulentus Rühm, 1956 (J.B. Goodey, 1960a) [p. 116]

= Aphelenchoides (Bursaphelenchus) fraudulentus Rühm, 1956 [pp. 220, 240-241, Fig. 71]

B. fuchsi Kruglik \& Eroshenko, 2004 [pp. 96-98, Fig. 1]

B. fungivorus Franklin \& Hooper, 1962 [pp. 136-139, Figs 1, 2]

= Huntaphelenchoides fungivorus (Franklin \& Hooper, 1962) Nickle, 1970 [p. 389]

B. georgicus Devdariani, Kakulia \& Khavatashili, 1980 [pp. 457-458, Fig. 1]

nomen nudum apud Hunt, 1993 [p. 134]

B. glochis Brzeski \& Baujard, 1997 [pp. 313-317, Figs 45-63, Tables 7, 8]

B. gonzalezi Loof, 1964 [pp. 204-205, 237-239, Fig. 15]

= Huntaphelenchoides gonzalezi (Loof, 1964) Nickle, 1970 [p. 389]

B. hellenicus Skarmoutsos, Braasch \& Michalopoulou, 1998 [pp. 625-628, Figs 1, 2]

B. hofmanni Braasch, 1998 [pp. 616-620, Figs 1, 2]

B. hunanensis Yin, Fang \& Tarjan, 1988 [pp. 3, 4, Figs 1-11, Tables 1, 2]

B. hunti (Steiner, 1935) Giblin \& Kaya, 1983 [pp. 48-49] ${ }^{3)}$ = Aphelenchoides hunti Steiner, 1935 [p. 106, Fig. 27]

$=$ Huntaphelenchoides hunti (Steiner, 1935) Nickle, 1970 [pp. 379, 381, 389-390, Figs 16, 46, 66, 87]

B. hylobianum (Korentchenko, 1980) Hunt, 1993 [p. 132] $]^{4)}$
= Parasitaphelenchus hylobianum Korentchenko, 1980 [pp. 1776-1779, Figs 5, 6, Tables 5, 6]

B. idius Rühm, 1956. (J.B. Goodey, 1960a) [p. 116]

= Aphelenchoides (Bursaphelenchus) idius Rühm, 1956 [pp. 220, 236-237, Fig. 67]

B. incurvus Rühm, 1956 (J.B. Goodey, 1960a) [p. 116]

= Aphelenchoides (Bursaphelenchus) incurvus Rühm, 1956 [pp. 220, 228-229, Fig. 60]

B. kevini Giblin, Swan \& Kaya, 1984 [pp. 178-182, Figs 1-5, Table 1]

B. kolymensis Korentchenko, 1980 [pp. 1772-1776, Figs 3, 4, Tables 3, 4] (Magnusson \& Kulinich, 1996) [pp. 156-159, Figs 1, 2 (redescription of type material with emended diagnosis)]

B. leoni Baujard, 1980 [pp. 170-172, Fig. 2]

B. lini Braasch, 2004b [pp. 3-7, Figs 1, 2, Table 1]

B. luxuriosae Kanzaki \& Futai, 2003 [pp. 565-569, Figs 1, 2, Tables 1-3]

B. maxbassiensis (Massey, 1971) Baujard, 1989 [p. 323]

= Omemeea maxbassiensis Massey, 1971a [pp. 289-291, Fig. 1]

B. minutus Walia, Negi, Bajaj \& Kalia, 2003 [pp. 1-3, Fig. 1]

B. mucronatus Mamiya \& Enda, 1979 [pp. 354-356, Fig. 1]

B. naujaci Baujard, 1980 [pp. 168-170, Fig. 1]

= B. bakeri apud Tarjan \& Baeza-Aragon, 1982 [pp. 127, 130] nec Rühm, 1964 (= junior synonym of $B$. sexdentati Rühm, 1960)

B. newmexicanus Massey, 1974 [pp. 186,188, Fig. 124]

B. nuesslini Rühm, 1956 (J.B. Goodey, 1960a) [p. 116]

$=$ Aphelenchoides (Bursaphelenchus) nuesslini Rühm, 1956 [pp. 219, 237-238, Fig. 68]

B. paracorneolus Braasch, 2000 [pp. 177-181, Figs 1-3, Table 1]

B. pinasteri Baujard, 1980 [pp. 172-175, Fig. 3]

= B. chitwoodi apud Tarjan \& Baeza-Aragon, 1982 [p. 131] (Hunt, 1993, p. 132) nec B. chitwoodi Rühm, 1956

Bursaphelenchus piniperdae ruehmpiniperdae n. subsp. ${ }^{1)}$

$=$ Aphelenchoides (Bursaphelenchus) piniperdae (Fuchs, 1937) Rühm, 1956 [pp. 218, 229-230, Fig. 61] nec Bursaphelenchus piniperdae Fuchs, 1937

B. pinophilus Brzeski \& Baujard, 1997 [p. 310, Figs 2044, Tables 5, 6]

B. pityogeni Massey, 1974 [pp. 186, 190, Fig. 125]

B. poligraphi poligraphi ${ }^{5)}$ Fuchs, 1937 [pp. 370-372, Figs 70-73] (J.B. Goodey, 1960a) [p. 116]

= Aphelenchoides poligraphi (Fuchs, 1937) T. Goodey, 1951 [p. 166] 
B. poligraphi ruehmpoligraphi n. subsp. ${ }^{5)}$

= Aphelenchoides (Bursaphelenchus) poligraphi apud Rühm, 1956 [pp. 219, 233-234, Fig. 64] nec B. poligraphi Fuchs, 1937

B. rainulfi Braasch \& Burgermeister, 2002 [pp. 973-976, Figs 1, 2, Tables 1, 2]

B. ratzeburgii Rühm, 1956 (J.B. Goodey, 1960a) [p. 116] = Aphelenchoides (Bursaphelenchus) ratzeburgii Rühm, 1956 [pp. 218, 224-225, Fig. 56]

B. sachsi Rühm, 1956 (J.B. Goodey, 1960a) [p. 116]

= Aphelenchoides (Bursaphelenchus) sachsi Rühm, 1956 [pp. 220, 235-236, Fig. 66]

B. scolyti Massey, 1974 [pp. 190-191, Fig. 126]

B. seani Giblin \& Kaya, 1983 [pp. 40-41, Figs 1-4]

B. sexdentati Rühm, 1960 (Hunt, 1993) [p. 133]

= Aphelenchoides (Bursaphelenchus) sexdentati Rühm, 1960 [pp. 205-207, Fig. 2]

= B. bakeri Rühm, 1964 [p. 220]; Tarjan \& BaezaAragon, 1982 [pp. 127, 130, 137]

B. silvestris (Lieutier \& Laumond, 1978) Baujard, 1980 [p. 175]

= Ipsaphelenchus silvestris Lieutier \& Laumond, 1978 [pp. 192-194, Fig. 3]

B. sinensis Palmisano, Ambrogioni, Tomiszek \& Brandstetter, 2004 [pp. 57-62, Figs 1-3, Table 1]

B. steineri Rühm, 1956 (J.B. Goodey, 1960a) [p. 116]

= Aphelenchoides (Aphelenchoides) steineri Rühm, 1956 [pp. 212-214, Fig. 52]

B. sutoricus Devdariani, 1974 [pp. 710-711, Fig. 2 (erroneously named Bursaphelenchus welchi on p. 711)]

=B. xerokarterus apud Tarjan \& Baeza-Aragon, 1982 [p. 131] nec B. xerokarterus Rühm, 1956

B. sychnus Rühm, 1956 (J.B. Goodey, 1960a) [p. 116]

= Aphelenchoides (Bursaphelenchus) sychnus Rühm, 1956 [pp. 220, 239-240, Fig. 70]

B. talonus (Thorne, 1935) J.B. Goodey, 1960a [p. 117]

= Aphelenchoides talonus Thorne, 1935 [pp. 132, 137138, Fig. 5 (e-g)]

= Aphelenchoides (Bursaphelenchus) talonus (Thorne, 1935) Rühm, 1956 [p. 241]

B. teratospicularis Kakulia \& Devdariani, 1965 [pp. 187191, Fig. 1]

B. thailandae Braasch \& Braasch-Bidasak, 2002 [pp. 854859, Figs 2, 3, Tables 1, 2]

B. tritrunculus Massey, 1974 [pp. 190, 193, 194, Fig. 128]

B. tusciae Ambrogioni \& Palmisano, 1998 [pp. 242-248, Figs 1-7, Table 1]

B. typographi (Kakulia, 1967) Ebsary, 1991 [p. 91]
= Devibursaphelenchus typographi Kakulia, 1967 [pp. 439-442, Figs 1, 2]

B. vallesianus Braasch, Shönfeld, Polomski \& Burgermeister, 2004 [pp. 72-78, Figs 1-4, Tables 1-3]

B. varicauda Thong \& Webster, 1983 [pp. 312-313, Figs $1,2]$

B. wekuae Kurashvili, Kakulia \& Devdariani, 1980 [pp. 86-87, Fig. 17]

B. wilfordi Massey, 1964 [pp. 151-153, Fig. 8 (c-f)]

B. willi (Massey, 1974) Baujard, 1989 [p. 323]

= Teragramia willi Massey, 1974 [pp. 213, 215-216, Fig. 144]

B. xerokarterus Rühm, 1956 (J.B. Goodey, 1960a) [p. 116]

= Aphelenchoides (Bursaphelenchus) xerokarterus Rühm, 1956 [pp. 219, 222-224, Fig. 55]

B. xylophilus (Steiner \& Buhrer, 1934) Nickle, 1970 [p. 390] [Nickle et al., 1981, pp. 391-392, Figs 118 (redescription, designation of lectotype; successful mating experiments between B. lignicolus and B. xylophilus)]

= Aphelenchoides xylophilus Steiner \& Buhrer, 1934 [pp. 950-951 Fig. 1]

= Paraphelenchoides xylophilus (Steiner \& Buhrer, 1934) Haque, 1967 [pp. 1251-1253]

= Bursaphelenchus lignicolus Mamiya \& Kiyohara, 1972 [p. 121, Fig. 1]

\section{SPECIES INQUIRENDAE VEL INCERTAE SEDIS}

Bursaphelenchus conurus (Steiner, 1932) J.B. Goodey, 1960a [p. 117, but see also Rühm, 1956, p. 241]

= Aphelenchoides conurus Steiner, 1932 [pp. 442-443, Fig. 4]

species incertae sedis apud Tarjan \& Baeza-Aragon, 1982 [p. 127]

species inquirenda apud Hunt, 1993 [p. 133]

Bursaphelenchus ruehmi Baker, 1962 [p. 200] ${ }^{6)}$

$=$ Aphelenchoides (Bursaphelenchus) conjunctus apud Rühm, 1956 [pp. 220, 241] nec Aphelenchoides conjunctus Fuchs, 1930

= Bursaphelenchus conjunctus (Fuchs, 1930) Andrássy, 1958 [p. 185]

= Bursaphelenchus conjunctus apud J.B. Goodey, 1960a [p. 116] nec Aphelenchoides conjunctus Fuchs, 1930

= Bursaphelenchus ruehmi J.B. Goodey, 1963 [p. 146] (= junior objective homonym)

species indeterminata apud Tarjan \& Baeza-Aragon, 1982 [p. 131]

species inquirenda apud Hunt, 1993 [p. 133] 


\section{DEPARTURES TO OTHER GENERA}

Laimaphelenchus lignophilus (Körner, 1954) Goodey, 1960a [p. 116]

=Aphelenchoides lignophilus Körner, 1954 [pp. 344-345, Fig. 59]

= Bursaphelenchus lignophilus (Körner, 1954) Meyl, 1961 [p. 83]

Aphelenchoides conjunctus (Fuchs, 1930) Filipjev, 1934 [p. 215] ${ }^{6)}$ nec Aphelenchoides (Bursaphelenchus) conjunctus apud Rühm, 1956 and B. conjunctus apud J.B. Goodey, 1960a (= Bursaphelenchus ruehmi Baker, 1962)

= Parasitaphelenchus conjunctus Fuchs, 1930 [pp. 629630, Figs 162-165]

$=$ Aphelenchoides (Schistonchus) conjunctus (Fuchs, 1930) Filipjev, 1934 [p. 215]

= Shistonchus conjunctus (Fuchs, 1930) Skrjabin, Shikhobalova, Sobolev, Paramonov \& Sudarikov, 1954 [p. 310]

species incertae sedis apud Tarjan \& Baeza-Aragon, 1982 [pp. 125-126, no bursa]

\section{NOMINA NUDA}

Bursaphelenchus populneus Kakulia, Devdariani \& Maglakelidze, 1980 [p. 109]

nomen nudum apud Hunt, 1993 [p. 134]

Bursaphelenchus tbilisensis Kakulia, Devdariani \& Maglakelidze, 1980 [pp. 109-110]

nomen nudum apud Hunt, 1993 [p. 134]

\section{AnNOTATIONS TO THE SPECIES LIST}

1) Bursaphelenchus piniperdae. Description and illustrations of this, the type species, in Rühm (1956) appear to represent a different taxon to that described in the original paper by Fuchs (1937) (see Table 1). Taxonomists have not recorded this species since 1980 (last record: Caucasus, Kurashvili et al., 1980). For more precise determination the species is included in Table 1, in the text key to Bursaphelenchus and in the trees of phenetic similarities (Figs 24, 25) as separate subspecies, namely B. piniperdae piniperdae Fuchs, 1937 and B. piniperdae ruehmpiniperdae $\mathrm{n}$. subsp. (=B. piniperdae apud Rühm, 1956 nec B. piniperdae piniperdae Fuchs, 1937). $B$. piniperdae ruehmpiniperdae $\mathrm{n}$. subsp. differs from $B$. piniperdae piniperdae in having the stylet $18-19 \mu \mathrm{m}$ long vs 11-12 $\mu \mathrm{m}$ in B. p. piniperdae; spicule length, measured along arc, of 14-19 vs 12-14 $\mu \mathrm{m}$ in B. p. piniperdae; ratio spicule length/capitulum width of 2.5 vs 1.5 in $B$. $p$. piniperdae; ratio depth of capitulum depression/capitulum width $=0.4$ vs 0.2 in $B$. p . piniperdae; spicule tip finely rounded $v s$ bluntly rounded in $B . p$. piniperdae; and tail of dispersal juvenile pointed $v s$ narrowly rounded in $B$. $p$. piniperdae.

It is important that the type species proposed by Fuchs (1937) is redescribed to modern standards so that taxonomic relationships can be unequivocally established.

2) Bursaphelenchus dongguanensis. Kaisa (2005) transferred B. dongguanensis to the genus Parasitaphelenchus, thereby proposing the combination $P$. dongguanensis (Fang, Zhao \& Zhuo, 2002) Kaisa, 2005. The new combination was based on an analysis of the published description of the species as no collection specimens were available for study. Kaisa studied collection material and published descriptions of nine out of 14 valid Parasitaphelenchus species and argued the case for transferring the species to Parasitaphelenchus on the basis of the a, c and $\mathrm{V}$ indexes of B. dongguanensis and the fact that the male tail was not strongly recurved. The presence of endoparasitic juveniles in B. dongguanensis was not established as the species was described only from the dead wood of wilted Pinus massoniana. The male tail recurvature in $B$. dongguanensis is very weak, although a similar tail curvature was illustrated for the type species Bursaphelenchus piniperdae by Fuchs (1937) and Rühm (1956), and also occurs in several other Bursaphelenchus species. The actual form of the male body was not illustrated when the species was proposed by Fang et al. (2002), the body of both male and female being depicted in an artificial U-shaped form (as in some of the older nematological publications), rather than as the heat relaxed habitus. In addition, B. dongguanensis was fixed in TAF, a process which in our experience makes nematodes too soft to draw conclusions about the real body shape. The spicules of $B$. dongguanensis are not fused. As all other quantitative characters overlap between Parasitaphelenchus and Bursaphelenchus, these cannot be considered as arguments to support the transference of B. dongguanensis to the genus Parasitaphelenchus. Additional support for this decision may be derived by comparing $B$. dongguanensis with the type species of both genera, namely Bursaphelenchus piniperdae Fuchs, 1937 and Parasitaphelenchus uncinatus (Fuchs, 1929) Fuchs, 1930. Males of P. uncinatus have only one pair of postcloacal papillae located near the bursal flap, whereas B. dongguanensis males have two such pairs. Males of $B$. piniperdae have one pair of large postcloacal papillae and three pairs of small glandpapillae (illustrated in Fuchs, 1937 and Rühm, 1956). Bursaphe- 
lenchus xylophilus, a widely distributed species often considered a 'typical' species for the genus, has two pairs of male postcloacal papillae located near the bursal flap, the same situation as in B. dongguanensis. We therefore do not accept the combination Parasitaphelenchus dongguanensis (Fang, Zhao \& Zhuo, 2002) Kaisa, 2005 as valid and the species is returned to the genus Bursaphelenchus.

3) The original description of Bursaphelenchus hunti (= Aphelenchoides hunti) by Steiner (1935) and the illustration in this paper (Fig. 27) were based only on nematodes from bulbs of Lilium tigrinum (Liliaceae) intercepted from Japan, not from fruits of tomatillo, Physalis ixocarpa (Solanaceae) intercepted from Mexico (see Nickle, 1970, p. 390).

4) Bursaphelenchus hylobianum juveniles reportedly inhabit the insect haemocoel and this species is apparently the only endoparasite within the genus. Korentchenko (1980) described this species as belonging to the genus Parasitaphelenchus, but Hunt (1993, p. 134) argued that the male tail morphology, spicule structure and disposition of the nine caudal papillae are characters of Bursaphelenchus, and transferred the species accordingly.

5) Bursaphelenchus poligraphi. The description and illustrations of this species by Rühm (1956) are slightly different from those in the original paper by Fuchs (1937) (Table 1). This species has not been recently redescribed, although DNA profiles attributed to this species have been published (Braasch et al., 1999, 2004). To facilitate more exact identification, this species is included in Table 1, in the text of key to Bursaphelenchus and in the trees of phenetic similarities (Figs 24, 25) as the subspecies: B. poligraphi poligraphi Fuchs, 1937 and B. poligraphi ruehmpoligraphi n. subsp. (=B. poligraphi apud Rühm, 1956 nec B. poligraphi poligraphi Fuchs, 1937). B. poligraphi ruehmpoligraphi n. subsp. differs from $B$. poligraphi poligraphi in having the spicule rostrum thornlike $v s$ conical in B. p. poligraphi; bursal flap conical $v s$ oval to rounded in $B$. p. poligraphi; male tail terminus pointed $v s$ rounded in $B$. p. poligraphi; spicule slender with the ratio of male spicule length (measured along the arc) to its width (measured posterior to rostrum in lateral view) being 5 or more, $v s$ spicule stout and corresponding ratio $<4$ in $B$. p. poligraphi; ratio of spicule length to capitulum width $=2.5$ or more $v s 2.0$ or less in $B$. $p$. poligraphi; spicule length along arc $>15-18 \mu \mathrm{m} v s$ 11$13 \mu \mathrm{m}$ in B. p. poligraphi; and stylet $12-14 \mu \mathrm{m}$ long $v s 10$ $\mu \mathrm{m}$ in B. p. poligraphi.
6) Aphelenchoides conjunctus. As described by Fuchs (1930), this species has all the features of aphelenchoidid nematodes (pharynx form, male spicule shape, female tail, male tail mucronate and lacking a bursa, two pairs of male postanal papillae, stylet $=8 \mu \mathrm{m}$, spicule length along arc $=14-18 \mu \mathrm{m}$ ). It may be considered as species inquirenda within Aphelenchoides, but not Bursaphelenchus, because of the absence of a terminal bursa and the spicule shape.

Baker (1962, p. 200) showed that that the species attributed to $B$. conjunctus by Rühm was different from the original description of Fuchs (1930). Rühm's species has a bursal flap in the male and therefore belongs to the genus Bursaphelenchus. Rühm's material was renamed by Baker (1962) as B. ruehmi. Baker also pointed out that B. conjunctus apud Rühm (=B. ruehmi) had also been mentioned by J.B. Goodey (1960). The same species was referred to as B. conjunctus by Andrássy (1958, p. 185). In this review, B. conjunctus Fuchs, 1930 is considered to be a species inquirenda within the genus Aphelenchoides whereas B. conjunctus apud Rühm, 1956 (= B. ruehmi) nec B. conjunctus Fuchs, 1930 is considered herein as species inquirenda within Bursaphelenchus.

\section{SOME REMARKS ON THE GENUS}

i) The generic differences between Bursaphelenchus and Parasitaphelenchus were discussed in detail by Hunt (1993) and emended by Kaisa (2005).

ii) In this account, following the argument in Thong and Webster (1991) and Mamiya (1984), the term 'dispersal juvenile' is used instead of 'dauerlarva'. The insect associated dispersal juvenile is a juvenile stage specialised for a phoretic transmission by an insect vector to a new habitat. In Parasitaphelenchus, the parasitic (fourthstage) juvenile is found as an endoparasite in the insect haemocoel, whereas in Bursaphelenchus the dispersal juvenile (J3/J4) is ectophoretic, although exceptionally, as in B. hylobianum, it appears to be endoparasitic.

iii) Vulva position: $\mathrm{V}=82$ and more in Parasitaphelenchus: (Hunt mentioned $85 \%$ or more, but Kaisa stressed that $P$. acroposthion, according to Steiner (1932), has $82 \%$ as the minimum value); whereas in Bursaphelenchus, $\mathrm{V}=$ 80 or less. However, at least four species of Bursaphelenchus (B. typographi, B. digitulus, B. erosus and B. dongguanensis) have $\mathrm{V}=85$ and more.

iv) Male spicules: Spicules are partially fused in Parasitaphelenchus, although Kaisa (2005) reported that the spicules were not fused on slide material of P. gallagheri 
and $P$. procercus, or in Figures 38 and 40 of the original description of P. papillatus Fuchs, 1937. In Bursaphelenchus the spicules are usually separate, but were reported to be partially fused in some species (Hunt, 1993).

v) Male tail curvature: The male tail is not strongly recurved in Parasitaphelenchus, but is so shaped in Bursaphelenchus. In the type-species Bursaphelenchus piniperdae, as well as in $B$. poligraphi, B. digitulus and several other species, the male tail is not strongly recurved.

vi) Kaisa (2005) also considered the following characters as distinguishing the genera: a-index $\geqslant 29$ in Parasitaphelenchus, but $<29$ in Bursaphelenchus (however, more than 70 Bursaphelenchus spp. have an a-index $>29$ and 31 Bursaphelenchus species have a $>40$ ); c-index $\geqslant 40$ in Parasitaphelenchus, but $<40$ in Bursaphelenchus (but B. eidmanni, B. poligraphi, B. dongguanensis, B. erosus and B. typographi have a female c-index $>40$ ).

vii) Of the listed characters, the most important one is biological, endoparasitic juveniles being the diagnostic feature of Parasitaphelenchus. Significant overlaps between the two genera may be found in the other listed characters, the most reliable of these being the recurved tail of Bursaphelenchus vs more or less straight in Parasitaphelenchus, and the usually separate spicules in Bursaphelenchus vs usually partially fused in Parasitaphelenchus.

viii) According to Mayr (1969) the genus taxon is a monophyletic group of species separated from other genera by a distinct gap (in morphological and other characters) and occupying a distinctly separate niche. Parasitaphelenchus is distinctly different from Bursaphelenchus in the endoparasitic habit of the fourth-stage juvenile $v s$ the ectophoretic dispersal juvenile (J3/J4) of Bursaphelenchus. Thus, Parasitaphelenchus is more specialised to insect parasitism and may have evolved from the genus Bursaphelenchus, the insect vector in the Bursaphelenchus cycle becoming the host of the parasitic juveniles of Parasitaphelenchus. As a result of this specialisation, a sclerotised mouth hook developed in the infective thirdstage juveniles of Parasitaphelenchus to facilitate invasion of the bark beetle grubs (Hunt, 1993). This structure, as well as the endoparasitic habit of the juveniles, may be considered as synapomorphies of Parasitaphelenchus.

ix) Among the generic synonyms of Bursaphelenchus, the genus Rhadinaphelenchus J.B. Goodey, 1960, which was synonymised with Bursaphelenchus by Bau- jard (1989), is of most interest. The only species of the genus, Rhadinaphelenchus cocophilus (Cobb, 1919) J.B. Goodey, 1960 is now considered to belong to Bursaphelenchus (Baujard, 1989; Giblin-Davis et al., 1989, 2003; Giblin-Davis, 1993; Fang et al., 2002a; see also discussion in Hunt, 1993). The most similar species to $B$. cocophilus is B. dongguanensis which has a similar spicule structure and an a-index $>80$. Bursaphelenchus cocophilus may be placed in the hunti-species group on the basis of spicule structure (lamina wide, dorsal and ventral limb well separate, see Figure 2A). Vectors of the group do not include members of the Scolytidae, but are restricted to beetles of the family Curculionidae and various Hymenoptera (Halictidae and Anthophoridae).

\section{BIONOMICS}

The phoretic juveniles are associated with insects. Vectors are mainly Coleoptera, particularly the Scolytidae, but also the Buprestidae, Cerambycidae and Curculionidae. Some species are associated with the insect orders Hymenoptera (Halictidae) or Lepidoptera (Sesiidae).

Associated plants are mainly trees, particularly Pinaceae, but also include trees from other families, including Araliaceae, Areaceae, Betulaceae, Cupressaceae, Fagaceae, Juglandaceae, Moraceae, Oleaceae, Rosaceae, Rubiaceae, Salicaceae, and Ulmaceae, as well as herbaceous plants belonging to Alliaceae and Solanaceae.

\section{Species groups}

Different criteria may be used to divide the large number of nominal species of the genus Bursaphelenchus into smaller, more convenient, 'species groups'. Tarjan and Baeza-Aragon (1982) proposed terminology for the spicule structure (Fig. 1) in Bursaphelenchus and gave a detailed classification of spicule characters and their states. Giblin and Kaya (1983) used this terminology to construct a species grouping which was based mainly on the shape of the spicules, complicated copulatory structures described and illustrated for all species of the genus. The classification of Braasch $(2001,2004 a)$, on the other hand, is based on the number of incisures in the lateral field, number and arrangement of the male caudal papillae, presence of a vulval flap in the female, and shape of the female tail. Unfortunately, these characters are available for only some of the nominal species, thereby limiting the utility of this scheme. 
In this paper only the spicule structure is used to separate the species into groups. These species groups are intended purely as identification units in order to facilitate species identification. However, some of these groups may be natural (i.e., phylogenetically based). The different parts of the spicule are illustrated in Figure 1. The most important spicule characters are the shape of the rostrum (a derivation of the ventral limb of the ancestral aphelenchoid spicule) and the shape of the condylus (derived from the dorsal spicule limb).

In the following dichotomous key, which is based on spicule structure, the six species groups are keyed out first and are then followed by keys for each species group. For each species group a brief diagnosis and list of species introduce the corresponding key, the species donating the group name being listed first (i.e., B. hunti is listed first in the species list of the hunti-group).

When constructing the text keys, two approaches for the identification process were employed. The first approach was to separate one species from the current set of species by a 'unique character'. The second approach was to split the current set of species into several non-overlapping subsets of species using an appropriate 'group character', the condition being that each species of the current set has only one of several alternative states of such a character. Unique characters are very rare in a large genus such as Bursaphelenchus, an example being the head region structure in B. maxbassiensis where the first head annulus is distinctly larger in diameter than the other annuli and strongly offset. Among the group characters, the type of spicule structure is the best, sorting the genus into six, non-overlapping, species groups. However, within the piniperdae-group, the most speciose of all the groups, it is difficult to select diagnostic characters because of the large variability and overlapping of characters amongst the many nominal species. In an attempt to overcome this difficulty, species of the piniperdae-group, therefore, appear more than once in the text key.

\section{Key to the species groups}

1. Dorsal and ventral limbs of male spicule not joined at spicule tip; spicule tip broad and blunt (Fig. 2A)

hunti-group

- Dorsal and ventral limbs of male spicule joined at spicule tip; spicule tip narrow and conoid ...... 2

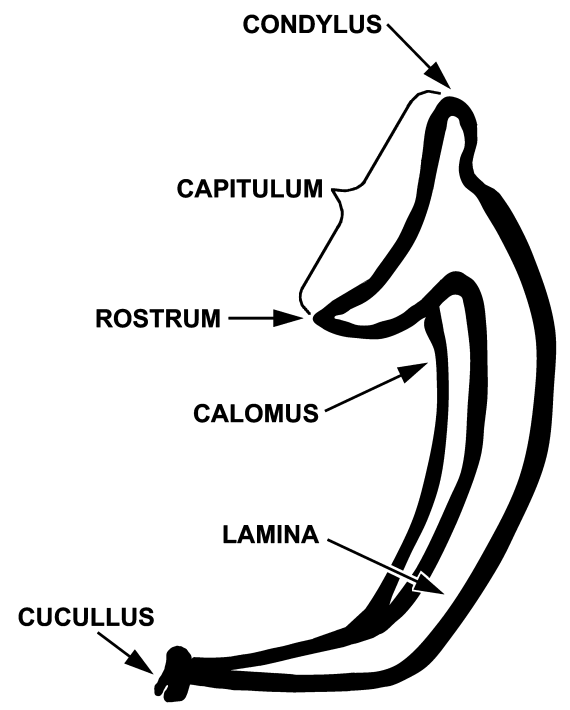

Fig. 1. Male spicule (lateral view) showing constituent parts.

2. Capitulum compact, rostrum and condylus fused (Fig. 2B) $\ldots \ldots \ldots \ldots \ldots \ldots \ldots$ aberrans-group

- Capitulum elongate, rostrum and condylus well developed and separate $\ldots \ldots \ldots \ldots \ldots \ldots \ldots \ldots . \ldots$

3. Spicule linear, with small rostrum located halfway along its length (Fig. 2C) ....... eidmanni-group

- Spicule hook-like, with prominent rostrum located more anteriorly ...................... 4

4. Condylus recurved posteriorly (Fig. 2D) .......... ........................... borealis-group

- Condylus straight or indistinct (Fig. 2E, F) .... 5

5. Capitulum flattened anteriorly, condylus small, dorsal contour of lamina distinctly angular in last third; cucullus usually present (Fig. 2E)

xylophilus-group

- Capitulum concave anteriorly; condylus elongate, dorsal contour of lamina smoothly curved or angular at midpoint, cucullus usually absent, but small cucullus sometimes present (Fig. 2F) .

piniperdae-group

\section{Keys to the species of Bursaphelenchus Fuchs, 1937}

These keys are based mainly on descriptions in the literature and on collection material, as listed in Table 1 (columns N_lit and N_col). 


\section{THE HUNTI-GROUP}

Dorsal and ventral limbs of spicule not joined at tip, which is broad and blunt.

Species: B. hunti, B. cocophilus, B. dongguanensis, B. fungivorus, B. gonzalezi, B. kevini and B. seani.

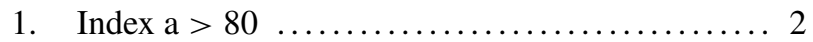

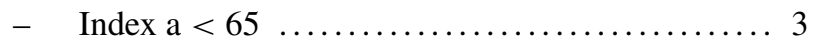

2. Index $c^{\prime}=5.6$ or more, weak fifth lateral line present centrally, male bursa oval to rounded in ventral view (Fig. 21B), spicule rostrum conical to rounded (Fig. 6B, C) ................... B. cocophilus

- $\quad$ Index $c^{\prime}=2.2$ or less, four lateral lines, male bursa truncate in ventral view (Fig. 21C), spicule rostrum thorn-like (Fig. 6A) .......... B. dongguanensis

3. Female tail terminus mucronate (Fig. 3A) ........ .................................. kevini

- Female tail terminus pointed (Fig. 3B) ......... 4

- Female tail terminus rounded (Fig. 3C) ....... 5

4. Junction between spicule rostrum and lamina of spicule angular (Fig. 20A), ratio female genital postuterine branch length to vulval body diam. $=2$ or less .............................. B. seani

- Junction between rostrum and lamina of spicule smoothly curved (Fig. 20B), ratio female genital postuterine branch length to vulval body diam. $=2.9$ or more ....................... Bonzalezi

5. Lateral field with three incisures (Fig. 13B) ....... .............................. B. hunti

- Lateral field with four incisures (Fig. 13C) ... B. fungivorus

\section{THE ABERRANS-GROUP}

Male spicule capitulum compact, rostrum and condylus fused.

Species: B. aberrans, B. idius, B. elytrus, B. sinensis.

1. Female tail tip strongly recurved (Fig. 10A) ....... ............................. B. aberrans

- Female tail tip not strongly recurved (tail tip straight or slightly curved ventrally (Fig. 10B) .. ....... 2

2. Female index $\mathrm{c}^{\prime}=2.7$ or less, six incisures in lateral field (Fig. 13E) ..................... B. idius

- Female index $c^{\prime}=3.2$ or more, four or fewer incisures in lateral field (Fig. 13A-C) .......... 3
3. Vulval flap absent (Fig. 7B), male bursa conical in ventral view (Fig. 21A), spicule length measured along arc $=24 \mu \mathrm{m}$ or more, found in America ... B. elytrus

- Vulval flap present (Fig. 7A), male bursa rounded in ventral view (Fig. 21B), spicule length measured along arc $=22 \mu \mathrm{m}$ or less, found in Asia and Europe

B. sinensis

\section{THE EIDMANNI-GROUP}

Spicule straight, linear, small conical rostrum located midway along spicule.

Species: B. eidmanni, B. digitulus, B. erosus, B. steineri, B. teratospicularis, B. typographi.

1. Female tail tip with distinct mucro (Fig. 3A) .... 2

- Female tail tip without mucro, digitate to rounded (Fig. 3C, D) ....................... 4

2. Female postuterine branch length/vulva-anus distance $<0.3$ (Fig. 23A, B) ............ B. erosus

- Female postuterine branch length/vulva-anus distance $>0.3$ (Fig. 23C, D) ................ 3

3. Female index $\mathrm{V}=74$ or less, male bursa minute and conical in ventral view (Fig. 21A); ratio of spicule length along arc to its width (excluding rostrum) = 10 or more (Fig. 16D) .............. B. steineri

- Female index $\mathrm{V}=84$ or more, male bursa rounded in ventral view (Fig. 21B), sometimes with slightly $\mathrm{m}$-shaped posterior line; ratio of spicule length along arc to its width (excluding rostrum) $=6$ or less (Fig. $16 \mathrm{~A}, \mathrm{~B}) \ldots \ldots \ldots \ldots \ldots \ldots \ldots \ldots$. digitulus

4. Female postuterine branch $=4$ or more vulval body diam. long (Fig. 5C, D) ............ B. eidmanni

- $\quad$ Female postuterine branch $=1.5$ or less vulval body diam. long (Fig. 5A) .................. 5

5. Index $\mathrm{V}=80$ or less, spicule length along $\operatorname{arc}=15$ $\mu \mathrm{m}$ or more $\ldots \ldots \ldots \ldots \ldots \ldots$. B. teratospicularis

- Index $\mathrm{V}=85$ or more, spicule length along arc $=12$ $\mu \mathrm{m}$ or less $\ldots \ldots \ldots \ldots \ldots \ldots \ldots \ldots$. typographi

\section{THE BOREALIS-GROUP}

Spicule condylus recurved posteriorly.

Species: B. borealis, B. cryphali, B. leoni, B. silvestris, B. tusciae.

1. Vulval flap absent (Fig. 7B) ......... B. cryphali

- Vulval flap present (Fig. 7A) ............... 2 
2. Male bursa oval or rounded in ventral view (Fig. 21B) ......................... Bilvestris

- Male bursa truncate in ventral view (Fig. 21C)..... ...................................... 3

3. Female index $\mathrm{c}^{\prime}=5$ or more $\ldots \ldots \ldots \ldots$ B. leoni

- Female index $\mathrm{c}^{\prime}=4.5$ or less $\ldots \ldots \ldots \ldots \ldots \ldots .4$

4. Female postuterine branch. $=4.7$ or more vulval body diam. long (Fig. 5C, D), male spicule condylus tip rounded (Fig. 9B)

B. tusciae

- Female postuterine branch $=3.5$ or less vulval body diam. long (Fig. 5A, B), male spicule condylus tip pointed (Fig. 9C)

B. borealis

\section{THE XYLOPHILUS-GROUP}

Spicule narrow, capitulum flattened, condylus small, lamina angular in posterior third, cucullus present (except in $B$. crenati).

Species: B. xylophilus, B. abruptus, B. baujardi, B. conicaudatus, B. crenati, B. eroshenkii, B. fraudulentus, B. kolymensis, B. luxuriosae, B. mucronatus.

1. Spicule cucullus absent (Fig. 4C) ....... B. crenati

- Spicule cucullus present (Fig. 4A) ............ 2

2. Vulval flap absent (Fig. 7B), five lateral incisures (Fig. 13D) B. eroshenkii

- Vulval flap present (Fig. 7A), lateral field with other number of incisures (Fig. 13A-C) $\ldots \ldots \ldots \ldots . . .3$

3. Spicule condylus reduced to indistinct, not offset from capitulum-calomus angle (Fig. 9D) .

$$
\text { B. conicaudatus }
$$

- Spicule condylus well developed, rounded (Fig. 9B)

4. Female tail tip strongly recurved (Fig. 10A) ....... .............................. B. luxuriosae

- Female tail tip straight or slightly curved ventrally (Fig. 10B) ........................... 5

5. Female tail tip truncate or finely rounded (V-shaped) (Fig. 3C, E) B. abruptus

- Female tail tip mucronate, pointed or broadly rounded (U-shaped) (Fig. 3A, B, D) ................ 6

6. Excretory pore located at median bulb level or more anterior (Fig. 8C, D) $\ldots \ldots \ldots \ldots \ldots \ldots \ldots \ldots \ldots$

- Excretory pore located posterior to median bulb (Fig. $8 \mathrm{~A}, \mathrm{~B})$

\section{9}

7. Spicule rostrum rounded to digitate (Fig. 6C), spicule length along $\operatorname{arc}=21 \mu \mathrm{m}$ or less .... B. kolymensis
- Spicule rostrum sharply conical to pointed (Fig. 6B), spicule length along arc $=22 \mu \mathrm{m}$ or more $\ldots \ldots .8$

8. Angle between line along capitulum (condylus-rostrum) and line extending spicule tip $=30^{\circ}$ or less (lines appear to be parallel) (Fig. 11B, C) ........

. B. baujardi

- Angle between line along capitulum (condylus-rostrum) and line extending spicule tip $=45^{\circ}$ or more (Fig. 11A) .................. Braudulentus

9. Male bursa truncate in ventral view (Fig. 21C), depth of capitulum depression/capitulum width $>0.1$ (Fig. 19B); dorsal contour of spicule lamina smoothly curved (Fig. 15A) ................ B. mucronatus

- Male bursa oval to rounded in ventral view (Fig. 21B), ratio of depth of capitulum depression/capitulum width $>0.1$ (Fig. 19A); dorsal contour of spicule lamina distinctly angular in posterior third (Fig. 15C) ......................... 10

10. Female tail tip usually broadly rounded (Fig. 3D); spicule rostrum-calomus junction angular (Fig. 20A), male tail terminus (lateral view) pointed (Fig. 22B)

\section{B. xylophilus}

- Female tail tip mucronate to pointed (Fig. 3A, B); spicule rostrum-calomus junction smoothly curved (Fig. 20B), male tail terminus shape (lateral view) narrowly rounded (Fig. 22C) ..... B. fraudulentus

\section{THE PINIPERDAE-GROUP}

Spicule stout, capitulum concave, rostrum and condylus well developed, condylus elongated, lamina smoothly curved or angular at midpoint, cucullus absent or present.

Species: B. piniperdae (consisting of two subspecies: B. piniperdae piniperdae Fuchs, 1937 and B. piniperdae ruehmpiniperdae n. subsp.), B. abietinus, B. bestiolus, B. chitwoodi, B. corneolus, B. eggersi, B. eremus, B. eucarpus, B. fuchsi, B. georgicus, B. glochis, B. hellenicus, B. hofmanni, B. hunanensis, B. hylobianum, $B$. incurvus, B. lini, B. maxbassiensis, B. minutus, B. naujaci, B. newmexicanus, B. nuesslini, B. paracorneolus, $B$. pinasteri, B. pinophilus, B. pityogeni, B. poligraphi (consisting of two subspecies: B. poligraphi poligraph Fuchs, 1937 and B. poligraphi ruehmpoligraphi n. subsp.), $B$. rainulfi, $B$. ratzeburgii, $B$. sachsi, $B$. scolyti, B. sexdentati, B. sutoricus, B. sychnus, B. talonus, B. thailandae, $B$. tritrunculus, B. vallesianus, B. varicauda, B. wekuae, $B$. wilfordi, B. willi, B. xerokarterus. 
1. Anterior head annulus distinctly larger in diam. than others and offset (Fig. 17C) .... B. maxbassiensis

- Head annuli of equal diam. or annulation indistinct under light microscope (Fig. 17A, B) ......... 2

2. Female tail tip with mucro (Fig. 3A) .......... 3

- Female tail tip pointed (Fig. 3B) ........... 14

- $\quad$ Female tail tip finely rounded (V-shaped) (Fig. 3C) ..................................... 31

- Female tail tip broadly rounded (U-shaped) (Fig.

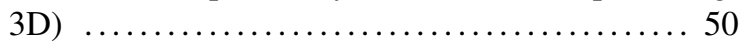

3. Male spicule tip with cucullus (Fig. 4A) ...... 4

- Male spicule tip without cucullus, sharp to angular

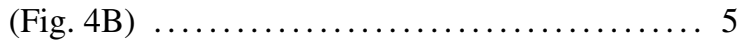

- Male spicule tip without cucullus, finely rounded to digitate (Fig. 4C) ....................... 6

- Male spicule tip without cucullus, bluntly rounded to widely rounded (Fig. 4D) $\ldots \ldots \ldots \ldots \ldots \ldots \ldots 11$

4. Excretory pore located at median bulb level (Fig. 8C) $\ldots \ldots \ldots \ldots \ldots \ldots \ldots \ldots$. pinophilus

- Excretory pore located at nerve ring or posterior (Fig. 8A) ............................ B. fuchsi

5. Female vulval flap present (Fig. 7A) ........... .......................... B. varicauda

- Female vulval flap absent (Fig. 7B) .... B. wekuae

6. Male index $\mathrm{c}<14 \ldots \ldots \ldots \ldots$........... Butoricus

- Male index $\mathrm{c}=15$ or more $\ldots \ldots \ldots \ldots \ldots \ldots . . \ldots$

7. Female tail tip strongly recurved (Fig. 10A) ....... . B. xerokarterus

- Female tail tip straight or slightly curved ventrally (Fig. 10B) ............................ 8

8. Female postuterine branch $<1$ vulval body diam. long (Fig. 5A) B. chitwoodi

- Female postuterine branch $>2.6$ vulval body diam. long (Fig. 5B, C)

9. Excretory pore located between nerve ring and median bulb (Fig. 8B) B. pinasteri

- Excretory pore located at nerve ring level or posterior (Fig. 8A) ......................... 10

10. Male spicule condylus truncate (Fig. 9A), female vulval flap absent (Fig. 7B) ......... B. eucarpus

- Male spicule condylus rounded (Fig. 9B), small, but distinct, female vulval flap present (Fig. 7A) ......

B. varicauda
11. Female postuterine branch $=5$ or more vulval body diam. long (Fig. 5C, D) ............. Baujaci

- Female postuterine branch $=4$ or less vulval body diam. long (Fig. 5A, B) ................. 12

12. Male spicule length along arc $=26 \mu \mathrm{m}$ or more, female index $\mathrm{c}=14$ or less ....... B. tritrunculus

Male spicule length along arc $=17 \mu \mathrm{m}$ or less, female index $\mathrm{c}=20$ or more $\ldots \ldots \ldots \ldots \ldots 13$

13. Female tail tip strongly recurved (Fig. 10A), male bursa truncate in ventral view (Fig. 21C) .........

B. ratzeburgii

- Female tail tip straight or slightly curved ventrally (Fig. 10B), male bursa conical in ventral view (Fig. 21A) ......................... B. thailandae

14. Spicule tip with cucullus (Fig. 4A) ......... 15

- Spicule tip without cucullus, sharp to finely rounded or digitate (Fig. 4B, C) ................ 18

- Spicule tip without cucullus, bluntly rounded to widely rounded (Fig. 4D) ......... B. thailandae

- Spicule tip without cucullus, broadly truncate (Fig. 4E) B. hylobianum

15. Female postuterine branch $=1$ or less vulval body diam. long (Fig. 5A) B. minutus

- Female postuterine branch $=4$ or more vulval body diam. long (Fig. 5C) ..................... 16

- $\quad$ Female postuterine branch $=2-3$ vulval body diam. long (Fig. 5B) ....................... 17

16. Female tail tip strongly recurved (Fig. 10A), male bursa conical in ventral view (Fig. 21A), stylet length $=12 \mu \mathrm{m}$ or less ................. B. corneolus

- Female tail tip straight or slightly curved ventrally (Fig. 10B), male bursa truncate in ventral view (Fig. 21C), stylet length $=16 \mu \mathrm{m}$ or more $\ldots . . B$. fuchsi

17. Two lateral incisures (Fig. 13A), one pair of male postanal papillae (Fig. 12A) ........ B. abietinus

- Three lateral incisures (Fig. 13B), two pairs of male postanal papillae (Fig. 12B) .... B. paracorneolus

18. Ratio of male spicule length along arc to its width measured posterior to rostrum $<3$ (Fig. 16A) ....

B. wilfordi

- Ratio of male spicule length along arc to its width measured posterior to rostrum $=3.5$ or more (Fig.

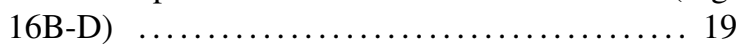

19. Female tail tip strongly recurved (Fig. 10A) .... 20 
- Female tail tip straight or slightly curved ventrally

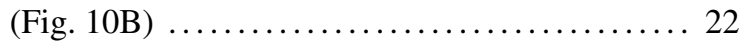

20. Male spicule length along arc $=18 \mu \mathrm{m}$ or more, two pairs of male postanal papillae (Fig. 12B), ratio of spicule length (along arc) to capitulum width (distance between ends of rostrum and condylus) $=$ 2.5 or more (Fig. 18C) B. glochis

- Male spicule length along arc $=15 \mu \mathrm{m}$ or less, one pair of male postanal papillae (Fig. 12A), ratio of spicule length (along arc) to capitulum width (distance between ends of rostrum and condylus) = 2.1 or less (Fig. 18B) .................... 21

21. Male spicule rostrum sharply pointed, short (Fig. 6B), spicular lamina dorsal line smoothly curved (Fig. 15A) female index $c>20$, excretory pore located posterior to median bulb (Fig. 8A, B)......

\section{B. xerokarterus}

- Male spicule rostrum narrowly rounded to digitate, long (Fig. 6C), spicular lamina dorsal line angular (Fig. 15B), female index $\mathrm{c}<20$, excretory pore located at median bulb level (Fig. 8C) ...........

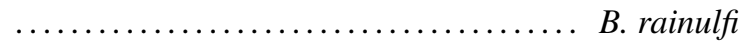

22. Spicule condylus pointed (Fig. 9C) .... B. eremus

- Spicule condylus blunt; rounded or truncate (Fig. 9A,

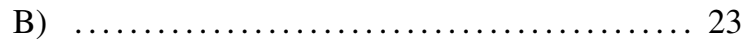

23. Spicular lamina dorsal line angular (Fig. 15B) ..... .................................... B. sachsi

- Spicular lamina dorsal line smoothly curved (Fig.

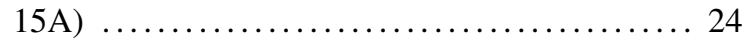

24. Spicule condylus truncate (Fig. 9A) ......... 25

- $\quad$ Spicule condylus rounded (Fig. 9B) ........ 27

25. Male bursa truncate in ventral view (Fig. 21C), female postuterine branch $<3.5$ vulval body diam. long (Fig. 5B) and 0.3 or less of vulva-anus distance (Fig. 23B) B. eucarpus

- Male bursa oval or conical in ventral view (Fig. 21A, B), female postuterine branch $>5$ vulval body diam. long (Fig. 5C, D) and 0.5 or more of vulva-anus distance (Fig. 23C, D) ................. 26

26. Male spicule rostrum conical (Fig. 6B), spicule stout, ratio male spicule length along arc to its width measured posterior to rostrum (lateral view) $<4$ (Fig. 16B); four pairs of male postanal papillae (Fig. 12D.1, D.2) ........... B. poligraphi poligraphi

- Male spicule rostrum thorn-like (Fig. 6A), spicule slender, ratio male spicule length along arc to its width measured posterior to rostrum (lateral view) $=5$ or more (Fig. 16C); two pairs of male postanal papillae (Fig. 12B) ......... B. poligraphi ruehmpoligraphi n. subsp.

27. Female index $\mathrm{c}^{\prime}=5.8$ or more.. ...... B. wekuae

- Female index $\mathrm{c}^{\prime}=4.9$ or less $\ldots \ldots \ldots \ldots \ldots . \ldots 28$

28. Stylet length $=19 \mu \mathrm{m}$ or more, male spicule rostrum rounded (Fig. 6C), female postuterine branch length $<1$ vulval body diam. long (Fig. 5A) ...........

B. hunanensis

- Stylet length less than $15 \mu \mathrm{m}$, male spicule rostrum conical or pointed (Fig. 6B), female postuterine branch length $>2$ vulval body diam. long (Fig. 5B,

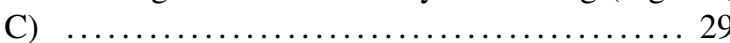

29. Male bursa truncate in ventral view (Fig. 21C), female index $\mathrm{c}=13$ or less ......... B. sychnus

- Male bursa oval, rounded or conical in ventral view (Fig. 21A, B), female index $\mathrm{c}=19$ or more ... 30

30. Female vulval flap absent (Fig. 7B), female postuterine branch length 2 or less vulval body diam. long (Fig. 5B), female index $\mathrm{V}=82$ or more .........

B. georgicus

- Female vulval flap present (Fig. 7A), female postuterine branch length 3.5 or more vulval body diam. long (Fig. 5C), female index $\mathrm{V}=77$ or less ......

B. pinasteri

31. Male spicule tip (lateral view) with cucullus (Fig.

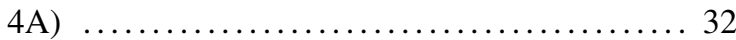

- Male spicule tip without cucullus, bluntly rounded to widely rounded or broadly truncate (Fig. 4D, E) ... 38

- Male spicule tip without cucullus, sharp, finely rounded or digitate (Fig. 4B, C) .............. 41

32. Excretory pore located at median bulb level (Fig. 8C) $\ldots \ldots \ldots \ldots \ldots \ldots \ldots \ldots \ldots$ B. vallesianus

- Excretory pore located at nerve ring or posterior (Fig.

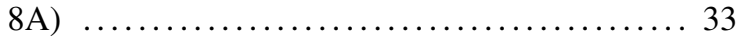

33. Female postuterine branch $=4$ or more vulval body diam. long (Fig. 5C) and extending for 0.7 of vulvaanus distance or more (Fig. 23D) $\ldots \ldots \ldots \ldots . \ldots 34$

- $\quad$ Female postuterine branch $=3$ or less vulval body diam. long (Fig. 5B) and extending for 0.6 of vulvaanus distance or less (Fig. 23B, C) .......... 35

34. Female tail tip strongly recurved (Fig. 10A), male bursa conical in ventral view (Fig. 21A), stylet length $=12 \mu \mathrm{m}$ or less ................. B. corneolus 
- Female tail tip straight or slightly curved ventrally (Fig. 10B), male bursa truncate in ventral view (Fig. 21C), stylet $=16 \mu \mathrm{m}$ or more $\ldots \ldots \ldots \ldots$. fuchsi

35. Two lateral incisures (Fig. 13A) ..... B. abietinus

- Three lateral incisures (Fig. 13B) ............ 36

36. One pair of male postanal papillae (Fig. 12A); angle between line along capitulum (condylus-rostrum) and line extending the spicule end $=15^{\circ}$ or more with intersection point dorsal (Fig. 11D) .........

B. hofmanni

- Two pairs male postanal papillae (Fig. 12B), angle between line along capitulum (condylus-rostrum) and line extending spicule end $=20^{\circ}$ or more with intersection point ventral (Fig. 11B)

37. Male bursa conical, oval or rounded in ventral view (Fig. 21A, B), female tail tip straight or slightly curved ventrally (Fig. 10B) ......... B. hellenicus

- Male bursa truncate in ventral view (Fig. 21C), female tail tip strongly recurved (Fig. 10A) .......

B. paracorneolus

38. Male spicule rostrum pointed (Fig. 6B) 39

- Male spicule rostrum thorn-like or rounded (Fig. 6A,

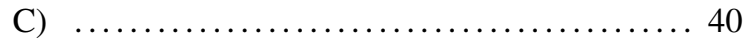

39. Female postuterine branch $=1.5$ or less body diam. long (Fig. 5A), female vulval flap absent (Fig. 7B), spicule condylus with rounded tip (Fig. 9B), male bursa truncate or rounded in ventral view (Fig. 21B, C) B. lini

- Female postuterine branch $=6$ or more body diam. long (Fig. 5D), female vulval flap present (Fig. 7A), spicule condylus with pointed tip (Fig. 9C), male bursa conical in ventral view (Fig. 21A) .........

B. bestiolus

40. Male bursa truncate in ventral view (Fig. 21C), spicule rostrum thorn-like (Fig. 6A), ratio depth of capitulum depression/capitulum width $>0.2$ (Fig. 19C) .......................... Bityogeni

- Male bursa conical in ventral view (Fig. 21A), spicule rostrum digitate (Fig. 6C), ratio depth of capitulum depression/capitulum width $=0.1$ or less (Fig. 19A) ...................... B. talonus

41. Female tail tip strongly recurved (Fig. 10A) .... 42

- Female tail tip straight or slightly curved ventrally (Fig. 10B) ......................... 46
42. Angle between line along capitulum (condylus-rostrum) and line extending spicule tip varying from $19^{\circ}$ with ventral intersection point, to $9^{\circ}$ with intersection point dorsal (lines look parallel, Fig. 11C) ..... 43

- Angle between line along capitulum (condylus-rostrum) and line extending spicule tip $=20-44^{\circ}$ with intersection point ventral (Fig. 11B) ......... 44

43. Excretory pore located at nerve ring or posterior (Fig. 8A), male bursa truncate in ventral view (Fig. 21C), two pairs of male postanal papillae (Fig. 12B) ..... ................................ B. scolyti

- Excretory pore located at median bulb level (Fig. $8 \mathrm{C}$ ), male bursa oval to rounded in ventral view (Fig. 21B), one pair of male postanal papillae (Fig. 12A) ......................... rainulfi

44. Male spicule rostrum digitate (Fig. 6C), male bursa rounded in ventral view (Fig. 21B), female index V $=70$ or less $\ldots \ldots \ldots \ldots \ldots \ldots \ldots \ldots \ldots$ B. eggersi

- Male spicule rostrum sharply conical to pointed (Fig. 6B), male bursa conical in ventral view (Fig. 21A), female index $\mathrm{V}=71$ or more $\ldots \ldots \ldots \ldots \ldots 45$

45. Male spicule condylus short, spicule length along arc $=18 \mu \mathrm{m}$ or more, ratio spicule length (along arc) to capitulum width (distance between ends of rostrum and condylus) $=2.5$ or more (Fig. 18C), female index $\mathrm{c}^{\prime}=4.2$ or more .............. B. glochis

- Male spicule condylus long, spicule length along arc $=16 \mu \mathrm{m}$ or less, ratio spicule length (along arc) to capitulum width (distance between ends of rostrum and condylus) $=2.2$ or less (Fig. 18B), female index $\mathrm{c}^{\prime}=3.6$ or less $\ldots \ldots \ldots \ldots \ldots \ldots \ldots$. nuesslini

46. Ratio of female postuterine branch length to vulvaanus distance $<0.2$ (Fig. 23A) ... B. hunanensis

- Ratio of female postuterine branch length to vulvaanus distance $>0.5$ (Fig. 23C, D) ...........47

47. Male spicule condylus truncate (Fig. 9A) ..... 48

- Male spicule condylus rounded (Fig. 9B) ..... 49

48. Male spicule rostrum conical (Fig. 6B), spicule stout, ratio male spicule length along arc to its width measured posterior to rostrum (lateral view) $<4$ (Fig. 16B) four pairs of male postanal papillae (Fig. 12D.1, D.2) $\ldots \ldots \ldots \ldots \ldots \ldots$. B. poligraphi poligraphi

- Male spicule rostrum thorn-like (Fig. 6A), spicule slender, ratio male spicule length along arc to its width measured posterior to rostrum (lateral view) $=5$ or more (Fig. 16C), two pairs of male postanal 
papillae (Fig. 12B) ....

B. poligraphi ruehmpoligraphi $\mathrm{n}$. subsp.

49. Male spicule rostrum small and conical (Fig. 6B), excretory pore located at median bulb or between nerve ring and median bulb (Fig. 8B, C); one pair of male postanal papillae (Fig. 12A), male bursa truncate in ventral view (Fig. 21C) .............

B. newmexicanus

- Male spicule rostrum large and digitate (Fig. 6C), excretory pore located at nerve ring or posterior (Fig. 8A); two pairs of male postanal papillae (Fig. 12B), male bursa rounded in ventral view (Fig. 21B) .....

........................... B. varicauda

50. Male spicule tip with cucullus (Fig. 4A) ........ .......................... B. hellenicus

- Male spicule tip without cucullus, bluntly rounded to broadly truncate (Fig. 4D, E) ............. 51

- Male spicule tip without cucullus, sharp to finely rounded or digitate (Fig. 4B, C) …...... 53

51. Female postuterine branch $=3$ or less vulval body diam. long (Fig. 5B); female index c $=14$ or less, male spicule extremely wide, ratio: spicule length along arc to its width measured posterior to rostrum (lateral view) $=3$ or less (Fig. 16A), one pair of male postanal papillae (Fig. 12A) ............ B. willi

- Female postuterine branch $=5$ or more vulval body diam. long (Fig. 5C, D); female index $\mathrm{c}=19$ or more, male spicule more slender, ratio: spicule length along arc to its width measured posterior to rostrum (lateral view) $=4$ or more (Fig. 16B), two or more pairs of male postanal papillae (Fig. 12B, C.1, C.2, D.1,

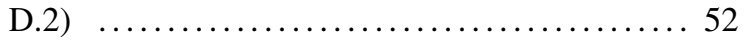

52. Male spicule condylus truncate (Fig. 9A), small female vulval flap present (Fig. 7A), male bursa truncate in ventral view (Fig. 21C) .... B. naujaci

- Male spicule condylus rounded (Fig. 9B), female vulval flap absent (Fig. 7B), male bursa oval to rounded in ventral view (Fig. 21B)

\section{B. piniperdae piniperdae}

53. Male bursa truncate in ventral view (Fig. 21C), one pair of male postanal papillae (Fig. 12A), male spicule condylus truncate (Fig. 9A) .............

B. incurvus

- Male bursa oval to rounded in ventral view (Fig. 21B), two or more pairs of male postanal papillae (Fig. 12B, C.1, C.2, D.1, D.2), male spicule condylus rounded (Fig. 9B) ..................... 54
54. Male spicule rostrum rounded (Fig. 6C), spicule length along arc $=17 \mu \mathrm{m}$ or less, female vulval flap present (Fig. 7A) ................ B. varicauda

- Male spicule rostrum sharply pointed (Fig. 6A, B), spicule length along arc $=17 \mu \mathrm{m}$ or more, female vulval flap absent (Fig. 7B) . ............. 55

55. Four pairs of male postanal papillae (one pair papillae and three pairs of gland papillae) (Fig. 12D.1, D.2), spicule length along arc $=19 \mu \mathrm{m}$ or less, ratio spicule length (along arc) to capitulum width (distance between ends of rostrum and condylus) $=2.5$ or more (Fig. 18C)

......... B. piniperdae ruehmpiniperdae $\mathrm{n}$. subsp.

- Two pairs of male postanal papillae (Fig. 12B), spicule length along arc $=19 \mu \mathrm{m}$ or more, ratio spicule length (along arc) to capitulum width (distance between ends of rostrum and condylus) $=2.2$ or less (Fig. 18B) ................ B. sexdentati

\section{Tabular key to Bursaphelenchus species}

The characters in this tabular, polytomous, or multientry key (see Table 1) were selected from keys, differential diagnoses and original descriptions of Bursaphelenchus species. Character states are standardised and illustrated because different authors have either used different expressions for the same character state or the same expression for different states. To split the measured characters and ratios into their optimum states, a particular search for the 'borders' between the various character states was undertaken in order to minimise overlap of character-states between species. The order of characters in the tabular key to (Table 1) is a compromise between their significance in identification and the availability of data on the character for the majority of nominal species within the genus. For instance, the position of the excretory pore and the number of lateral lines are very important diagnostic characters, but are known only for 60 and 37, respectively, of the 75 species in the genus. Characters $\mathrm{C} 1-\mathrm{C} 15$ are ordered according to their efficacy in splitting the largest group of the previous step to the smallest subgroups of species, thus decreasing the number of identification steps. Characters C16-32 are ordered as in the species description: measurements, ratios and qualitative characters first for both sexes (stylet and cephalic annuli), then for male spicule, male and female, correspondingly. Aphelenchoides ritzemabosi is included in Table 1 as the outgroup for the analysis of similarity of species (below). Data for the outgroup 


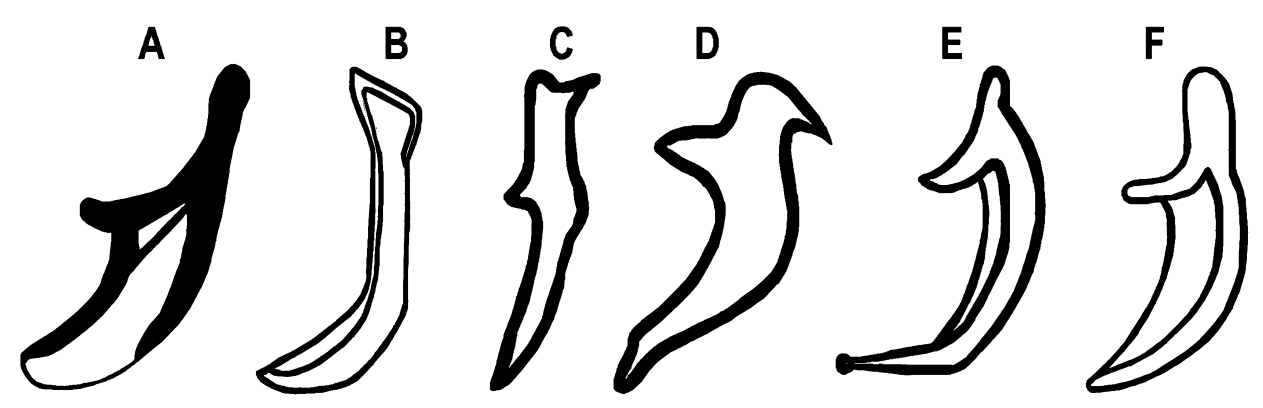

Fig. 2. Character 1: Spicule structure. A: Dorsal and ventral limbs not joined at spicule tip, which is broad and blunt (hunti-group); B: Capitulum compact, rostrum and condylus fused (aberrans-group); C: Spicule linear, small conical rostrum in middle of ventral limb (eidmanni-group); D: Condylus recurved posteriorly (borealis-group); E: Narrow, capitulum flattened, condylus small, lamina angular in last third, cucullus present (xylophilus-group); F: Stout, capitulum concave, condylus elongated, lamina smoothly curved or angular at midpoint, cucullus usually absent although small cucullus sometimes present (piniperdae-group).

species were taken from the slide collection of the Zoological Institute (St Petersburg) as well as from Siddiqi (1974). To make the cluster analysis of the outgroup and ingroups representative, the state 4 (male bursa absent) in C25 was included. Two additional columns are: N_lit = number of studied male specimens (figures and descriptions) in the literature sources; and N_col = number of studied male specimens in collection materials.

\section{DIAGNOSTIC CHARACTERS}

\section{C1: Spicule structure (Fig. 2)}

1: dorsal and ventral limbs not joining at spicule tip, which is broad and blunt (hunti-group) (Fig. 2A);

2: capitulum compact, rostrum and condylus fused (aberrans-group) (Fig. 2B);

3: spicule linear, small conical rostrum located at $c a$ half of spicule length (eidmanni-group) (Fig. 2C);

4: condylus recurved posteriorly (borealis-group) (Fig. 2D);

5: narrow, capitulum flattened, condylus small, lamina angular in last third, cucullus generally present (xylophilus-group) (Fig. 2E);

6: stout, capitulum concave, condylus elongate, lamina smoothly curved or angular at midpoint, cucullus usually absent, but small cucullus sometimes present (piniperdae-group) (Fig. 2F).

Note: species groups were employed by Giblin and Kaya (1983) and Braasch (2001). Here, species groups are based on spicule structure and are considered to be purely diagnostic.

\section{C2: Female tail tip (Fig. 3)}

1: mucronate (Fig. 3A);

2: pointed (Fig. 3B);
3: finely rounded (V-shaped) (Fig. 3C);

4: broadly rounded (U-shaped) (Fig. 3D);

5: truncate (Fig. 3E).

Note: this character was used by Rühm (1956), Tarjan and Baeza-Aragon (1982), Thong and Webster (1983), Yin et al. (1988) and Braasch (2001).
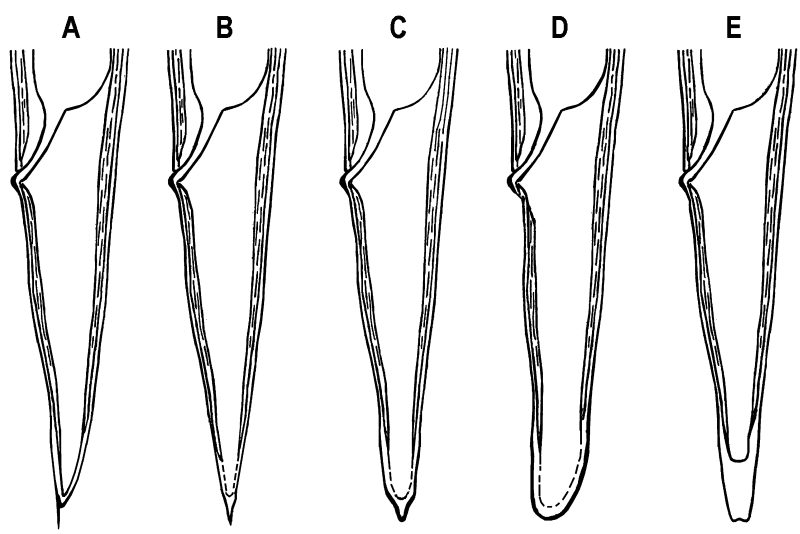

Fig. 3. Character 2: Female tail tip. A: Mucronate; B: Pointed; $C$ : Finely rounded (V-shaped); D: Broadly rounded (U-shaped); E: Truncate.

\section{C3: Male spicule tip (lateral view) (Fig. 4)}

1: with cucullus (Fig. 4A);

2: without cucullus, sharp to angular (Fig. 4B);

3: without cucullus, finely rounded to digitate (Fig. 4C);

4: without cucullus, bluntly rounded to widely rounded (Fig. 4D);

5: without cucullus, broadly truncate (Fig. 4E).

Note: this character was used by Tarjan and Baeza-Aragon (1982), Yin et al. (1988) and Braasch and Schmutzenhofer (2000). 


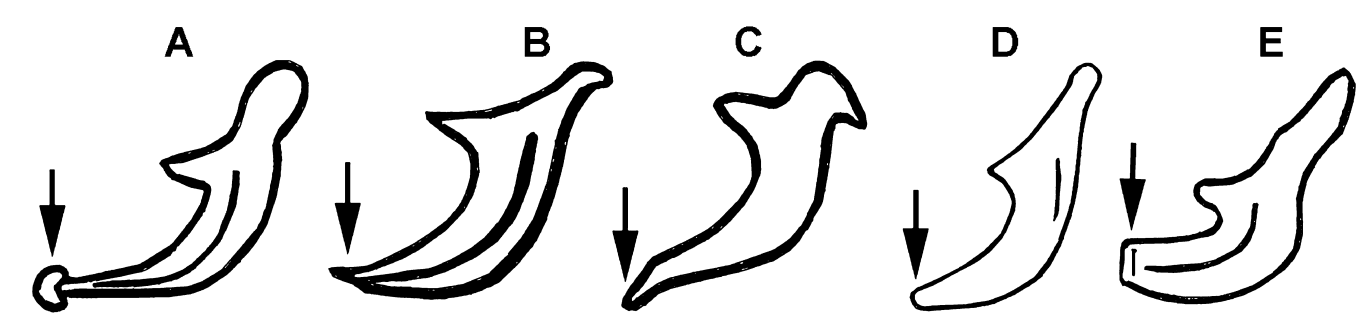

Fig. 4. Character 3: Male spicule tip (lateral view). A: With cucullus; B: Sharp to angular, cucullus absent; C: Finely rounded to digitate, cucullus absent; D: Bluntly rounded to widely rounded, cucullus absent; E: Broadly truncate, cucullus absent.

A

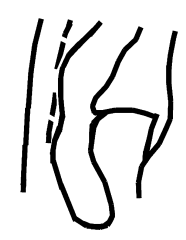

B

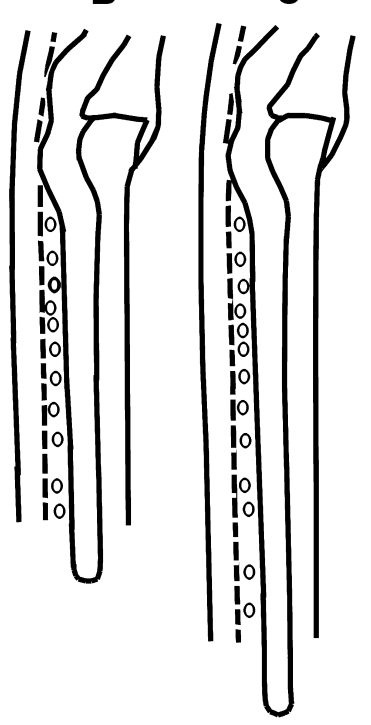

D

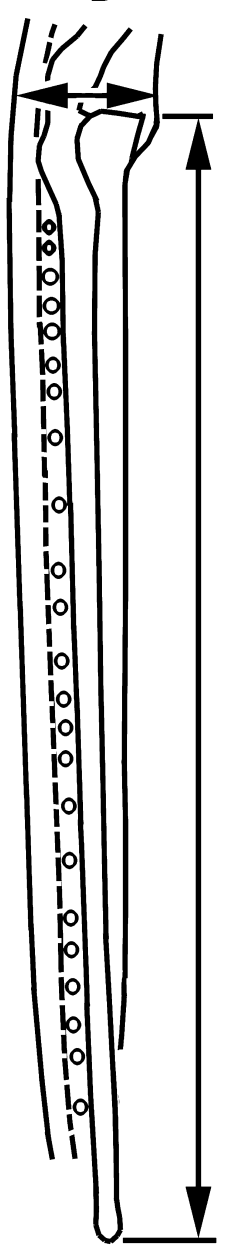

Fig. 5. Character 4: Ratio of female genital postuterine branch length to vulval body diameter. A: 1.5 or less; $B$ : 1.6-3.5; $C$ : 3.6-6.3; D: 6.4 or more. (Note: Method of measuring is shown in D.)

C4: Ratio of female postuterine branch length to vulval body diameter (Fig. 5)

1: 1.5 or less (Fig. $5 \mathrm{~A})$;

2: 1.6-3.5 (Fig. 5B);

3: 3.6-6.3 (Fig. 5C);

4: 6.4 or more (Fig. 5D).

Note: this character was used by Thong and Webster (1983).

\section{C5: Male spicule rostrum (Fig. 6)}

1: thorn-like (Fig. 6A);

2: sharply conical to pointed or acute (Fig. 6B);

3: digitate (Fig. 6C);

4: bluntly conical to almost flattened (Fig. 6D).

Note: this character was used by Rühm (1956) and Yin et al. (1988).
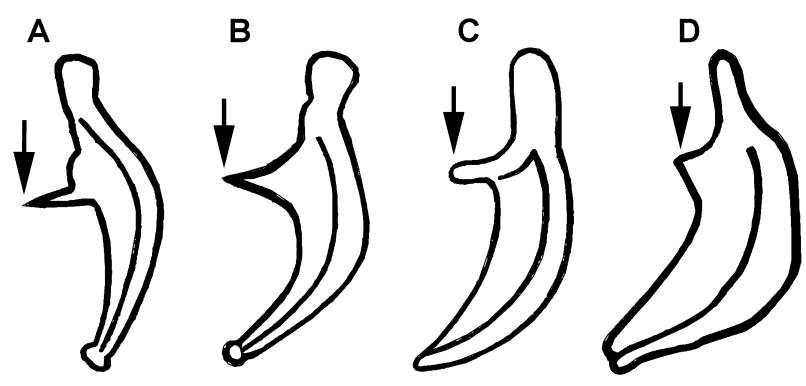

Fig. 6. Character 5: Male spicule rostrum. A: Thorn-like; B: Sharply conical to pointed or acute; C: Digitate; D: Bluntly conical.

C6: Female vulval flap (Fig. 7)

1: present (Fig. 7A);

2: absent (Fig. 7B).

Note: this character was used by Lieutier and Laumond (1979), Tarjan and Baeza-Aragon (1982), Giblin and Kaya (1983), Yin et al. (1988) and Braasch (2001). 


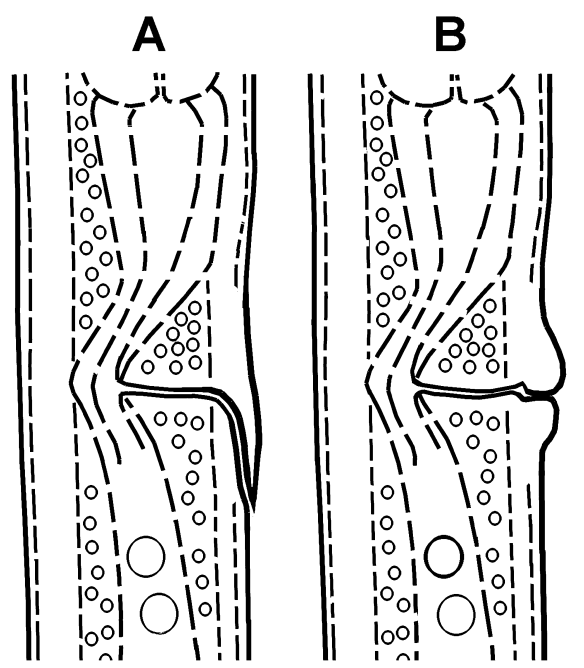

Fig. 7. Character 6: Female vulval flap. A: Present; B: Absent.

\section{C7: Excretory pore position (Fig. 8)}

1: at nerve ring or posterior (Fig. 8A);

2: between nerve ring and median bulb (Fig. 8B);

3: at median bulb (Fig. 8C);

4: anterior to median bulb (Fig. 8D).

Note: this character was used by Fuchs (1937), Massey (1971), Thong and Webster (1983) and Walia et al. (2003).

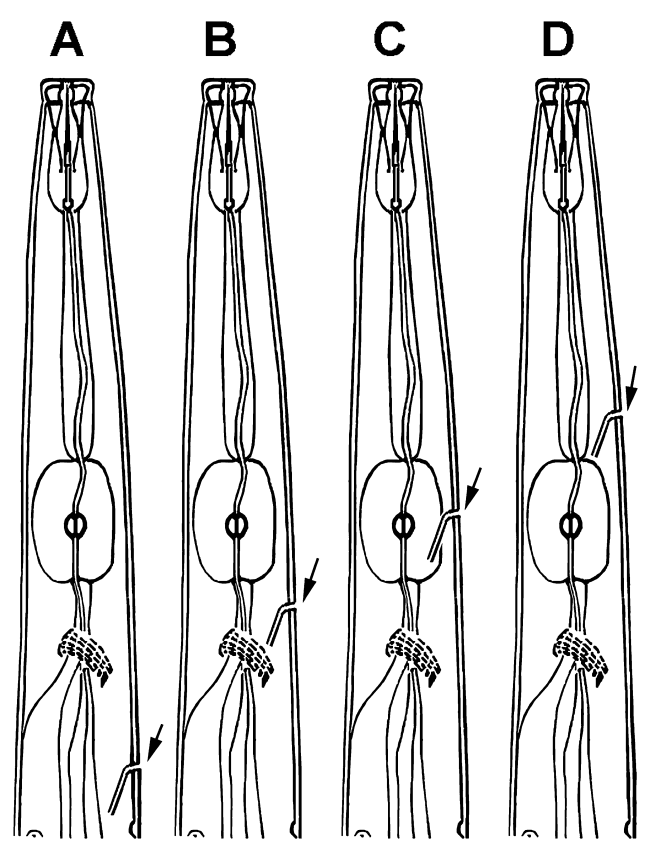

Fig. 8. Character 7: Excretory pore position (arrows). A: At nerve ring or posterior; $B$ : Between nerve ring and median bulb; $C$ : At median bulb; D: Anterior to median bulb.
C8: Male spicule condylus shape (Fig. 9)

1: truncate (Fig. 9A);

2: rounded (Fig. 9B);

3: pointed (Fig. 9C);

4: reduced to indistinct, not offset from capitulum-calomus angle (Fig. 9D).

Note: this character was used by Tarjan and Baeza-Aragon (1982), Yin et al. (1988) and Braasch (2001).

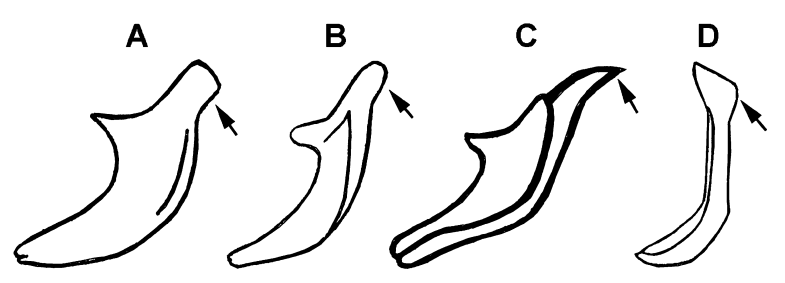

Fig. 9. Character 8: Male spicule condylus shape. A: Truncate; B: Rounded; C: Pointed; D: Reduced or indistinct, not offset from capitulum-calomus angle.

C9: Female tail tip curvature (Fig. 10)

1: Female tail tip strongly recurved (Fig. 10A);

2: Female tail tip straight or slightly curved ventrally (Fig. 10B).

Note: this character was used by Braasch and Schmutzenhofer (2000) and Braasch (2001).

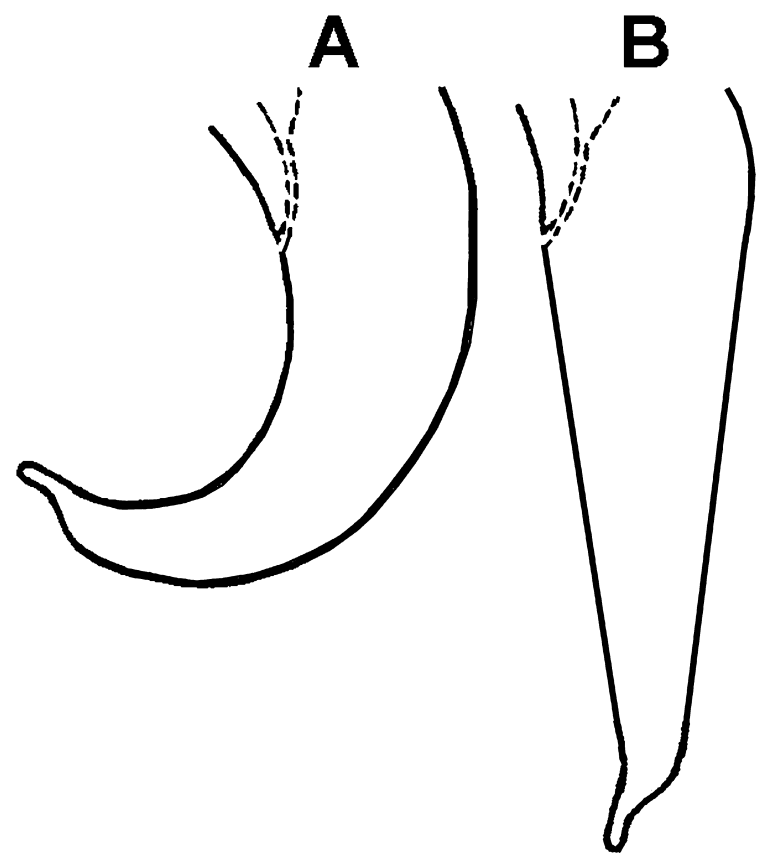

Fig. 10. Character 9: Female tail tip ventral curvature. A: Tail tip strongly recurved; B: Tail tip straight or slightly curved ventrally. 


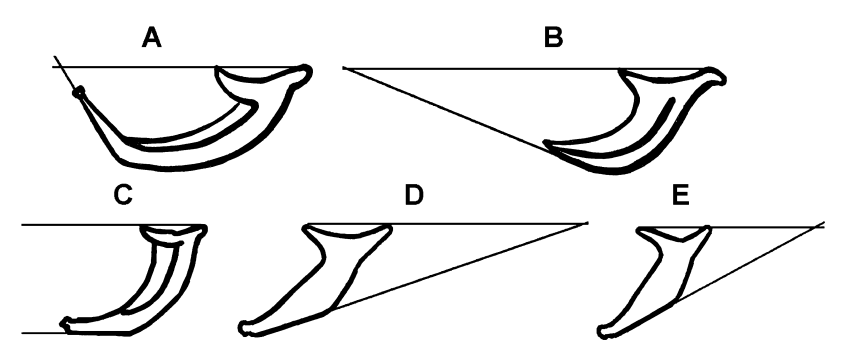

Fig. 11. Character 10: Angle between lines: along capitulum (condylus-rostrum) and extending the spicule end, in degrees. A: $45^{\circ}$ and more, point of intersection ventral; $B: 20-44^{\circ}$, point of intersection ventral; $C$ : From $19^{\circ}$ with point of intersection ventral, to $9^{\circ}$ with point of intersection dorsal; D: $10-29^{\circ}$, point of intersection dorsal; E: More than $30^{\circ}$, point of intersection dorsal.

C10: Angle between line along capitulum (condylus-rostrum) and line extending the spicule tip, in degrees (Fig. 11)

1: $45^{\circ}$ and more, intersection point ventral (Fig. 11A);

2: $20-44^{\circ}$, intersection point ventral (Fig. 11B);

3: from $19^{\circ}$ with intersection point ventral, to $9^{\circ}$ with intersection point dorsal (Fig. 11C);

4: 10-29 $9^{\circ}$ intersection point dorsal (Fig. 11D);

5: more than $30^{\circ}$, intersection point dorsal (Fig. 11E).

Note: this character was used, as a qualitative one, by GiblinDavis et al. (1993), Kolossova (1998) and Kanzaki and Futai (2003). Here the character is quantified.

\section{C11: Number of pairs of male postanal papillae} (including glandpapillae) (Fig. 12)

1: one (Fig. 12A);

2: two (Fig. 12B);
3: three (Fig. 12C.1, C.2);

4: four (Fig. 12D.1, D.2).

Note: this character was used by Fuchs (1937), Rühm (1956), Franklin and Hooper (1962), Tarjan and Baeza-Aragon (1982), Brzeski and Baujard (1997), Braasch and Schmutzenhofer (2000), Braasch (2001) and Kanzaki and Futai (2002a, 2003).

\section{C12: Number of lateral incisures (Fig. 13)}

1: two (i.e., one band in lateral field) (Fig. 13A);

2: three (i.e., two bands in lateral field) (Fig. 13B);

3: four (i.e., three bands in lateral field) (Fig. 13C);

4: five (i.e., four bands in lateral field) (Fig. 13D);

5: six (i.e., five bands in lateral field) (Fig. 13E).

Note: this character was used by Baujard (1980), Yin et al. (1988), Braasch et al. (1998), Braasch and Schmutzenhofer (2000), Braasch (2001) and Braasch and Braasch-Bidasak (2002). All the species descriptions with 'lateral field lines absent' are considered here as having an unknown number of lines and are marked by '?' in the tabular key.

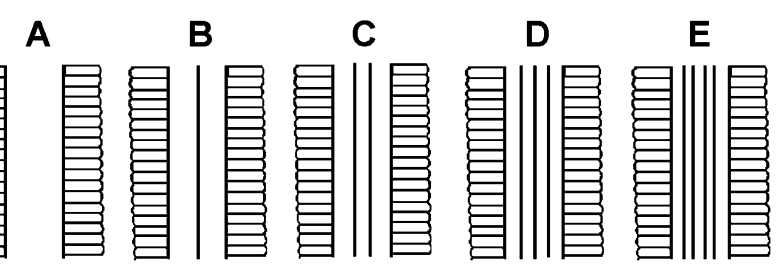

Fig. 13. Character 12: Number of lateral incisures. A: Two incisures (i.e., lateral field in one band); B: Three incisures (i.e., two bands in lateral field); C: Four incisures (i.e., three bands in lateral field); D: Five incisures (i.e., four bands in lateral field); E: Six incisures (i.e., five bands in lateral field).
A

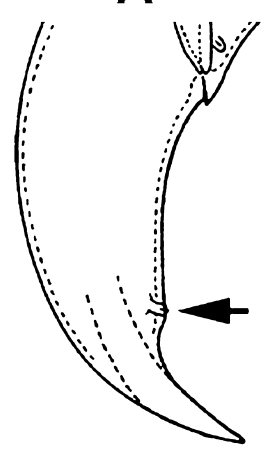

B

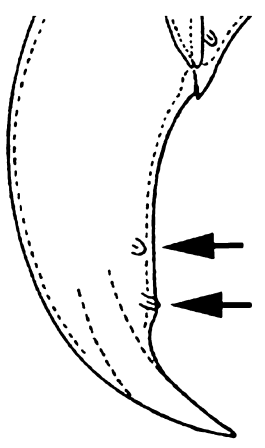

C.1

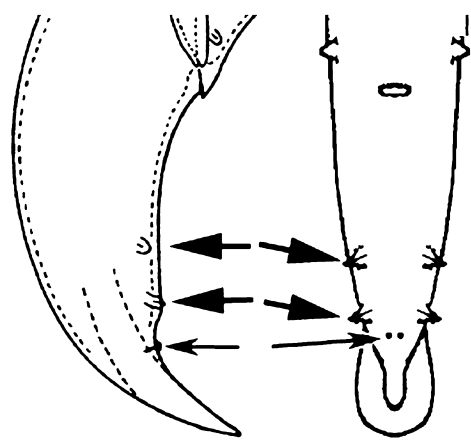

D.1

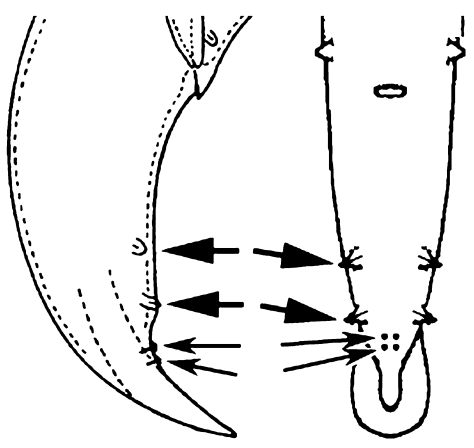

Fig. 12. Character 11: Number of pairs of male postanal papillae (including glandpapillae). Lateral view: A: One; B: Two; C.1: Three; D.1: Four. Ventral view: C.2: Three; D.2: Four. Large papillae marked by large arrows, small papillae (glandpapillae) by small arrows. 


\section{C13: Male spicule lamina midpoint (Fig. 14)}

1: exceptionally broad to mitten-shaped (Fig. 14A);

2: not exceptionally broad (Fig. 14B).

Note: this character was used by Yin et al. (1988).
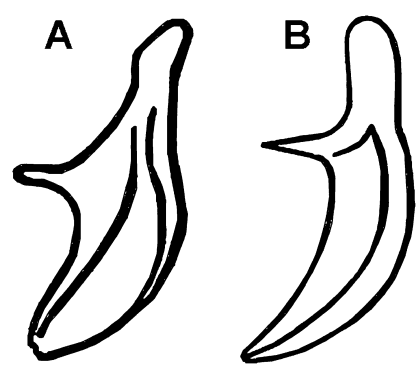

Fig. 14. Character 13. Midpoint of male spicule lamina. A: Exceptionally broad to mitten-shaped; B: Not exceptionally broad.

\section{C14: Male spicule lamina dorsal line (Fig. 15)}

1: smoothly and symmetrically curved (Fig. 15A);

2: angular at midpoint (Fig. 15B);

3: angular in last third or a quarter part (Fig. 15C).

Note: this character was used by Franklin and Hooper (1962) and Yin et al. (1988).
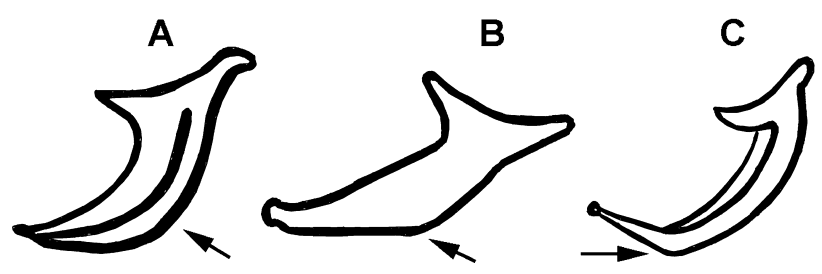

Fig. 15. Character 14: Spicule lamina dorsal contour. A: Smoothly and symmetrically curved; B: Angular at midpoint; $C$ : Angular in last third or quarter.

C15: Ratio of male spicule length along arc to its width measured posterior to rostrum (lateral view) (Fig. 16)

1: $<3.4$ (Fig. 16A);

2: 3.4-5.8 (Fig. 16B);

3: 5.9-9.0 (Fig. 16C);

4: $>9.0$ (Fig. 16D).

Note: this character was used as a qualitative one by Tarjan and Baeza-Aragon (1982) and Yin et al. (1988). Here the character is quantified.
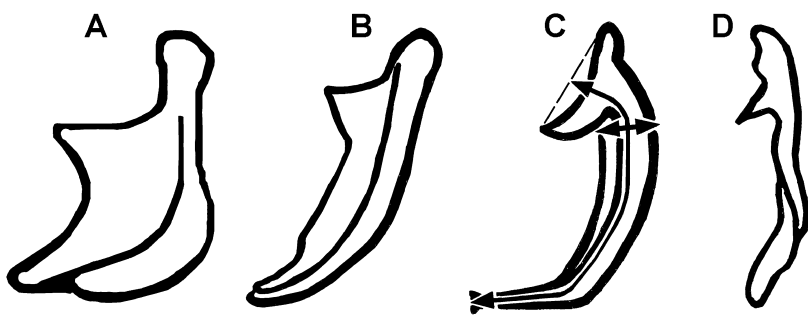

Fig. 16. Character 15: Ratio of male spicule length measured along arc to its width measured posterior to rostrum (lateral view). A: Less than 3.4; B: 3.4-5.8; C: 5.9-9.0; D: More than 9.0. (Note: Method of measuring is shown in C.)

C16: Stylet length:

1: $<11 \mu \mathrm{m}$;

2: $11-19 \mu \mathrm{m}$;

3: $>19 \mu \mathrm{m}$.

Note: this character was used by Fuchs (1937), Rühm (1956), Massey (1971), Tarjan and Baeza-Aragon (1982) and Yin et al. (1988).

\section{C17: Cephalic annuli (Fig. 17)}

1: indistinct under light microscope (Fig. 17A);

2: distinct under light microscope, of equal diameter (Fig. 17B);

3: distinct under light microscope, anterior annulus distinctly larger in diameter than others and offset (Fig. 17c).

Note: this character was used by Massey (1971a).
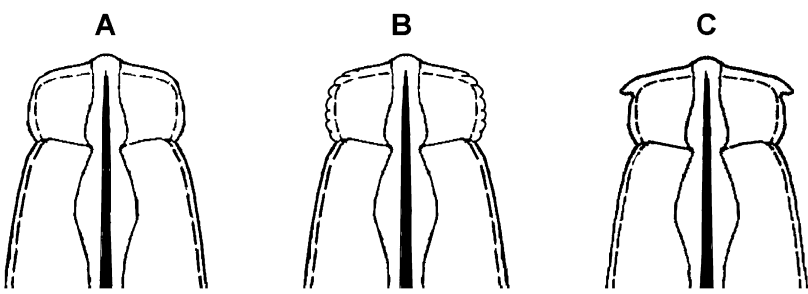

Fig. 17. Character 17: Cephalic annuli. A: Indistinct or absent under light microscope (LM); B: Distinct under LM, of equal width; C: Distinct under LM, anterior annulus distinctly larger in diameter than others and offset.

C18: Male spicule length measured along arc (method of measuring is shown in Fig. 16C)

1: $<13 \mu \mathrm{m}$;

2: $13-23 \mu \mathrm{m}$

3: $>23 \mu \mathrm{m}$.

Note: this character was used by Fuchs (1937), Rühm (1956), Tarjan and Baeza-Aragon (1982) and Yin et al. (1988). 
C19: Ratio of spicule length (along arc)/capitulum width (distance between ends of rostrum and condylus)

(Fig. 18)

1: $<1.5$ (Fig. 18A);

2: $1.5-2.2$ (Fig. 18B);

3: 2.3-3.0 (Fig. 18C);

4: 3.1-4.0 (Fig. 18D);

5: $>4.0$ (Fig. 18E).

Note: this character was used as a qualitative one by Yin et al. (1988). Here the character is quantified.

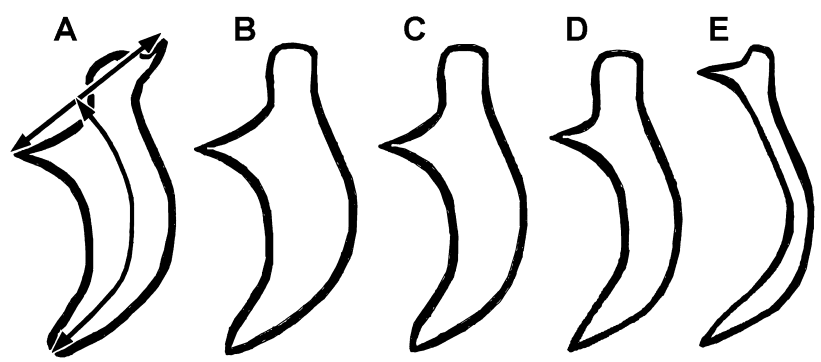

Fig. 18. Character 19: Ratio of spicule length (along arc) / capitulum width (distance between ends of rostrum and condylus). A: Less 1.5; B: 1.5-2.2; C: 2.3-3.0; D: 3.1-4.0; E: More than 4.0. (Note: Method of measuring is shown in A.)

C20: Ratio of depth of capitulum depression/capitulum width (Fig. 19)

1: 0.1 or less (Fig. 19A);

2: 0.11-0.20 (Fig. 19B);

3: $>0.2$ (Fig. 19C).

Note: this character was used as a qualitative one by Yin et al. (1988). Here the character is quantified.
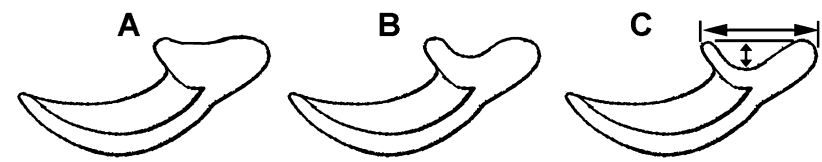

Fig. 19. Character 20: Ratio of depth of capitulum depression / capitulum width. A: 0.1 or less; B: 0.11-0.20; C: More than 0.2. (Note: Method of measuring is shown in C.)

\section{C21: Junction of spicule rostrum and calomus (Fig. 20)}

1: angular (Fig. 20A);

2: smoothly curved (Fig. 20B).

Note: this character is used here for the first time.
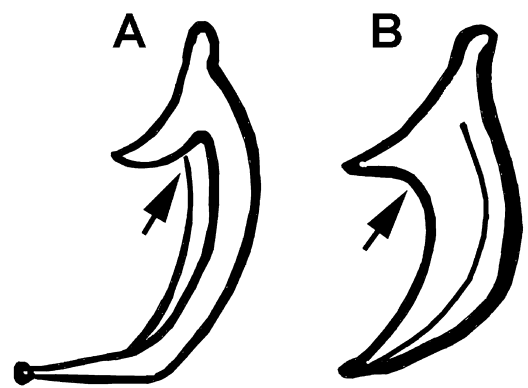

Fig. 20. Character 21: Junction of rostrum and calomus in male spicule. A: Angular; B: Smoothly curved.

C22: Male body length

1: $<360 \mu \mathrm{m}$;

2: $370-710 \mu \mathrm{m}$;

3: $720 \mu \mathrm{m}$ or more.

Note: this character was used by Fuchs (1937), Rühm (1956), Tarjan and Baeza-Aragon (1982) and Yin et al. (1988).

\section{C23: Male index a}

1: 27 or less;

2: $28-79$;

3: $>80$.

Note: this character was used by Fuchs (1937), Rühm (1956), Tarjan and Baeza-Aragon (1982) and Yin et al. (1988).

\section{C24: Male index $c$}

1: 14 or less;

2: $15-50$;

$3:>50$.

Note: this character was used by Fuchs (1937), Rühm (1956), Tarjan and Baeza-Aragon (1982) and Yin et al. (1988).

\section{C25: Male bursal flap shape (ventral view) (Fig. 21)}

1: conical to finely pointed (Fig. 21A);

2: oval to rounded (Fig. 21B);

3: truncate, posterior edge straight or curved inwards (Fig. 21C);

4: absent.

Note: this character was used by Rühm (1956), Giblin and Kaya (1983) and Braasch and Schmutzenhofer (2000). A fourth state (bursal flap absent) is added for the outgroup used in the analysis of the general phenetic similarity (Aphelenchoides ritzemabosi). Males of all species of Bursaphelenchus have a bursal flap, this being the main diagnostic feature for the genus and also for the family Parasitaphelenchidae. 


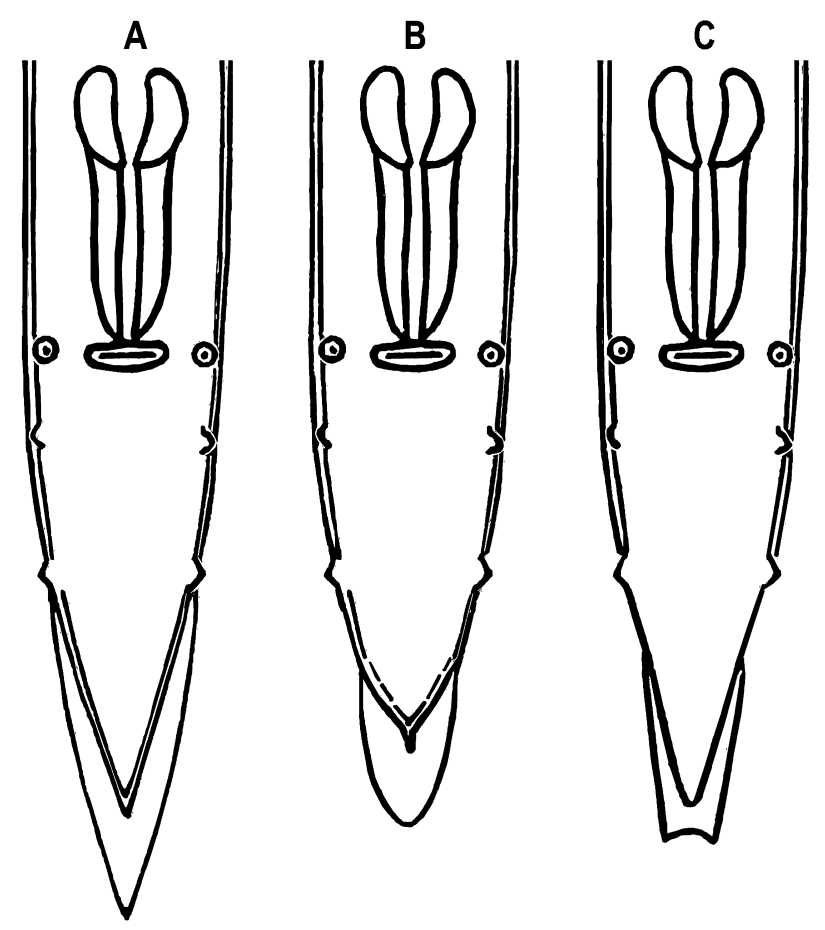

Fig. 21. Character 25: Male bursa shape (ventral view). A: Conical to finely pointed; B: Oval to rounded; C: Truncate, posterior edge straight or curved inwards.

C26: Male tail terminus shape (lateral view) (Fig. 22)

1: mucronate (Fig. 22A);

2: pointed (Fig. 22B);

3: narrowly rounded (Fig. 22C);

4: rounded (Fig. 22D).

Note: this character was used by Braasch (1998) and Braasch and Schmutzenhofer (2000).
C27: Female body length

1: $<390 \mu \mathrm{m}$;

2: $400-1400 \mu \mathrm{m}$;

3: $>1400 \mu \mathrm{m}$.

Note: this character was used by Fuchs (1937), Rühm (1956), Tarjan and Baeza-Aragon (1982) and Yin et al. (1988).

C28: Female index a

1: 27 or less;

2: $28-40$;

3: 41-58;

4: $>58$.

Note: this character was used by Fuchs (1937), Rühm (1956), Tarjan and Baeza-Aragon (1982) and Yin et al. (1988).

C29: Female index c

1: 15 or less;

2: $16-45$;

3: 46 or more.

Note: this character was used by Fuchs (1937), Rühm (1956), Tarjan and Baeza-Aragon (1982) and Yin et al. (1988).

C30: Female index $c^{\prime}$

1: 2.2 or less;

2: $2.3-4.1$

3: $4.2-5.5$

4: 5.6 or more.

Note: this character was used by Loof (1964), Tarjan and Baeza-Aragon (1982), Brzeski and Baujard (1997), Braasch and Schmutzenhofer (2000) and Kanzaki et al. (2000).

A

B

C
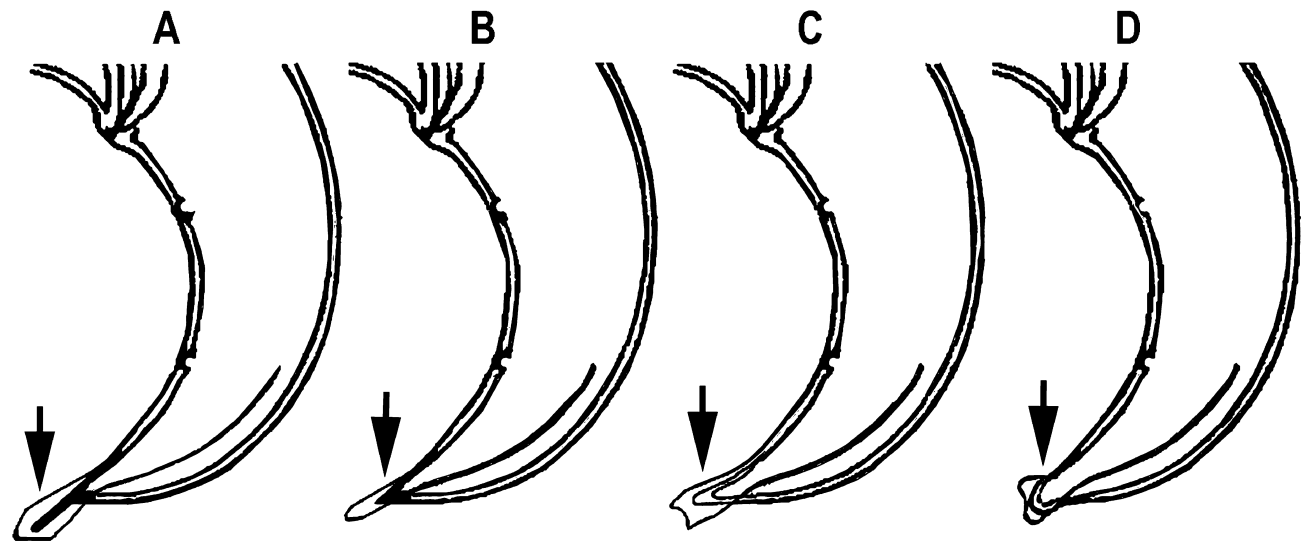

Fig. 22. Character 26: Male tail terminus shape (lateral view). A: Mucronate; B: Pointed; C: narrowly rounded; D: Rounded. 


\section{C31: Female index $V$}

1: 65 or less;

2: $66-83$;

3: 84 or more.

Note: this character was used by Fuchs (1937), Rühm (1956), Tarjan and Baeza-Aragon (1982) and Yin et al. (1988).

C32: Ratio offemale postuterine branch length to vulva-anus distance (Fig. 23)

1: $<0.2$ (Fig. 23A);

2: 0.2-0.3 (Fig. 23B);

3: 0.31-0.69 (Fig. 23C);

4: 0.7 or more (Fig. 23D).

Note: this character was used by Baujard (1980), Braasch and Schmutzenhofer (2000) and Braasch and Braasch-Bidasak (2002).
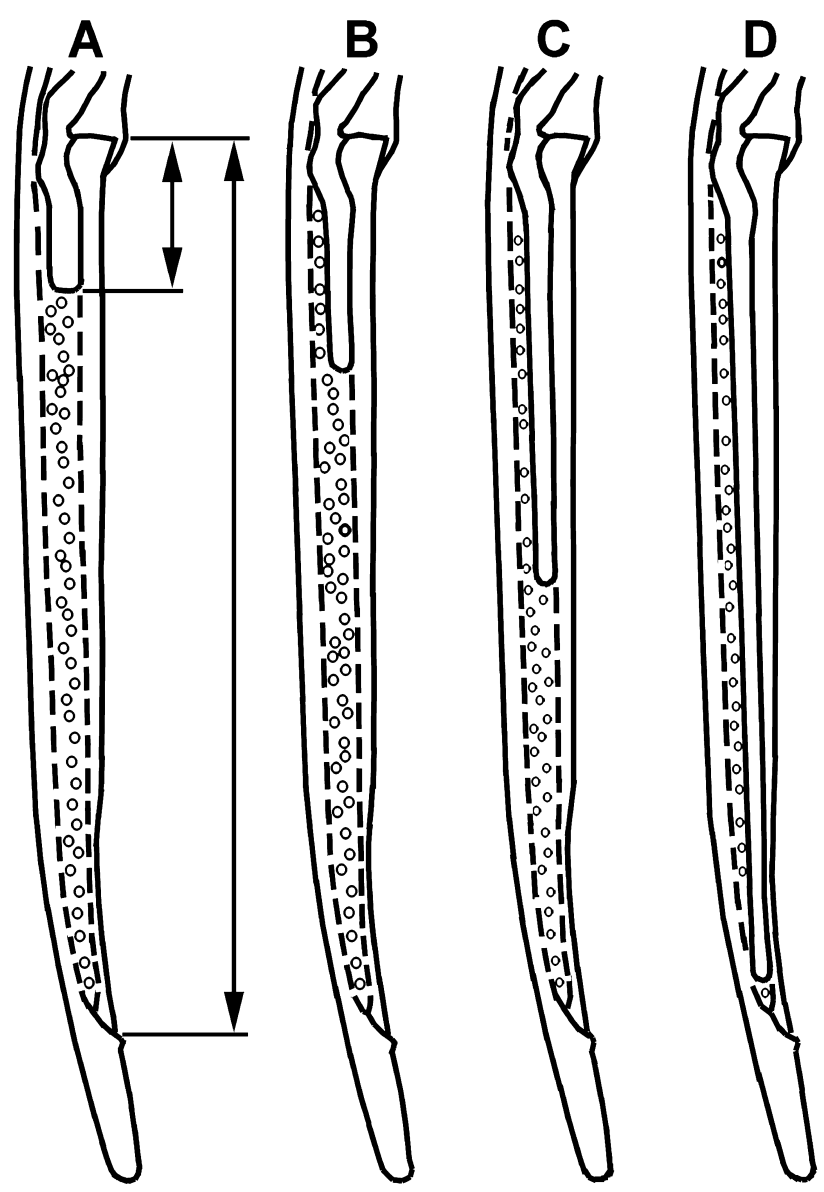

Fig. 23. Character 32: Ratio of female genital postuterine branch length to vulva-anus distance. A: Less than 0.2; B: 0.20.3; C: 0.31-0.69; D: 0.7 or more. (Note: Method of measuring is shown in A.)

\section{NOTES ON SOME SPECIES IN THE TABULAR KEY (TABLE 1)}

i) Bursaphelenchus bestiolus. Female postuterine branch length of 8-9 times body diam. was given in Massey (1974); but in the figure, the postuterine branch is 6.6 body diam. long. In Table 1 the summarised range of 6.6-9.0 is used.

ii) Bursaphelenchus borealis. J4 ectophoretic juveniles have the excretory pore anterior to the median bulb.

iii) Bursaphelenchus cryphali. Male characters are mainly given by Rühm (1956); males were not described by Fuchs (1930).

iv) Bursaphelenchus erosus. Described only from males.

v) Bursaphelenchus gonzalezi. Male characters were measured from the drawing as they were not mentioned in the original description. The spicule is $18 \mu \mathrm{m}$, not 13 $\mu \mathrm{m}$ long, as given in tables by Yin et al. (1988) and later repeated by Braasch (2001). Here the range $13-18 \mu \mathrm{m}$ is used (Table 1).

vi) Bursaphelenchus hylobianum. According to Korentchenko (1980), the male has one pair of large precloacal papillae and two pairs of small postcloacal papillae; but according to Braasch and Braasch-Bidasak (2002), there is one pair of postanal papillae and one unpaired adanal papilla. Both possible papillae patterns are included here in a range of the character states (Table 1).

vii) Bursaphelenchus lini. In Table 1 for B. lini c and $\mathrm{c}^{\prime}$ indexes are calculated from the figures and table in Braasch (2004b) by using the end of the intestine as demarcating the beginning of the tail. This somewhat perplexing species differs from other Bursaphelenchus spp. in the obscure rectum and anus in females, wide stylet lumen and absence of basal knobs or thickenings of stylet. In these features B. lini is close to Ektaphelenchidae, although the male does have a terminal bursa.

viii) Bursaphelenchus scolyti. The length of spicule (7 $\mu \mathrm{m})$ was calculated by Yin et al. (1988) from the closest scale given for the head in Massey (1974). The real scale is different, however, a fact that can be proved by calculation of the male tail length from the same figure and comparing it with the value of L/c-index in Massey's description. The real spicule length, as calculated from the drawing, is $16 \mu \mathrm{m}$.

ix) Bursaphelenchus seani. The male spicule is 26$27 \mu \mathrm{m}$ long as calculated from the scale and testing the 
scale from tail length $=\mathrm{L} / \mathrm{c}$ index. The $14 \mu \mathrm{m}$ spicule length given by Yin et al. (1988) is an error.

x) Bursaphelenchus xylophilus. The disposition of the male papillae has been studied most thoroughly in this species. There are two postcloacal pairs of papillae located very together at $c a$ mid-tail; one pair of precloacal papillae and one unpaired precloacal papilla (Nickle et al., 1981; Mota et al., 1999).

\section{List of records, with names of natural vectors, associated plants and taxonomic notes}

Table 2 gives the country by country distribution of Bursaphelenchus species, summarised from the records listed in the Appendix. In the Appendix, Bursaphelenchus species are listed alphabetically with the references for each species record listed chronologically. All available data are listed for each reference (country, vectors and their families; associated plants and their families). If data on a vector or a plant are absent they are omitted without special comment (every effort was made to ensure that the literature sources were as comprehensive and up-to-date as possible). Names of plant families are given according to Takhtajan (1987). The list includes data only on the natural vectors and plants, experimental vectors and plants being excluded.

\section{REMARKS ON THE APPENDIX}

1) The records of $B$. cocophilus do not cover all the literature and are only intended to demonstrate the diversity of distribution and the associated vector and plant taxa.

2) The records of B. xylophilus do not cover all the literature and are only intended to demonstrate the diversity of distribution and the associated vector and plant taxa. A detailed review, to be published separately, is planned.

3) Braasch et al. 2001 (pp. 134-136, Figs 2, 5, Table 1) identified two females as $B$. xylophilus plus four males and 16 juveniles in a wood sample imported from Byelorussia. Molecular DNA confirmation of the species identification was not possible and a re-examination of the record is needed.

\section{Recommended standard for species descriptions within the genus Bursaphelenchus Fuchs, 1937}

The current research has led to the realisation of the desirability of a minimum standard for future species descriptions/redescriptions in this genus. The standard proposed herein includes characters already listed and used in keys and other taxonomic papers by the most experienced specialists in the identification of Bursaphelenchus species. The combination of characters in the list below is necessary in order to reliably distinguish the existing nominal species. It was shown by using the Pickey 8 software (Dianov \& Lobanov, 2004), module 'Test of taxa differences', that if any four of these characters were removed, an 'unrecognisable group' of two or more species resulted. This will be described in a future publication on the computerised identification of Bursaphelenchus species.

In the list below, alternative character states for each qualitative character (in brackets) are separated by a slash (/). Measured characters should be expressed in $\mu \mathrm{m}$.

\section{General characters (common for male and female)}

Cephalic annuli (indistinct under light microscope / of equal diameter / anterior annulus distinctly greater in diameter than others and offset). Excretory pore position (at nerve ring or posterior / between nerve ring and median bulb / at median bulb / anterior to median bulb). Number of lateral incisures.

\section{Male}

Body length. Stylet length. Ratios a and c. Number of pairs of male caudal papillae and their arrangement pattern relative to cloacal aperture and bursal flap. Male bursa shape, ventral view: (conical to finely pointed / oval to rounded / truncate with posterior edge curved inwards). Male tail terminus shape, lateral view: (mucronate / pointed / narrowly rounded / rounded).

\section{Spicule}

Length along arc. Ratio of spicule length along arc to its width measured posterior to rostrum (lateral view). Ratio of depth of capitulum depression/capitulum width. Ratio of spicule length (along arc) to capitulum width. Angle between line along capitulum (condylus-rostrum) and line extending the spicule end (in degrees) with an indication of the point of intersection (ventral/dorsal). Spicule structure type (species group name: aberrans-, borealis-, eidmanni-, hunti-, piniperdae-, xylophilus-group). Rostrum 


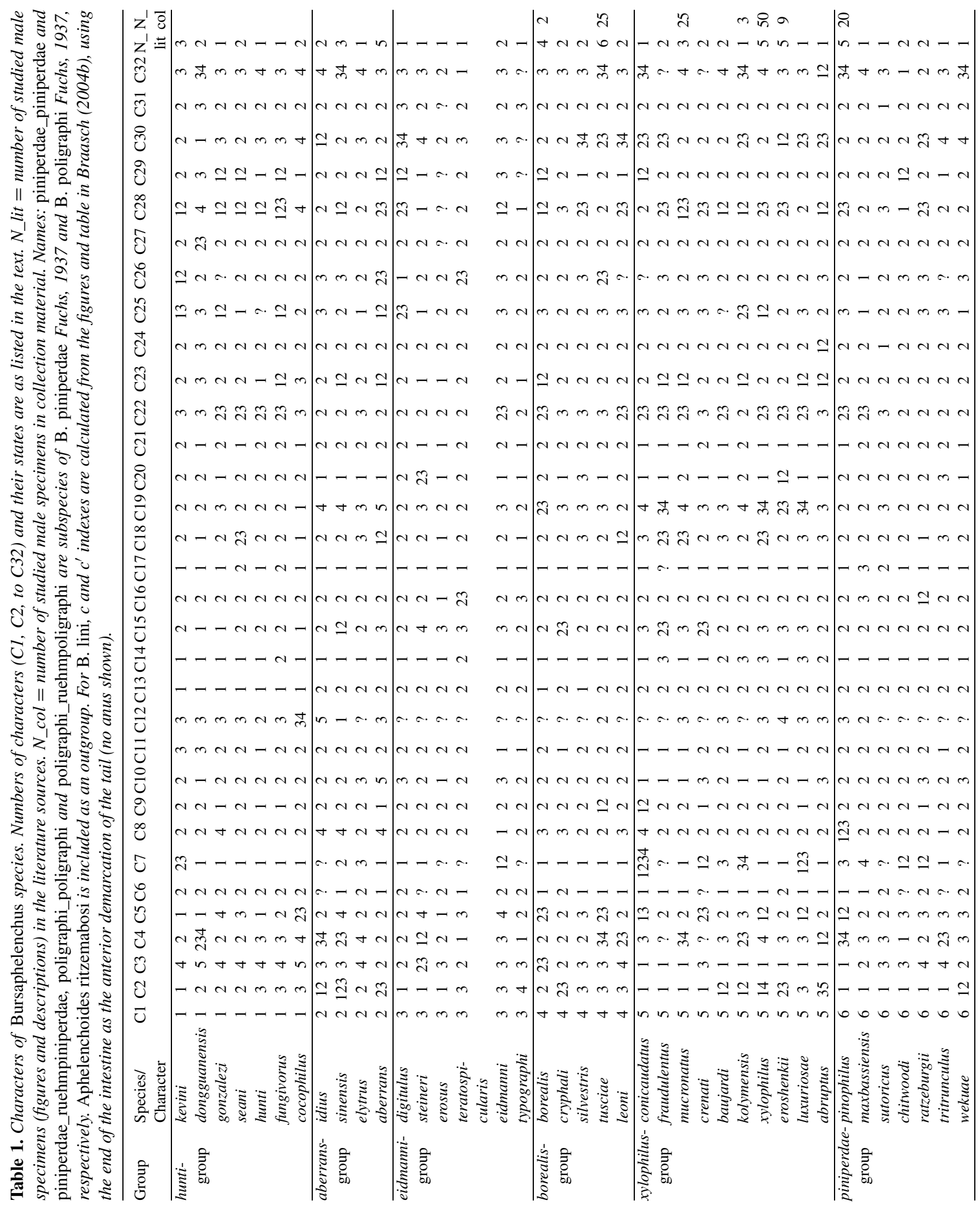

Vol. 7(3), 2005 


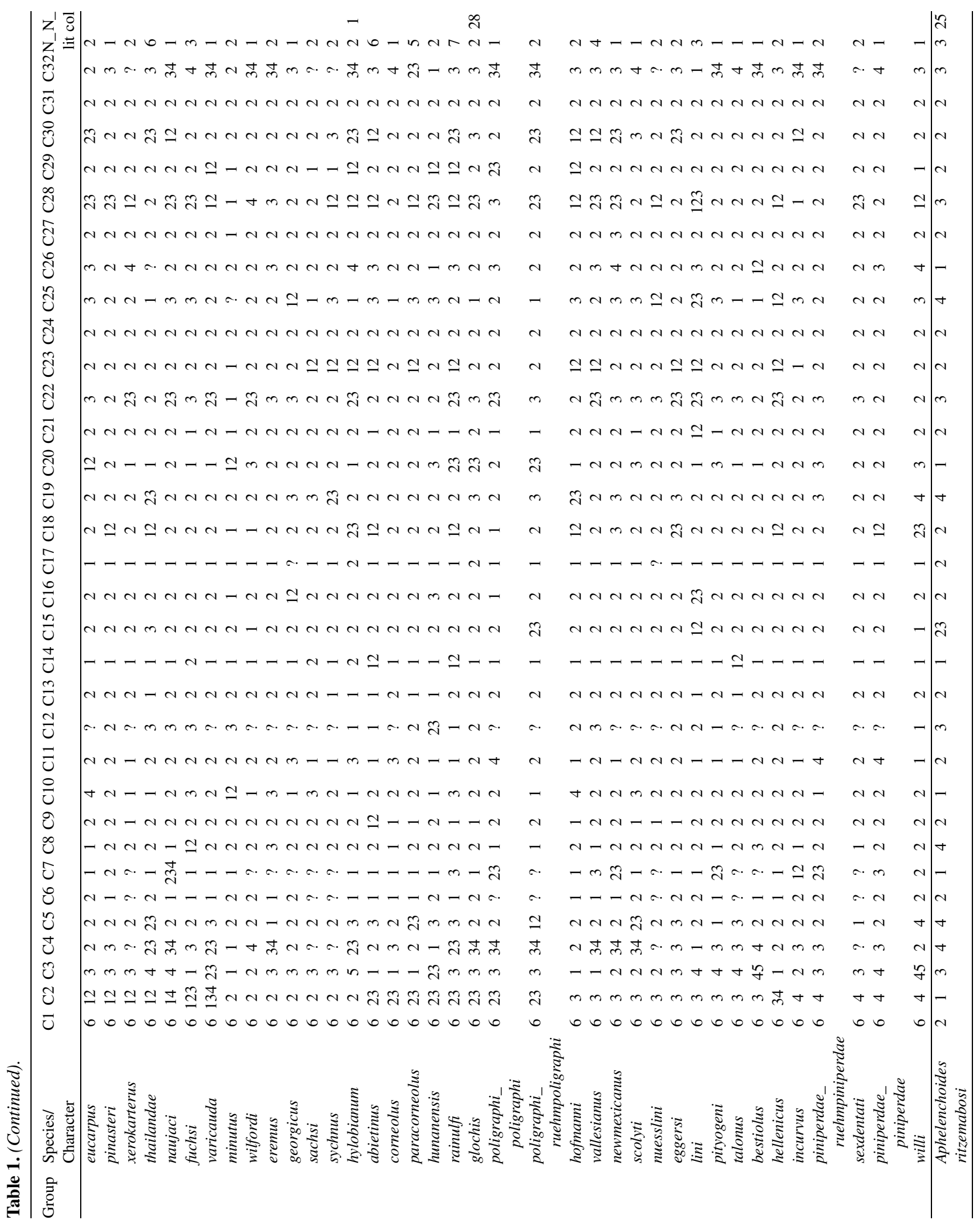


shape (thorn-like / sharply conical to pointed or acute / digitate / bluntly conical to almost flattened). Shape of junction of rostrum and calomus (angular / smoothly curved). Condylus, posterior curvature (recurved posteriorly / not recurved posteriorly). Condylus shape (truncate / rounded / pointed / reduced to indistinct). Spicule tip, lateral view (with cucullus / without cucullus: sharp to angular / finely rounded to digitate / bluntly rounded to widely rounded / broadly truncate). Lamina midpoint (exceptionally broad to mitten-shaped / not exceptionally broad). Lamina dorsal line (smoothly and symmetrically curved / angular at midpoint / angular in last third or quarter).

\section{Female}

Body length. Stylet length. a, c, c', V indexes. Vulval flap (present / absent). Vulval flap length. Ratio of female genital postuterine branch length to vulval body diameter. Ratio of female genital postuterine branch length to vulvaanus distance. Tail tip shape (mucronate / pointed / finely rounded / broadly rounded / truncate). Tail tip curvature (strongly recurved / straight to slightly curved ventrally).

\section{Dispersal juvenile}

Tail tip shape of J3/J4 ectophoretic stage (mucronate / pointed, finely rounded / broadly rounded / truncate).

\section{Habitat}

Type locality and other localities. Associated plant species (Latin name with authority). Location in plant. Associated vector species (Latin name with authority). Location of the dispersal juvenile in/on vector.

\section{Dendrograms of general phenetic similarity}

The dendrogram of general phenetic similarity (type of cluster analysis: distance; UPGMA, standard distance: mean character difference) based on Table 1 is given in Figure 24 (for all characters) and Figure 25 (spicule characters only, namely characters $1,3,5,8,10,13$ 15, 18-21 in Table 1). PAUP4.0v10 software (Swofford, 2001) was used for the cluster analysis. Aphelenchoides ritzemabosi was used as the outgroup to root the tree.

\section{Discussion}

Clusters represent assemblages of species within the multidimensional space of the diagnostic characters, as analysed by the algorithm employed (here the general similarity algorithm has been used). If the diagnostic group (based on the combination of a few diagnostic characters) forms, either completely or partially, a separate cluster in a multidimensional space of all the important diagnostic characters, it may be concluded that these few characters were well-selected for the group diagnosis and that there is, therefore, a high probability of the group being a natural one (i.e., originating from a single ancestor and morphologically distinct).

However, there are many clusters on the dendrogram and it is not possible to provide a brief and convenient taxonomic diagnosis for all of them, i.e., not all of them represent natural groups. The most important additional argument to support a cluster as being a natural taxon is a specific niche for the constituent species. This niche should be different from the niches of adjacent clusters. For this reason, a dendrogram needs to be verified by niche-specific criteria (e.g., systematic position of the associated plants, insects, fungi). Of course, niche parameters should be independent, i.e., not included in the dataset from which the dendrogram is generated. Even if a diagnostic species group coincides generally well with its dendrogram cluster, some of its members may be more distant from the main cluster of species.

The main issue of this discussion is whether the diagnostic groups of species proposed herein are natural. From the two dendrograms (Figs 24, 25), the one based on spicule characters (Fig. 25) better reflects the natural relationships among the species. Sclerotised and complicated structures have been recommended as the basis for the analysis of relationships (Remane, 1952) and the male spicules represent the best such structures in Bursaphelenchus and the superfamily Aphelenchoidoidea as a whole. To verify the relationships shown in the dendrograms (Figs 24, 25), the data relating to the taxonomic position of vectors and associated plants for different Bursaphelenchus species were used. The list of records of natural vectors, plants and their families from the cited literature sources is given in the Appendix.

In general, the biological link between vectors of the family Scolytidae (bark beetles) and the associated plants of the family Pinaceae (the main nutrition source for both the insect and the nematode) is dominant (i.e., most frequent). The 'vector-associated plant' link may be referred to as the 'transmission-associated complex' (TA complex). The task is to follow changes in the TA complex within the genus Bursaphelenchus at the level of the family of the vectors and associated plants. The complex 


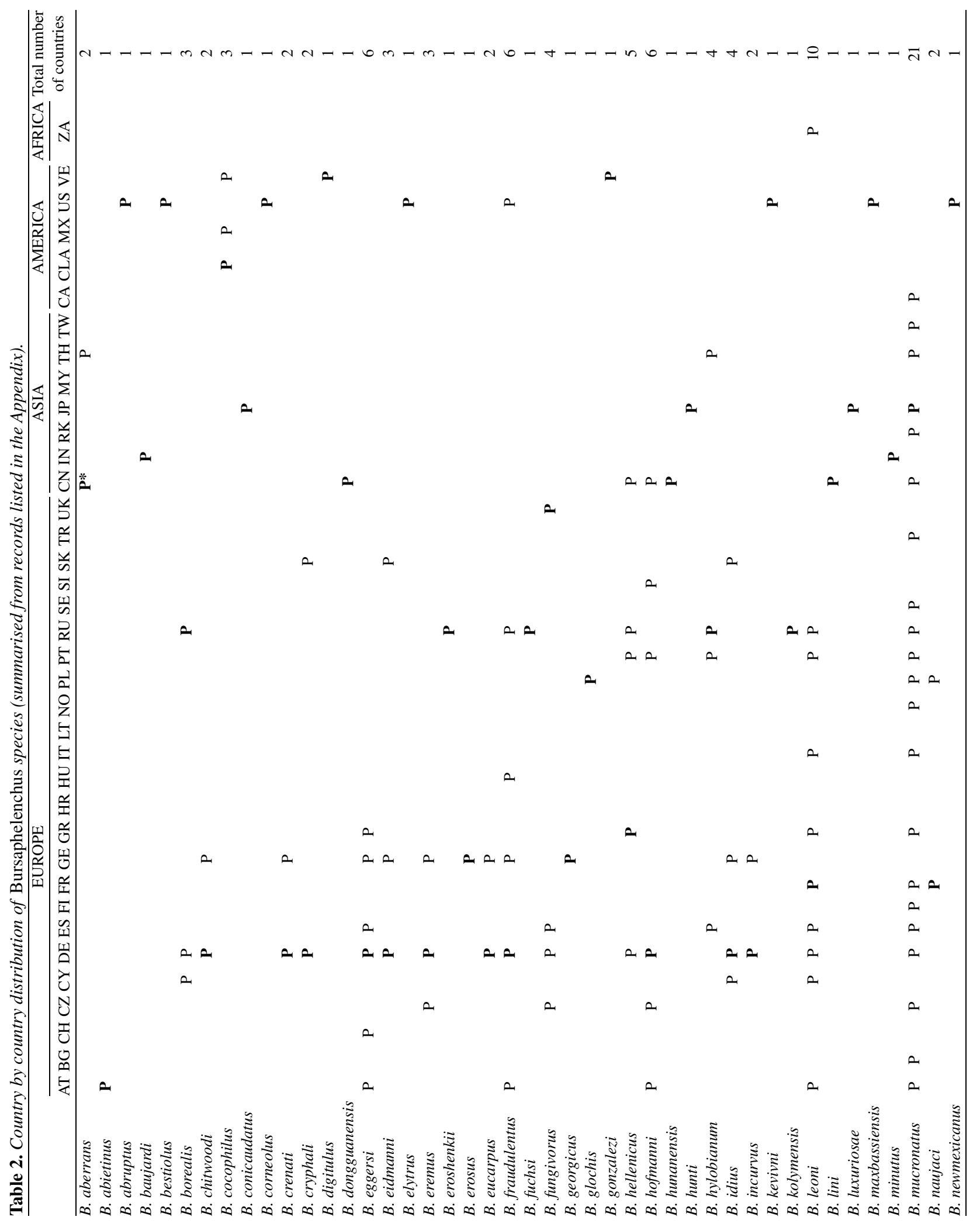




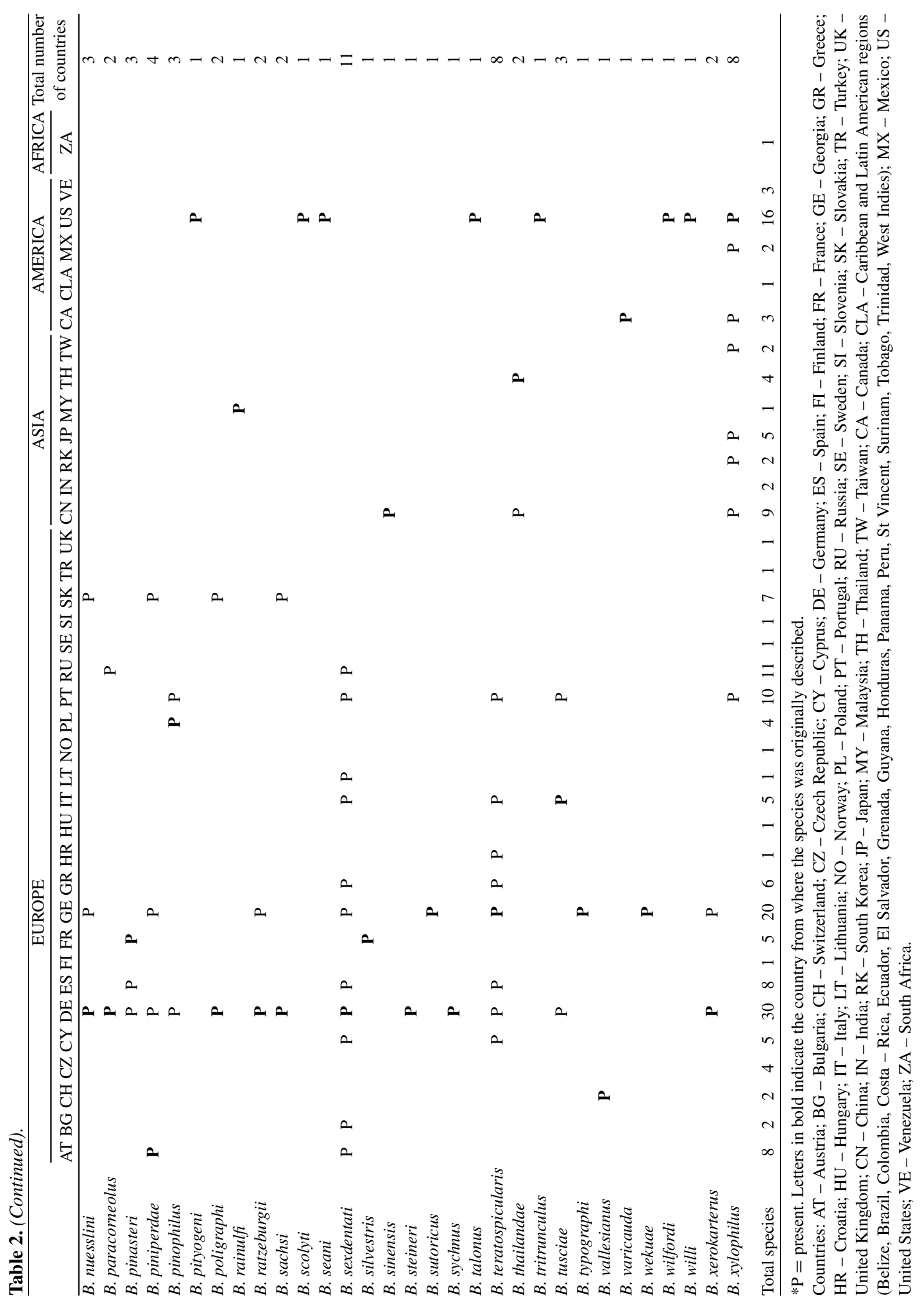


A. Ryss et al.

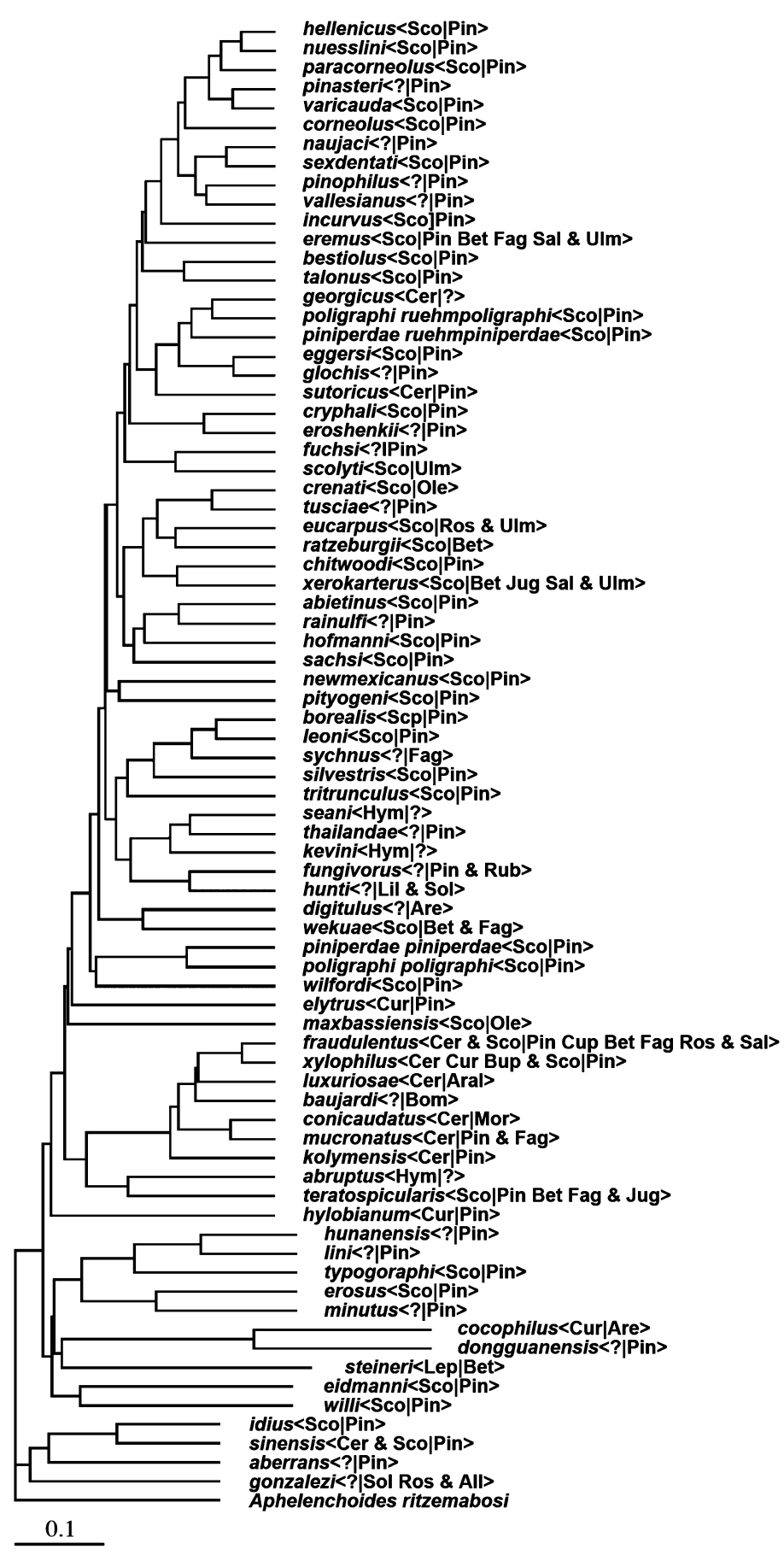

Fig. 24. Dendrogram of general phenetic similarity (UPGMA, standard distance: mean character difference) of Bursaphelenchus species based on all characters (Table 1). In brackets: Vector families: Bup = Buprestidae; Cer =Cerambycidae; Cur = Curculionidae; Sco = Scolytidae; Hym = Halictidae; Lep = Sesiidae; Plant families: All = Alliaceae; Aral = Araliaceae; Are = Areaceae; Bet $=$ Betulaceae; Cup = Cupressaceae; Fag = Fagaceae; Jug = Juglandaceae; Mor = Moraceae; Ole =Oleaceae; Pin = Pinaceae, Ros = Rosaceae $;$ Rub = Rubiaceae $;$ Sal = Salicaceae; Sol = Solanaceae $;$ Ulm = Ulmaceae. Names: piniperdae_piniperdae and piniperdae_ruehmpiniperdae, poligraphi_poligraphi and poligraphi_ruehmpoligraphi refer to subspecies of B. piniperdae Fuchs, 1937 and B. poligraphi Fuchs, 1937, respectively. Aphelenchoides ritzemabosi is included as an outgroup. 


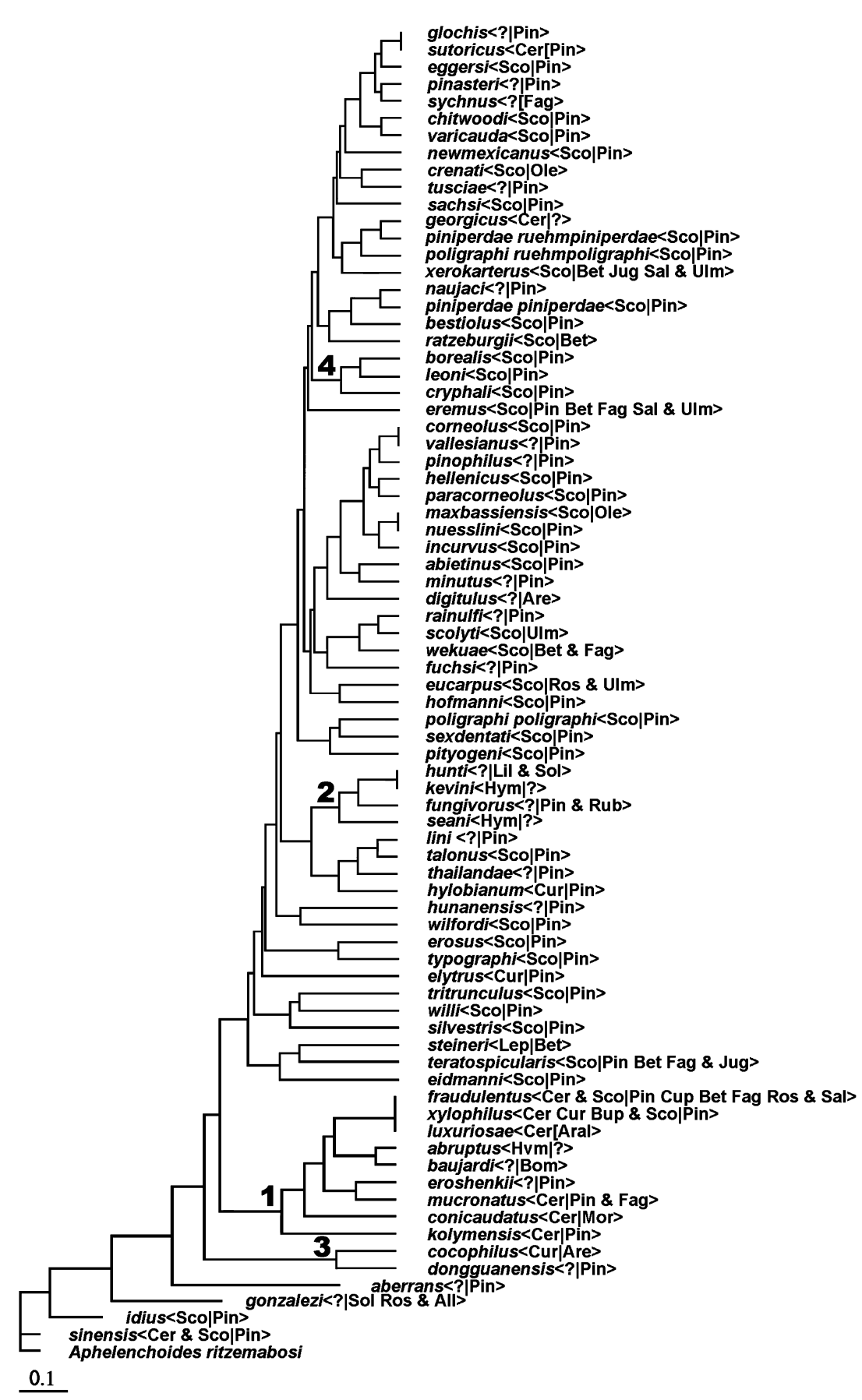

Fig. 25. Dendrogram of general similarity (UPGMA, standard distance: mean character difference) of Bursaphelenchus spp., based only on spicule characters $(1,3,5,8,10,13-15,18-21$ in Table 1). In brackets: Vector families: Bup = Buprestidae; Cer = Cerambycidae; Cur = Curcullionidae $;$ Sco = Scolytidae; Hym = Halictidae; Lep = Sesiidae. Plant families: All = Alliaceae; Aral = Araliaceae; Are = Areaceae; Bet = Betulaceae; Cup = Cupressaceae $;$ Fag = Fagaceae; Jug = Juglandaceae $;$ Mor = Moraceae; Ole $=$ Oleaceae; Pin = Pinaceae, Ros =Rosaceae; Rub=Rubiaceae; Sal =Salicaceae; Sol =Solanaceae $;$ Ulm =Ulmaceae. Clusters are numerated as: 1: 'xylophilus' cluster; 2: 'hunti' cluster; 3: 'cocophilus' cluster; 4: 'borealis' cluster. Names: piniperdae_piniperdae and piniperdae_ruehmpiniperdae, poligraphi_poligraphi and poligraphi_ruehmpoligraphi refer to subspecies of B. piniperdae Fuchs, 1937 and B. poligraphi Fuchs, 1937, respectively. Aphelenchoides ritzemabosi is included as an outgroup. 
Scolytidae-Pinaceae may be considered as primitive for the genus as it is typical for species at the root of the dendrogram, as well as for the more advanced groups in the upper part of the tree (Fig. 25).

The greatest deviation from the initial vector-associated plant combination may be seen in the xylophilus-group comprising B. xylophilus, B. abruptus, B. baujardi, B. conicaudatus, B. eroshenkii, B. fraudulentus, B. kolymensis, B. luxuriosae and B. mucronatus (cluster 1 in Fig. 25 ). This species-group has changed the presumed initial scolytid vector to beetles that are mainly from the family Cerambycidae. The xylophilus-group may therefore be considered as a 'natural' species group.

Bursaphelenchus crenati, a member of the xylophilusgroup (in the diagnostic sense), clusters outside the main group. This species has the same shape of spicule as the other species in the group, yet lacks a cucullus. Only beetles of the family Scolytidae are known to vector this species and it may therefore be concluded that $B$. crenati is a member of the diagnostic xylophilusgroup, but not the natural xylophilus-group (which is vectored by Cerambycidae). The presence of a cucullus therefore appears to be a highly significant character in the identification of this economically important group.

The hunti-group consists of two assemblages. One includes four species (cluster 2 in Fig. 25): B. hunti, B. seani, B. kevini and B. fungivorus, and may also be considered as a natural group. The basic TA complex of Scolytidae-Pinaceae has changed, Hymenoptera now serving as vectors and the associated plants belong to Liliaceae, Solanaceae and Rubiaceae. Another cluster (cluster 3 in Fig. 25) consists of the two rather similar species B. cocophilus and B. dongguanensis. This cluster is situated near the root of the dendrogram (Fig. 25).

The main part of the borealis-group (B. borealis, $B$. cryphali, B. leoni), a diagnostic group based on the posteriorly recurved condylus of the male spicule, forms cluster 4 in Figure 25. For this group the ScolytidaePinaceae complex is typical.

Other species-groups may be considered as purely diagnostic assemblages. In Figure 25, the aberrans-group is, based on the primitive characters, paraphyletic, its species being located at the root of the diagram (with TA complex Scolytidae-Pinaceae). The most numerous species-group is the piniperdae-group. It is undoubtedly paraphyletic and represents the majority of the genus with the exception of the above-mentioned natural groups (clusters 1-4 in Fig. 25) and the primitive paraphyletic assemblage of the aberrans-group. The basic Scolytidae-
Pinaceae complex is typical for the piniperdae-group with rare changes of the vector to Cerambycidae (B. sutoricus, $B$. georgicus) and the associated plants to Fagaceae ( $B$. sychnus).

\section{EVOLUTIONARY TRENDS WITHIN THE TA COMPLEX}

The initial TA complex of Scolytidae-Pinaceae is changeable but only rarely does the preferred vector shift to the Cerambycidae (the xylophilus-group) or Hymenoptera (the hunti-group), thereby leading to the formation of natural species-groups. In other cases the change of the vector to Cerambycidae (B. georgicus, $B$. sutoricus) or Lepidoptera (B. steineri) did not lead to the formation of natural superspecies groups, nor did the transition to other plant associations, such as: Oleaceae $(B$. crenati, B. maxbassiensis), Solanaceae (B. hunti, B. gonzalezi), Rosaceae (B. gonzalezi), Alliaceae (B. gonzalezi), Liliaceae (B. hunti), Rubiaceae (B. wilfordi), Ulmaceae (B. scolyti, B. xerokarterus), Betulaceae (B. hofmanni), Fagaceae (B. wekuae, B. sychnus), Araliaceae (B. luxuriosae), or Arecaceae (B. digitulus). It is clear that, although vector selection is changeable (Kulinich \& Orlinsky, 1998), it is comparatively more important for the evolution of the genus Bursaphelenchus than associations with plants at the family level.

The third trophic component associated with the nematode are fungi, an association that may be of even greater significance in the origin and evolution of the genus Bursaphelenchus (Giblin-Davis et al., 2003). However, data on the fungi species occurring in natural Bursaphelenchus associations are as yet insufficient for the detailed comparative analysis necessary to elucidate relationships.

\section{Acknowledgements}

The authors are grateful to Drs Ana Catarina Penas, Maria Antónia Bravo and Prof. R. Giblin-Davis for their critical review of the manuscript and important advice; to Prof. I. Kerzhner for detailed taxonomic review, and for critical review and suggestions; Drs A. Lobanov and M. Dianov for consultations on the evaluation of character diagnostic values and computer technology for taxonomists; Dr T.G. Devdariani and Prof. I.Ya. Eliava for translation from Georgian; Prof. B. Zhao for translation from Chinese and Dr L. Hongmei for providing some Chinese literature. NATO support (CLG grant 978 881) attributed to all authors is hereby acknowledged. The Portuguese authors were initially supported by grant 32 619/99 of 
the Portuguese POCTI project, Fundação para a Ciência e Tecnologia (FCT) and are now currently being supported by the European Union 5th Framework, project QLK5-CT-2002-00672 PHRAME (Development of improved Pest Risk Analysis techniques for quarantine pests, using pinewood nematode, Bursaphelenchus xylophilus, in Portugal as a model system). The Russian authors were supported by the RFBR-NSFC program, project 03-0439022 (Pathological mechanisms of pine wilt disease).

\section{References}

ABAD, P. (2004). Satellite DNA used as a species specific probe for identification of the pine wood nematode Bursaphelenchus xylophilus. In: Mota, M. \& Vieira, P. (Eds). The pinewood nematode, Bursaphelenchus xylophilus. Proceedings of an International Workshop, University of Évora, Portugal, August 20-22, 2001. Nematology monographs and perspectives, Volume 1. Leiden, The Netherlands, E. J. Brill, pp. 155-163.

Abelleira, A., Escuer, M., Arias, M. \& Mansilla, J. (2003). The genus Bursaphelenchus Fuchs (Nematoda: Aphelenchida) in north-west Spain. Nematology 5, 677-685.

Adams, J.C. \& Morehart, A.L. (1982). Decline and death of Pinus spp. in Delaware caused by Bursaphelenchus xylophilus. Journal of Nematology 14, 382-385.

Ambrogioni, L. \& CAROPPO, S. (1998). Morphology and morphometrics of Italian populations of Bursaphelenchus species. Nematologia Mediterranea 26, 97-116.

Ambrogioni, L. \& Palmisano, A.M. (1998). Description of Bursaphelenchus tusciae sp. n. from Pinus pinea in Italy. Nematologia Mediterranea 26, 243-254.

Ambrogioni, L., Cerchiarini, G., Irdani, T. \& Tossani, N. (1994). Preliminary study on the distribution of Bursaphelenchus spp. (Nematoda) in Italian pine stands. Redia 77, 273278.

ANDRÁssy, I. (1958). Szabadonelo fonalfergek, Nematoda libera. Budapest, Magyarorszag allatvilaga, $362 \mathrm{pp}$.

Araújo, J.C.A., AraúJo, A.E. \& SAntos, A.F. (1998). Population dynamics of Rhynchophorus palmarum and its association with Bursaphelenchus cocophilus on oil palm in the state of Amazonas, Brazil. Fitopatologia Brasileira 23, 23-26.

BAKER, A.D. (1962). Checklist of the nematode superfamilies Dorylaimoidea, Rhabditoidea, Tylenchoidea and Aphelenchoidea. Leiden, The Netherlands, E. J. Brill, 261 pp.

BAUJARD, P. (1980). Trois nouvelles espèces de Bursaphelenchus (Nematoda: Tylenchida) et remarques sur le genre. Revue de Nématologie 3, 167-177.

BAUJARD, P. (1989). Remarques sur les genres des sousfamilles Bursaphelenchinae Paramonov, 1964 et Rhadinaphe- lenchinae Paramonov, 1964 (Nematoda: Aphelenchoididae). Revue de Nématologie 12, 323-324.

Baujard, P., Boulbria, A., Ham, R., Laumond, C. \& Scotto La Massese, C. (1979). Premières données sur la nématofauna associée aux dépérissement du pin maritime dans l'Ouest de la France. Annales des Sciences Forestières 36, 331-339.

BALDER, H. (1987). Neuartiges Eichensterben in Berlin. Allgemeine Forst-Zeitschrift 42, 684-685.

BALDER, H. (1989). Studies on a new type of dieback symptoms on oaks in the Berlin forest. Nachrichtenblatt des Deutschen Pflanzenschutzdienstes 41, 1-6.

Beckenbach, K., BlaXter, M. \& Webster, J.M. (1999). Phylogeny of Bursaphelenchus species derived from analysis of ribosomal internal transcribed spacer DNA sequences. Nematology 1, 539-548.

Bolla, R.I. \& Wood, R. (2004). Pinewood nematode: pathogenic or political? In: Mota, M. \& Vieira, P. (Eds). The pinewood nematode, Bursaphelenchus xylophilus. Proceedings of an International Workshop, University of Évora, Portugal, August 20-22, 2001. Nematology monographs and perspectives, Volume 1. Leiden, The Netherlands, E. J. Brill, pp. 31-54.

Bowers, W.W., HudAK, J. \& RASKe, A.G. (1992). Host and vector surveys for the pinewood nematode, Bursaphelenchus xylophilus (Steiner and Buhrer) Nickle (Nematoda: Aphelenchoididae) in Canada. Information Report Newfoundland and Labrador Region, Forestry Canada (N-X-285), 55 pp.

BRAASCH, H. (1991). [First detection of Bursaphelenchus mucronatus Mamiya \& Enda, 1979 in Germany and its presence in wood imported from USSR, with further details on the description of the species.] Archiv für Phytopathologie und Pflanzenschutz, Berlin 27, 209-218.

BRAASCH, H. (1998). Bursaphelenchus hofmanni sp. n. (Nematoda, Aphelenchoididae) from spruce wood in Germany. Nematologica 44, 615-621.

BRAASCH. H. (2000). Bursaphelenchus paracorneolus sp. nov. (Nematoda: Parasitaphelenchidae) aus Koniferenholz in Deutschland und Bemerkungen zu seiner Biologie und Verbreitung. Annales Zoologici 50, 177-182.

BRAASCH, H. (2001). Bursaphelenchus species in conifers in Europe: distribution and morphological relationships. EPPO Bulletin 31, 127-142.

BRAASCH, H. (2004a). Morphology of Bursaphelenchus xylophilus compared with other Bursaphelenchus species. In: Mota, M. \& Vieira, P. (Eds). The pinewood nematode, Bursaphelenchus xylophilus. Proceedings of an International Workshop, University of Évora, Portugal, August 20-22, 2001. Nematology monographs and perspectives, Volume 1. Leiden, The Netherlands, E. J. Brill, pp. 127-143.

BRAASCH, H. (2004b). A new Bursaphelenchus species (Nematoda: Parasitaphelenchidae) sharing characters with Ektaphelenchidae from the People's Republic of China. Zootaxa 624, 1-10. 
BRAASCH, H. \& BRAASCH-BIDASAK, R. (2002). First record of the genus Bursaphelenchus Fuchs, 1937 in Thailand and description of B. thailandae sp. n. (Nematoda: Parasitaphelenchidae). Nematology 4, 853-863.

BraAsch, H. \& BURgermeister, W. (2002). Bursaphelenchus rainulfi sp. n. (Nematoda: Parasitaphelenchidae), first record of the genus Bursaphelenchus Fuchs, 1937 from Malaysia. Nematology 4, 971-978.

BRaAsch, H. \& Philis, J. (2002). New records of Bursaphelenchus spp. in Cyprus. Nematologia Mediterranea 30, 55-57.

BraAsch, H. \& Schmutzenhofer, H. (2000). Bursaphelenchus abietinus sp. n. (Nematoda: Parasitaphelenchidae) associated with fir bark beetles (Pityokteines spp.) from declining trees in Austria. Russian Journal of Nematology 8, 1-6.

BraAsch, H., Burgermeister, W. \& PAstrik, K. (1995). Differentiation of three Bursaphelenchus species by means of RAPD-PCR. Nachrichtenblatt des Deutschen Pflanzenschutzdienstes 47, 310-314.

BraAsch, H., Swart, A., Tribe, G. \& Burgermeister, W. (1998). First record of Bursaphelenchus leoni in South Africa and comparison with some other Bursaphelenchus spp. EPPO Bulletin 28, 211-216.

BraAsch, H., Metge, K. \& Burgermeister, W. (1999). Bursaphelenchus-Arten (Nematoda, Parasitaphelenchidae) in Nadelgehölzen in Deutschland und ihre ITS-RFLP-Muster. Nachrichtenblatt des Deutschen Pflanzenschutzdienstes 51, 312-320.

BraAsch, H., Burgermeister, W., Harmey, M.A., Michalopoulos-Skarmoutsos, H., TomiczeK, C. \& CARoppo, S. (2000). Pest risk analysis of pinewood nematode related Bursaphelenchus species in view of South European pine wilt and wood imports from Asia. Final Report of EU Research Project, Fair CT 95-0083, 251 pp.

Braasch, H., Tomiczek, C., Metge, K., Hoyer, U., Burgermeister, W., Wulfert, I. \& Shönefeld, U. (2001). Records of Bursaphelenchus spp. (Nematoda, Parasitaphelenchidae) in coniferous timber imported from the Asian part of Russia. Forest Pathology 31, 129-140.

Braasch, H., Bennewitz, A. \& Hantusch, W. (2002). Bursaphelenchus fungivorus - ein Nematode aus der Gruppe der Holznematoden im Pflanzsubstrat eines Gewächshauses und in Holz-und Rindenimport. Nachrichtenblatt des Deutschen Pflanzenschutzdienstes 54, 1-4.

BraAsch, H., Shonfeld, U., Polomski, J. \& BurgerMEISTER, W. (2004). Bursaphelenchus vallesianus sp. n. - a new species of the Bursaphelenchus sexdentati group. Nematologia Mediterranea 32, 71-79.

Brammer, A.S. \& Crow, W.T. (2001). Red ring nematode, Bursaphelenchus cocophilus (Cobb) Baujard (Nematoda: Secernentea: Tylenchida: Aphelenchina: Aphelenchoidea: Bursaphelenchina) formerly Rhadinaphelenchus cocophilus. EENY-236, Entomology and Nematology Department, Florida Cooperative Extension Service, Institute of
Food and Agricultural Sciences, University of Florida, pp. 1-4 (http://edis.ifas.ufl.edu/IN392)

Brathwaite, C.W. \& SiddiQI, M.R. (1975). Rhadinaphelenchus cocophilus. CIH Descriptions of plant-parasitic nematodes. St Albans, Herts, Commonwealth Institute of Helminthology, Set 5, No 72, 4 pp.

BRZESKI, M.W. \& BAUJARD, P. (1997). Morphology and morphometrics of Bursaphelenchus (Nematoda: Aphelenchoididae) species from pine wood of Poland. Annales Zoologici 47, 305-319.

BRZESKI, M.W. \& BRZESKI, J. (1997). Survey of Bursaphelenchus (Nematoda: Aphelenchoididae) species in pine wood in Poland. Fragmenta Faunistica 40, 103-109.

BRZESKI, M.W. \& SLIPINSKA, G.W. (1996). Detection of the nematode of pine in pine wood. Ochrona Roslin 40, 12-13.

CARLING, D.E. (1984). Some insects associates of the pinewood nematode in eastern Virgínia. Canadian Journal of Forest Research 14, 826-829.

Caroppo, S., Ambrogioni, L., Cavalli, M. \& Coniglio, D. (1998). Occurrence of pinewood nematodes Bursaphelenchus and their possible vectors in Italy. Nematologia Mediterranea $26,87-92$.

ChAng, R. \& LU, S. (1996). [Investigations of the occurrence of pine wilt disease and its naturally infected hosts in the Fushan Botanical Garden.] Taiwan Journal of Forest Science 11, 207-210.

Chang, R., ChaO, J., FAn, Y., LU, S. \& Jou, W. (1995). [Investigation the insect vector of pine wilt disease in Taiwan.] Plant Protection Bulletin 37, 448. [Abstr.]

CHENG, H.R. (1983). [The occurrence of a pine wilting disease caused by a nematode found in Nanjing.] Forest Pest and Disease 4, 1-5.

CHENG, H.R. (1988). [Some investigations on the generation and distribution of Bursaphelenchus xylophilus in China.] Journal of Jiangsu Forestry Science and Technology 2, 28-30.

CHoI, Y.E. \& Moon, Y.S. (1989). [Survey on distribution of pine wood nematode (Bursaphelenchus xylophilus) and its pathogenicity to pines trees in Korea.] Korean Journal of Plant Pathology 5, 277-286.

Совв, N.A. (1919). A newly discovered nematode (Aphelenchus cocophilus n. sp.) connected with a serious disease of the coconut palm. West Indian Bulletin 17, 203-210.

CorbetT, M.K. (1959). Diseases of the coconut palm. III. Red ring. Principes 3, 83-86.

DAN, Y. \& YU, S. (2003). [Identification of Bursaphelenchus spp. on pine wood in Yunnan Province.] Acta Phytopathologica Sinica 33, 401-405.

DEAN, C.G. (1979). Red ring disease of Cocos nucifera L. caused by Rhadinaphelenchus cocophilus (Cobb, 1919) Goodey, 1960. An annotated bibliography and review. Technical Communication No. 47, Farnham Royal, UK, Commonwealth Agricultural Bureaux, $70 \mathrm{pp}$. 
DEVDARIANI, T.G. (1974). [A new nematode species from Monochamus sutor.] Soobshcheniya Akademii Nauk Gruzinskoi SSR 76, 709-712.

Devdariani, T.G., KaKulia, G.A. \& Khavatashili, D.D. (1980). [New species of nematode of small maple Capricorn beetle (Rhopalopus macropus).] Soobshcheniya Akademii Nauk Gruzinskoi SSR 98, 457-459.

DiAnOv, M.B. \& LoBANOV, A.L. (2004). PICKEY. Computeraided multientry identification system for biological taxonomists. Version 8.0 for Windows 2000 and Windows XP. Zoological Institute RAS, St Petersburg, Russia. Software.

Dropkin, V.H. \& Foudin, A.S. (1979). Report of the occurrence of Bursaphelenchus lignicolus induced pine wilt disease in Missouri. Plant Disease Reporter 63, 904-905.

Dropkin, V.H., Foudin, A., Kondo, E., Linit, M., SMITH, M. \& RobBins, K. (1981). Pinewood nematode: a threat to U.S. forests? Plant Disease 65, 1022-1027.

DwINELL, L.D. (1993). First report of pinewood nematode (Bursaphelenchus xylophilus) in Mexico. Plant Disease 77, 846. [Abstr.]

EBINE, S. (1980). Cedrus deodara, a new host for Bursaphelenchus lignicolus, and behavior of Monochamus alternatus, the vector of the nematode. Forest Pests 29, 201-205.

EBSARY, B.B. (1991). Catalog of the Order Tylenchida (Nematoda). Ottawa, Canada, Agriculture Canada, Publication 1869/B, 196 pp.

ERoshenko, A.S. \& Kruglik, I.A. (1996). [Nematodes pathogenic to Korean pine in the Far Southeast of Russia.] In: Owston, P.W., Schlosser, W.E., Efremov, D.F. \& Miner, C.L. (Eds). Kedrovo-Shirokolistvennye Lesa Dalnego Vostoka. Khabarovsk, Russia, pp. 196-197.

Escuer, M., Árias, M. \& Bello, A. (2002). Nematodes associated with coniferous woods in Spain. Nematology 4, 265. [Abstr.]

Escuer, M., Árias, M. \& Bello, A. (2004a). Occurrence of the genus Bursaphelenchus Fuchs, 1937 (Nematoda: Aphelenchida) in Spanish conifer forests. Nematology 6, 155-156.

Escuer, M., Árias, M. \& Bello, A. (2004b). The genus Bursaphelenchus (Nematoda) in Spain. In: Mota, M. \& Vieira, P. (Eds). The pinewood nematode, Bursaphelenchus xylophilus. Proceedings of an International Workshop, University of Évora, Portugal, August 20-22, 2001. Nematology monographs and perspectives, Volume 1. Leiden, The Netherlands, E. J. Brill, pp. 93-99.

ESSER, R.P. \& MEREDITH, J.A. (1987). Red ring nematode. Nematology Circular No 14, Florida Department of Agriculture and Consumer Services, Division of Plant Industry, Gainesville.

FANG, Y., ZhaO, J. \& ZhUO, K. (2002a). Description of Bursaphelenchus dongguanensis sp. n. in China (Nematoda: Aphelenchoididae). Journal of Huazhong Agricultural University 21, 109-111.

FANG, Y., ZHUO, K. \& ZHAO, J. (2002b). Description of Bursaphelenchus aberrans n. sp. (Nematoda: Parasitaphelenchi- dae) isolated from pine wood in Guangdong Province, China. Nematology 4, 791-794.

FilipJEV, I.N. (1934). [Nematodes harmful and useful in the rural economy.] Moscow-Leningrad, Ogiz-Selkhozgiz, 440 pp.

FrANKLIN, M.T. \& HoOPER, D.J. (1962). Bursaphelenchus fungivorus $\mathrm{n}$. sp. (Nematoda: Aphelenchoidea) from rotting gardenia buds infected with Botrytis cinerea. Nematologica $8,136-142$.

Fuchs, A.G. (1929). Die Parasiten einiger Rüssell- und Borkenkäfer. Zoologische für Parasitenkunde 2, 248-285.

FuCHS, A.G. (1930). Neue an Borken- und Russelkäfer gebundene Nematoden, halbparasitische und Wohnungseinmeiter. Freilebende Nematoden aus Moos und Walderde in Borkenund Rüsselkäfergängen. Zoologische Jahrbücher, Abteilung für Systematik Oekologie und Geographie der Tiere, Jena 59, 505-646.

FUCHS, A.G. (1937). Neue parasitische und halbparasitische Nematoden bei Borkenkäfern und einige andere Nematoden. I. Teil die Parasiten der Waldgartner Myelophilus piniperda $\mathrm{L}$. und minor Hartig und die Genera Rhabditis Dujardin, 1845 und Aphelenchus Bastian, 1865. Zoologische Jahrbücher, Abteilung für Systematik Oekologie und Geographie der Tiere, Jena 70, 291-380.

Gerber, K., Giblin-Davis, R., Griffith, R., Escobar Goyes, J. \& CARTAYA, A.A. (1989). Morphometric comparisons of geographic and host isolates of the red ring nematode, Rhadinaphelenchus cocophilus. Nematropica 19, 151159.

GIBLIN, R.M. \& KAYA, H.K. (1983). Bursaphelenchus seani n. sp. (Nematoda: Aphelenchoididae), a phoretic associate of Anthophora bomboides stanfordiana Cockerell, 1904 (Hymenoptera: Anthophoridae). Revue de Nématologie 6, 39-50.

GiBlin, R.M., SWAN, J.L. \& KAYA, H.K. (1984). Bursaphelenchus kevini n. sp. (Aphelenchida: Aphelenchoididae), an associate of bees in the genus Halictus (Hymenoptera: Halictidae). Revue de Nématologie 7, 177-187.

GIBLIN-DAVIS, R.M. (1993). Interactions of nematodes with insects. In: Wajid, M. (Ed.). Nematode interactions. New York, USA, Chapman \& Hall, pp. 302-304.

Giblin-Davis, R.M., Mundo-Ocampo, M., Baldwin, J.G., Gerber, K. \& Griffin, R. (1989). Observation on the morphology of the red ring nematode, Rhadinaphelenchus cocophilus (Nemata: Aphelenchoididae). Revue de Nématologie 12, 285-292.

Giblin-Davis, R.M., Mundo-OCAMPo, M., BaLdWin, J.G., Norden, B.B. \& BATRA, S.W.T. (1993). Description of Bursaphelenchus abruptus n. sp. (Nemata: Aphelenchoididae), an associate of a digger bee. Journal of Nematology 25, 161-172.

Giblin-DaVis, R.M., DaVies, K.A., Morris, K. \& Thomas, W.K. (2003). Evolution of parasitism in insecttransmitted plant nematodes. Journal of Nematology 35, 133141. 
Goodey, J.B. (1960a). The classification of the Aphelenchoidea Fuchs, 1937. Nematologica 5, 111-126.

Goodey, J.B. (1960b). Rhadinaphelenchus cocophilus (Cobb, 1919) n.comb. the nematode associated with the "Red ring" disease of coconut. Nematologica 5, 98-102.

Goodey, T. (1933). Plant parasitic nematodes and the diseases they cause. London, UK, Methuen \& Co. Ltd, 306 pp.

Goodey, T. (1951). Soil and freshwater nematodes. London, UK, Methuen \& Co. Ltd, 390 pp.

Goodey, T. (1963). Soil and freshwater nematodes, 2nd edition, revised by J.B. Goodey. London, UK, Methuen \& Co. Ltd, 544 pp.

Griffith, R. \& Koshy, P.K. (1990). Nematode parasites of coconut and other palms. In: Luc, M., Sikora, R.A. \& Bridge, J. (Eds). Plant parasitic nematodes in subtropical and tropical agriculture. Wallingford, UK, CABI Publishing, pp. 363-386.

Harrison, N.A. \& Jones, P. (2003). Diseases of coconut. In: Ploetz, R.C. (Ed.). Diseases of tropical fruit crops. Wallingford, UK, CABI Publishing, pp. 197-225.

Haque, M.M. (1967). [A new genus Paraphelenchoides (Nematoda, Aphelenchoididae).] Zoologicheskii Zhurnal 46, 1251-1253.

Hoyer, U., Burgermeister, W. \& BraAsch, H. (1998). Identification of Bursaphelenchus species (Nematoda: Aphelenchoididae) on the basis of amplified ribosomal DNA (ITSRFLP). Nachrichtenblatt des Deutschen Pflanzenschutzdienstes 50, 273-277.

HunT, D.J. (1993). Aphelenchida, Longidoridae and Trichodoridae: Their systematics and bionomics. Wallingford, Oxon, UK, CAB International, $352 \mathrm{pp}$.

IWAHORI, H., KANZAKI, N. \& FUtAI, K. (2004). Bursaphelenchus xylophilus and B. mucronatus in Japan. In: Cook, R. $\&$ Hunt, D.J. (Eds). Proceedings of the Fourth International Congress of Nematology, 8-13 June 2002, Tenerife, Spain. Nematology monographs and perspectives, Volume 2. Leiden, The Netherlands, E. J. Brill, pp. 793-803.

JIANG, L. (1988). [The investigation of pine wood nematode and the identification of nematodes.] Anhui Forest Science and Technology 1, 18-21.

JiKumARU, S. \& TOGASHI, K. (1999). Biologies of Bursaphelenchus mucronatus and its vector, Monochamus saltuarius, in a Pinus densiflora stand. In: Futai, K., Togashi, K. \& Ikeda, $\mathrm{T}$. (Eds). Sustainability of pine forests in relation to pine wilt and decline. Proceedings of the Symposium, Tokyo, Japan, 26-30 October 1998. Kyoto, Japan, Shokado Shoten, pp. 136139.

KaISA, T.R. (2005). Proposal of Parasitaphelenchus dongguanensis (Fang, Zhao \& Zhuo, 2002) n. comb. (Nematoda: Parasitaphelenchidae). Zootaxa 839, 1-8.

KaKUlia, G.A. (1967). [New nematode genus Devibursaphelenchus n. g. (Nematoda: Aphelenchoididae).] Soobschcheniya Akademii Nauk Gruzinskoi SSR 46, 439-443.
KAKULIA, G.A. (1971). [Nematode fauna of Ips typographus in the Georgian SSR.] Parazitologicheskii Sbornik 2, 53-56.

KAKUlia, G.A. \& DEVDARIANI, T.G. (1965). [A new species of nematode Bursaphelenchus teratospicularis Kakulia \& Devdariani, sp. nov. (Nematoda: Aphelenchoidea).] Bulletin of the Academy of Sciences of the Georgian SSR 38, 187-191.

KaKulia, G.A. \& Devdariani, T.G. (1967). [Nematode fauna of Scolytus scolytus F. in East Georgia.] Bulletin of the Academy of Sciences of the Georgian SSR 46, 469-474.

KaKulia, G.A. \& Maglakelidze, L. (1973). [Nematode fauna of Hylurgops palliatus in the Georgian SSR.] Parazitologicheskii Sbornik, Tbilisi 3, 76-78.

KAKulia, G.A. \& Shalibashvili, G. (1976a). [The nematode fauna of Hylaster ater in the pine forests of the Pitsundskii and Ritsinskii reserves.] Zapovedniki Gruzii, Sbornik Trudov 4, 259-262.

KaKulia, G.A. \& Shalibashvili, K. (1976b). [The nematode fauna of Pityokeines curvidens Germ. in the conifer forests of Abkhaziya.] Zapovedniki Gruzii, Sbornik Trudov 4, 317-320.

Kakulia, G.A., Devdariani, T.G. \& Maglake LidZE, L.M. (1980). [Nematodes of Cerambycidae, parasites of trees in Eastern Georgia.] Konferentsiya Ukrainskogo Parazitlogicheskogo Obshchestva. Tezisy dokladov. Chast II, 109-110.

KANZAKI, N. \& FUTAI, K. (2002a). Observation on the arrangement of caudal papillae of Bursaphelenchus conicaudatus and B. fraudulentus. Japanese Journal of Nematology 32, 21-24.

KANZAKI, N. \& FUTAI, K. (2002b). A PCR primer set for determination of phylogenetic relationships of Bursaphelenchus species within the xylophilus group. Nematology 4, 35-41.

KANZAKI, N. \& FUtAI, K. (2003). Description and phylogeny of Bursaphelenchus luxuriosae n. sp. (Nematoda: Aphelenchoididae) isolated from Acalolepta luxuriosa (Coleoptera: Cerambycidae). Nematology 5, 565-572.

KANZAKI, N., TsUdA, K. \& FUtAI, K. (2000). Description of Bursaphelenchus conicaudatus n. sp. (Nematoda: Aphelenchoididae), isolated from the yellow-spotted longicorn beetle, Psacothea hilaris (Coleoptera: Cerambycidae) and fig trees, Ficus carica. Nematology 2, 165-168.

KhaliknaZAROV, B. \& KhurRAMOV, K. (1989). [Nematodes of fodder beet and table beet in the Surkhandar'insk region.] Byulleten'Vsesoyuznogo Instituta Gel'mintologii im. K. I. Skryabina 50, 129-132.

KHAN, F.A. \& GBADEgesin, R.A. (1991). On the occurrence of nematode induced pine wilt disease in Nigeria. Pakistan Journal of Nematology 9, 57-58.

KIsHI, Y. (1995). The pine wood nematode and the Japanese pine sawyer. Forests pests in Japan - No. 1. Tokyo, Japan, Thomas Co. Ltd, 302 pp.

KiYohaRA, T. \& TokUSHIge, Y. (1971). Inoculationa experiments of a nematode, Bursaphelenchus sp., onto pine trees. Journal of the Japanese Forestry Society 53, 210-218. 
Knowles, K., Beaubien, Y., Wingfield, M.J., Baker, F.A. \& FRENCH, D.W. (1983). The pinewood nematode new in Canada. The Forestry Chronicle 59, 40.

Kolossova, N.V. (1998). Bursaphelenchus eroshenkii sp. n. (Nematoda: Aphelenchoididae) from the Russian Far East, with a key to some species of Bursaphelenchus Fuchs, 1937. Russian Journal of Nematology 6, 161-164.

Kondo, E., Foudin, A., Linit, M., Smith, M., Bolla, R., Winter, R. \& Dropkin, V. (1982). Pine wilt disease - nematological, entomological, biochemical, investigations. University of Missouri-Columbia, Agricultural Experiment Station, $56 \mathrm{pp}$.

KoREnTCHEnKo, E.A. (1980). [New species of nematodes from the family Aphelenchoididae, parasites of stem pests of the Dahurian Larch.] Zoologicheskii Zhurnal 59, 1768-1780.

KÖRNER, H. (1954). Die Nematodefauna des vergehenden Holzes und ihre Beziehungen zu den Insekten. Zoologische Jahrbücher, Abteilung für Systematik, Öekologie und Geographie der Tiere 82, 245-353.

KrugliK, I.A. \& EROShENKo, A.S. (2004). [Bursaphelenchus fuchsi sp. n. (Nematoda: Bursaphelenchidae) - new nematode species from wood of pine Pinus koraiensis, Primorsky Territory.] In: Sonin, M.D. (Ed.). Paraziticheskie nematody rastenii i nasekomykh. Moscow, Russia, Nauka, pp. 96-99.

Kubatova, A., Novotny, D., Prasil, K. \& MráčeK, Z. (2000). The nematophagous hyphomycete Esteya vermicola found in the Czech Republic. Czech Mycology 52, 227-235.

Kulinich, O.A. \& Kolossova, N.V. (1995). The potential of the pinewood nematode Bursaphelenchus xylophilus to become established in countries of the former USSR. Russian Journal of Nematology 3, 35-48.

Kulinich, O.A. \& ORLINSKI, P.D. (1998). Distribution of conifer beetles (Scolytidae. Curculionidae, Cerambycidae) and wood nematodes (Bursaphelenchus spp.) in European and Asian Russia. EPPO Bulletin 28, 39-52.

Kulinich, O.A., Kruglik, A., Eroshenko, A. \& Kolosova, N. (1994). Ocurrence and distribution of the nematode Bursaphelenchus mucronatus in the Russian Far East. Russian Journal of Nematology 2, 113-119.

Kurashvili, B.E., Kakulia, G.A. \& Devdariani, T.G. (1980). [Parasitic nematodes of the bark-beetles in Georgia.] Tbilisi, Georgia, Metsniereba, 172 pp.

La, Y.J., Moon, Y.S., Yeo, W.H., Shin, S.C. \& BaK, W.C. (1999). Recent status of pine wilt disease in Korea. In: Futai, K., Togashi, K. Ikeda, T. (Eds). Sustainability of pine forests in relation to pine wilt and decline. Proceedings of the Symposium, Tokyo, Japan, 26-30 October 1998. Kyoto, Japan, Shokado Shoten, pp. 239-241.

LaI, Y., Zhang, S., HuANG, H., Lu, Z. \& SHI, Y. (1996). [Monochamus alternatus withered pine.] Journal of the Zhejiang Forestry College 13, 75-81.

Lee, S.M., Choo, H.Y., Park, N.C., Moon, Y.S. \& Kim, J.B. (1990). [Nematodes and insects associated with dead trees, and pine wood nematode detection in Monochamus alternatus.] Korean Journal of Applied Entomology 29, 1419.

LI, G.W. (1983). [Discovery and preliminary investigation on pine wood nematodes in China.] Forest Science and Technology 7, 25-28.

LIAO, J.L., ZHANG, L.H. \& FENG, Z.X. (2001). Reliable identification of Bursaphelenchus xylophilus by rDNA amplification. Nematologia Mediterranea 29, 131-135.

Lieutier, F. \& LAUmond, C. (1978). Nematodes parasites et associés à Ips sexdentatus et Ips typographus (Coleoptera, Scotylidae) en region Parisienne. Nematologica 24, 187-200.

LinIT, M. (1988). Nematode-vector relationships in the pine wilt disease system. Journal of Nematology 20, 227-235.

LinIT, M., Kondo, E. \& SMITH, T. (1983). Insects associated with the pinewood nematode, Bursaphelenchus xylophilus (Nematoda: Aphelenchoididae), in Missouri. Environmental Entomology 12, 467-470.

Loof, P.A.A. (1964). Free-living and plant-parasitic nematodes from Venezuela. Nematologica 10, 201-300.

Magnusson, C. \& Kulinich, O.A. (1996). A taxonomic reappraisal of the original description, morphology and status of Bursaphelenchus kolymensis Korentchenko, 1980 (Aphelenchida: Aphelenchoididae). Russian Journal of Nematology 4, 155-161.

Magnusson, C. \& Schroeder, L.M. (1989). First record of Bursaphelenchus species (Nematoda) in Monochamus beetles in Scandinavia. Anzeiger für Schädlingskunde, Pflanzenschutz und Umweltschutz 62, 53-54.

Magnusson, C., Thunes, K., SAlinas, S.H. \& HammerAAS, B. (2002). Survey of the pine wood nematode (PWN) Bursaphelenchus xylophilus in Norway 2001. Planteforsk Rapport 26/2002, 14 pp.

Magnusson, C., OvergaArd, H., Nyeggen, H., Thunes, K., Salinas, S.H. \& HammeraAs, B. (2004). Survey of the pine wood nematode (PWN) Bursaphelenchus xylophilus in Norway 2002. Grønn kunnskap 8, 1-13.

MamiYA, Y. (1972). Pine wood nematode, Bursaphelenchus lignicolus Mamiya and Kiyohara, as causal agent of pine wilting disease. Review of Plant Protection Research 5, 4660.

MamiYA, Y. (1984). The pine wood nematode. In: Nickle, W.R. (Ed.). Plant and insect nematodes. New York \& Basel, Marcel Dekker, Inc., pp. 589-627.

MamiYA, Y. (1999). Review on the pathogenicity of Bursaphelenchus mucronatus. In: Futai, K., Togashi, K. \& Ikeda, T. (Eds). Sustainability of pine forests in relation to pine wilt and decline. Proceedings of the Symposium, Tokyo, Japan, 26-30 October 1998. Kyoto, Japan, Shokado Shoten, pp. 57-63.

MamiYA, Y. (2004). Pine wilt disease in Japan. In: Mota, M. \& Vieira, P. (Eds). The pinewood nematode, Bursaphelenchus xylophilus. Proceedings of an International Workshop, University of Évora, Portugal, August 20-22, 2001. Nematology 
monographs and perspectives, Volume 1. Leiden, The Netherlands, E.J. Brill, pp. 9-20.

MAMIYA, Y. \& ENDA, N. (1979). Bursaphelenchus mucronatus n. sp. (Nematoda: Aphelenchoididae) from pine wood and its biology and pathogenicity to pine trees. Nematologica 25, 353-361.

MamiYA, Y. \& KiYohara, T. (1972). Description of Bursaphelenchus lignicolus $\mathrm{n}$. sp. (Nematoda: Aphelenchoididae) from pine wood and histopathology of nematode-infested trees. Nematologica 18, 120-124.

Massey, C.L. (1964). The nematode parasites and associates of the fir engraver beetle, Scolytus ventralis Le Conte in New Mexico. Journal of Insect Pathology 6, 133-155.

MASSEY, C.L. (1966). The nematode parasites and associates of Dendroctonus adjunctus (Coleoptera: Scolytidae) in New Mexico. Annals of the Entomological Society of America 59, 425-440.

MAssey, C.L. (1971a). Omemeea maxbassiensis n. gen., n. sp. (Nematoda: Aphelenchoididae) from galleries of the bark beetle Lepersinus californicus Sw. (Coleoptera: Scolytidae) in North Dakota. Journal of Nematology 3, 289-291.

MASSEY, C.L. (1971b). Nematode associates of several species of Pissodes (Coleoptera: Curculionidae) in the United States. Annals of the Entomological Society of America 64, 162-169.

MASSEY, C.L. (1974). Biology and taxonomy of nematode parasites and associates of bark beetles in the United States. United States Department of Agriculture, Washington, Agricultural Handbook No. 446, 233 pp.

MAYr, E. (1969). Principles of systematic zoology. New York, St Louis, San Francisco, Toronto, London, Sydney. McGraw Hill, 428 pp.

McNamara, D.G. \& Stoen, M. (1988). A survey for Bursaphelenchus spp. in pine forests in Norway. EPPO Bulletin 18, 353-363.

MEYL, A. (1961). Die freilebenden Erd- und Süsswassernematoden (Fadenwürmer). In: Brohmer, P., Ehrmann, P. \& Ulmer, G. (Eds). Die Tierwelt Mitteleuropas. Leipzig, Germany, Quelle \& Meyer, pp. 81-83.

Michalopoulos-Skarmoutsos, H., Skarmoutsos, G., Kalapanida, M. \& Karageorgos, A. (2004). Surveying and recording of nematodes of the genus Bursaphelenchus in conifer forests in Greece and pathogenicity of the most important species. In: Mota, M. \& Vieira, P. (Eds). The pinewood nematode, Bursaphelenchus xylophilus. Proceedings of an International Workshop, University of Évora, Portugal, August 20-22, 2001. Nematology Monographs and Perspectives, Volume 1. Leiden, The Netherlands, E. J. Brill, pp. 113-126.

MicoletZKY, H. (1922). Die freilebenden Erd-Nematoden mit besonderer Berücksichtigung der Steiermark und der Bukowina, zugleich mit einer Revision sämtlicher nicht mariner, freilebenden Nematoden in Form von Genus - Beschreibunger und Bestimmungsschlüsseln. Archiv für
Naturgeschichte, Verlags-Buchhnadlung R. Stricker, Berlin, Abteilung A, Heft 8-9, 1-650.

Mota, M.M., Braasch, H., Bravo, M.A., Penas, A.C., Burgermeister, W., Metge, K. \& Sousa, E. (1999). First report of Bursaphelenchus xylophilus in Portugal and in Europe. Nematology 1, 727-734.

NiCKLE, W.R. (1970). A taxonomic review of the genera of the Aphelenchoidea (Fuchs, 1937) Thorne, 1949 (Nematoda: Tylenchida). Journal of Nematology 2, 375-392.

Nickle, W.R., Golden, A.M., Mamiya, Y. \& Wergin, W.P. (1981). On the taxonomy and morphology of the pinewood nematode, Bursaphelenchus xylophilus (Steiner \& Buhrer 1934) Nickle 1970. Journal of Nematology 13, 385392.

Palmisano, A.M. \& Ambrogioni, L. (1994). Nematodi Aphelenchoidoidea associati con Pinus spp. in Italia. Redia 77, 225-240.

Palmisano, A.M., Ambrogioni, L. \& CAroppo, S. (1992). Bursaphelenchus mucronatus (Nematoda: Aphelenchoididae) su Pinus pinaster in Italy. Redia 75, 517-527.

Palmisano, A.M., Ambrogioni, L. \& CARoppo, S. (1994). First record of a Bursaphelenchus species from Pinus pinaster in Italy. EPPO Bulletin 24, 467-474.

Palmisano, A.M., Ambrogioni, L., Tomiczek, C. \& BRAndSTETTER, M. (2004). Bursaphelenchus sinensis sp. n. and B. thailandae Braasch et Braasch-Bidasak in packaging wood from China. Nematologia Mediterranea 32, 57-65.

Penas, A.C., Bravo, M.A., Pires, J. \& Mota, M. (2002). Bursaphelenchus species found in maritime pine in Portugal. Nematology 4, 473. [Abstr.]

Penas, A.C., Correia, P., Bravo, M.A., Mota, M. \& TEnreiro, R. (2004). Species of Bursaphelenchus Fuchs, 1937 (Nematoda: Parasitaphelenchidae) associated with maritime pine in Portugal. Nematology 6, 437-453.

Perez, M. \& Plumas, G. (1999). First report in Cuba of Bursaphelenchus sp. (Nematoda: Aphelenchoididae) on male pines (Pinus caribaea). Revista de Proteccion Vegetal 14, 5961.

PHILIS, J. (1996). An outlook on the association of Bursaphelenchus leoni with wilting pines in Cyprus. Nematologia Mediterranea 24, 221-225.

Philis, J. \& BRAASCH, H. (1996). Occurrence of Bursaphelenchus leoni (Nematoda: Aphelenchoididae) in Cyprus and its extraction from pine wood. Nematologia Mediterranea 24, 119-123.

Remane, A. (1952). Die Grundlagen des natürlichen Systems, der vergleichenden Anatomie und der Phylogenetik. Leipzig, Akademische Verlagsgesellschaft, $400 \mathrm{pp}$.

Ridley, G., BAIN, J. \& DicK, M. (2001). Exotic nematode found in pine trees in Melbourne, Victoria. New Zealand Journal of Forestry 46, 41-42.

Riga, E. \& Webster, J.M. (1992). Use of sex pheromones in the taxonomic differentiation of Bursaphelenchus spp. 
(Nematoda), pathogens of pine tree. Nematologica 38, 133145.

Robbins, K. (1982). Distribution of the pinewood nematode in the United States. In: Appleby, J.E. \& Malek, R.B. (Eds). Proceedings of the national pine wilt disease workshop. III. Natural History Survey, Champaign, IL, USA, pp. 3-6.

RÜHM, W. (1956). Die Nematoden der Ipiden. Parasitologische Schriftenreihe 6, 1-435.

RÜHM, W. (1960). Ein Beitrag zur Nomenklatur und Systematik einiger mit Scolytiden vergesellschafteter Nematodenarten. Zoologischer Anzeiger 164, 201-213.

RÜHM, W. (1964). Ein Beitrag zur Vergesellschaftung zwischen Nematoden und Insekten (Pelodera bakeri n. sp. (Nematoda: Rhabditoidea, Rhaditidae) eine mit Calvertius tuberosus Perm. et Germ. (Coleoptera, Curculionidae, Hylobiinae) vergesellschaftete Nematodenart an Araucaria araucana (Mol.) Koch.) Zoologischer Anzeiger 173, 212-220.

Rutherford, T.A., MAmiYA, Y. \& Webster, J.M. (1990). Nematode-induced pine wilt disease: factors influencing its occurrence and distribution. Forest Science 36, 145-155.

SALAZAR, L. (1980). Observations on the distribution of Rhadinaphelenchus cocophilus in coconut tree sections affected by red ring disease. Agronomia Costarricence 4, 187-189.

Schauer-Blume, M. (1987). Bursaphelenchus "mucronatus" (Nematoda, Aphelenchoididae) an Laubbäumen in Deutschland. Nachrichtenblatt des Deutschen Pflanzenschutzdienstes 39, 152-154.

Schauer-Blume, M. \& Sturhan, D. (1989). Vorkommen von Kiefernematoden (Bursaphelenchus spp.) in der Bundesrepublik Deutschland? Nachrichtenblatt des Deutschen Pflanzenschutzdienstes 41, 133-136.

SChMutzenhofer, H. (1981). A nematode involved in the silver fir decline in Austria. Proceedings of the $17^{\text {th }}$ IUEFRO Congress, Kyoto, Japan. [Abstr.]

Schönfeld, U., APEL, K.H. \& BRAASCH, H. (2001). Nematoden der Gattung Bursaphelenchus (Nematoda, Parasitaphelenchidae) in den Kiefernwäldern des Landes Brandenburg - Ergebnisse eines Monitorings. Nachrichtenblatt des Deutschen Pflanzenschutzdienstes 53, 180-184.

Schuiling, M. \& VAN DinTHER, J.B.M. (1981). Red ring disease in the Paricatuba oilpalm estate, Para, Brazil. Zeitschrift für Angewandte Entomologie 91, 154-169.

SIDDIQI, M.R. (1974). Aphelenchoides ritzemabosi. CIH Descriptions of plant-parasitic nematodes. St Albans, UK, Commonwealth Institute of Helminthology, Set 3, No. 32, pp. 1-4.

Silva, H.M. \& Martins e Silva, H. (1991). Metamasius sp. (Coleoptera: Curculionidae) vector of Rhadinaphelenchus cocophilus causal agent of the oil palm red ring. Pesquisa em Andamento Unidade de Execução de Pesquisa de Ambito Estadual de Belem 17, 4 pp.

Skarmoutsos, G. \& Skarmoutsos, H. (1999). First record of Bursaphelenchus nematodes from pine forests in Greece. Plant Disease 83, 879.
Skarmoutsos, G., BraAsch, H. \& Michalopoulou, H. (1998). Bursaphelenchus hellenicus sp. n. (Nematoda, Aphelenchoididae) from Greek pine wood. Nematologica 44, 623-629.

Skrjabin, K.I., Shikhobalova, A.A., Sobolev, A.A., PARAMONOV, A.A. \& SUdARIKOV, V.E. (1954). [Camallanata, Rhabdidata, Tylenchata, Trichocephalata, Dioctophymata and the distribution of parasitic nematodes in their hosts.]. In: Skrjabin, K.I. (Ed.). Opredeliteli paraziticheskikh nematod 4. Moscow, Izdatelstvo Akademii Nauk SSR, 927 pp.

Sousa, E., Bravo, M.A., Pires, J., Naves, P., Penas, A.C., BonifÁCIO, L. \& MotA, M. (2001). Bursaphelenchus xylophilus (Nematoda: Aphelenchoididae) associated with Monochamus galloprovincialis (Coleoptera; Cerambycidae) in Portugal. Nematology 3, 89-91.

STEINER, G. (1932). Some nemic parasites and associates of the mountain pine beetle (Dendroctonus monticolae). Journal of Agricultural Research 45, 437-444.

STEINER, G. (1935). Opuscula miscellanea nematologica, II. Proceedings of the Helminthological Society of Washington 2, 104-110.

STEINER, G. \& BUhrer, E.M. (1934). Aphelenchoides xylophilus n. sp., a nematode associated with blue-stain and other fungi in timber. Journal of Agricultural Research 48, 949951.

SWOFFORD, D.L. (2001). PAUP*. Phylogenetic analysis using parsimony (*and other methods). Version 4.0b10. Sunderland, MA, USA, Sinauer Associates.

TAKHTAJAN, A.L. (1987). Systema magnoliophytorum. Leningrad, Russia, Nauka, 439 pp.

Tarès, S., Abad, P., Bruguier, N. \& de Guiran, G. (1992). Identification and evidence for relationships among geographical isolates of Bursaphelenchus spp. (pinewood nematode) using homologous DNA probes. Heredity 68, 157164.

TARès, S., Lemontey, J.M., De Guiran, G., \& Abad, P. (1993). Cloning and characterization of a highly conserved satellite DNA sequence specific for the phytoparasitic nematode Bursaphelenchus xylophilus. Gene 129, 269-273.

TARJAn, A.C. \& BAEZA-Aragon, C. (1982). An analysis of the genus Bursaphelenchus Fuchs, 1937. Nematropica 12, 121-144.

TEnKÁCovÁ, I. \& Mituch, J. (1987). Nematodes new for the fauna of Czechoslovak Socialist Republic with the affinity to scolytids (Coleoptera, Scolytidae). Helminthologia 24, 281291.

TenkÁcovÁ, I. \& Mituch, J. (1988). [Nematofauna of the Scolytidae on silver fir (Abies alba Mill.) from the Polana region.] Forestry Journal, Bratislava 34, 125-131.

TENKÁCOVÁ, I. \& MituCH, J. (1991). [Nematoda of the subbark beetles (Coleoptera: Scolytidae) from the High Tatras.] Zbornic Prác o Tataranskom Národnom Parku 31, 173-182. 
Thong, C.H.S. \& WeBsteR, J.M. (1983). Nematode parasites and associates of Dendroctonus spp. and Trypodendron lineatum (Coleoptera: Scolytidae), with a description of Bursaphelenchus varicauda n. sp. Journal of Nematology 15, 312-318.

Thong, C.H.S. \& Webster, J.M. (1991). Dauerlarve: is there one in Bursaphelenchus xylophilus? Revue de Nématologie 14, 635-636.

Thorne, G. (1935). Nemic parasites and associates of the mountain pine beetle, Dendroctonus monticolae in Utah. Journal of Agricultural Research 51, 131-144.

TomiczeK, C. (2000). A survey for Bursaphelenchus spp. in conifers in Austria and implications to Austria forests. XXI IUFRO World Congress 2000, Kuala Lumpur, Malaysia, 399. [Abstr.]

Tomiczek, C., BraAsch, H., Burgermeister, W., Metge, K., Hoyer, U. \& Brandstetter, M. (2003). Identification of Bursaphelenchus spp. isolated from Chinese packaging wood imported to Austria. Nematology 5, 573-581.

Tomminen, J. (1990). Presence of Bursaphelenchus mucronatus (Nematoda: Aphelenchoididae) fourth dispersal stages in selected conifer beetles in Finland. Silva Fennica 24, 273278.

Tomminen, J., Nuorteva, M., Pulkkinen, M. \& Vokevo, J. (1989). Occurrence of the nematode Bursaphelenchus mucronatus Mamiya \& Enda, 1979 (Nematoda: Aphelenchoididae) in Finland. Silva Fennica 23, 271-277.

TZEAN, S. \& JAN, S. (1985). The occurrence of pinewood nematode, Bursaphelenchus xylophilus, in Taiwan. Proceedings of the 6th ROC symposium of electron microscopy, pp. 38-39. [Abstr.]

UREK, G. \& SiCA, S. (2003). [Plant parasitic nematodes affecting the above ground plant parts in Slovenia.] Slovenskega Posvetovanje o Varstu Rastlin, Slovenije, 4-6 marec 2003, pp. 486-488.

Vieira, P., Mota, M. \& Eisenback, J. (2003). Pinewood nematode taxonomic database. Mactode Publications. (CDROM)

Vieira, P., Valadas, V., Akbulut, S., Mota, M. \& Ryss, A. (2004). First report of Bursaphelenchus mucronatus from Turkey, associated with Pinus nigra. XXVII ESN International Symposium, Rome, 14-18 June 2004, 112. [Abstr.]

VILAGIOVA, I. (1993). [Helminths of bark beetles (Coleoptera: Scolytidae) in suburban region of Kosíce city.] Forestry Journal, Bratislava 39, 183-188.

Vilagiova, I. \& Mituch, J. (1991). [Nematofauna of feed marks of Myelophilus piniperdae (Linnaeus, 1758) and Ips sexdentatus (Boerner, 1867) on Scotch pine - Pinus sylvestris L.] Forestry Journal, Bratislava 37, 343-348.

Vosilite, B.S. (1990). A new nematode species, Diplogasteroides sexdentati $\mathrm{sp}$. $\mathrm{n}$. and some biological data on the ectonematodes of stenograph bark beetle. In: Sonin, M.D. (Ed.). Helminths of insects. Leiden, The Netherlands, E. J. Brill, pp. 27-36.
Walia, K.K., Negi, S., Bajaj, H.K. \& Kalia, D.C. (2003). Two new species of Bursaphelenchus Fuchs, 1937 (Nematoda: Aphelenchoididae) from pine wood and insect frass from India. Indian Journal of Nematology 33, 1-5.

WANG, G. \& YIE, Z. (1998). [Distribution of Bursaphelenchus mucronatus in diseased pines and sampling techniques.] Journal of Zheijang Forestry Science and Technology 18, 37 41.

WANG, H., PAN, C. \& Chen, Y. (2004). A new record species of genus Bursaphelenchus Fuchs, 1937 (Nematoda: Parasitaphelenchidae) in Pinus massoniana from China. Journal of Xiamen University 5, 727.732.

WANG, Y. \& SHI, Y. (1986). [Bursaphelenchus mucronatus and pine wilt.] Forest Pest and Disease 4, 7-8.

Wang, Y., Ge, L., Wang, J., Hu, J. \& Wang, C. (1999). [Precautions against Bursaphelenchus mucronatus in Taizhou.] Journal of Zhejiang Forestry Science and Technology 19, 45-47.

Wingfield, M.J., Blanchette, R.A., Nicholls, T.H. \& RobBINS, K. (1982). Association of pine wood nematode with stressed trees in Minnesota, Iowa and Wisconsin. Plant Disease 66, 934-937.

YANG, B. (1985) [The identification of nematodes on pine trees.] Scientia Silvae Sinicae 21, 305-309.

YANG, B. (2004). The history, dispersal and potential threat of pine wood nematode in China. In: Mota, M. \& Vieira, P. (Eds). The pinewood nematode, Bursaphelenchus xylophilus. Proceedings of an International Workshop, University of Évora, Portugal, August 20-22, 2001. Nematology monographs and perspectives, Volume 1. Leiden, The Netherlands, E. J. Brill, pp. 21-24.

Yen, J., TZEAN, S. \& ChANG, R. (1997). [Occurrence of pine wilt disease in Taiwan red pine, Pinus taiwanensis, in Taiwan.] Plant Protection Bulletin 6, 49-57.

Yi, C., BYUn, B., PARK, J., YANG, S. \& ChANG, K. (1989). [First finding of the pine wood nematode, Bursaphelenchus xylophilus (Steiner et Buhrer) Nickle and its insect vector in Korea.] Research Reports of the Forestry Research Institute Seoul 38, 141-149.

Yin, K., FAnG, YU. \& TARJAn, A.C. (1988). A key to species in the genus Bursaphelenchus with a description of Bursaphelenchus hunanensis sp. $\mathrm{n}$. (Nematoda: Aphelenchoididae) found in pine wood in Hunan Province, China. Proceedings of the Helminthological Society of Washington 55, 1-11.

ZHANG, L., KonG, F. \& YANG, B. (2002). Intra and interspecific variation in Bursaphelenchus xylophilus and B. mucronatus revealed by mt DNA polymorphism. Forest Research 15, 7-12.

ZhaO, J., Yu, S., YaO, J., Lin, C., Ding, D. \& Wang, H. (2004). [PWN risk assessment in Huangshan Scenic Área II. Monitoring of nematode carried by pine borer beetles.] Forest Research 17, 72-76. 


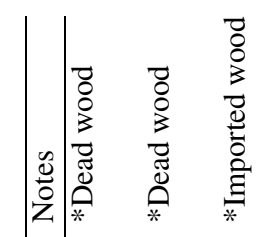

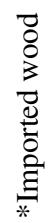

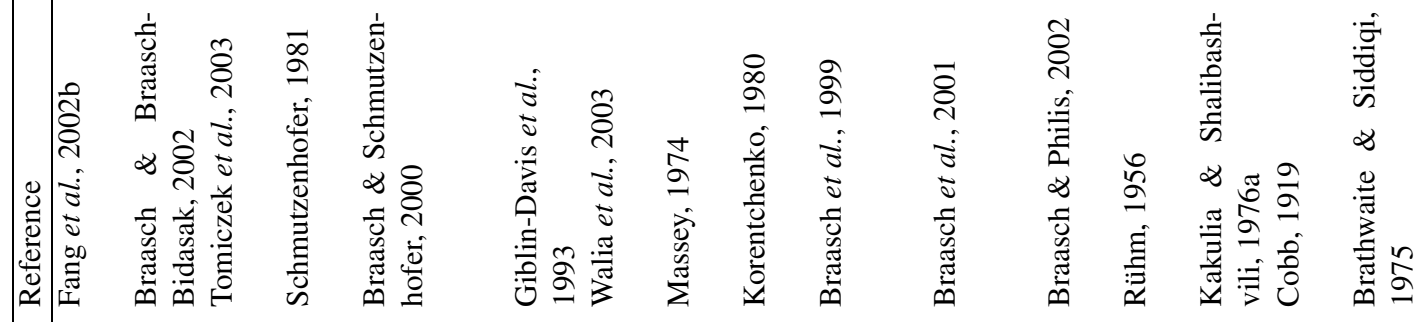

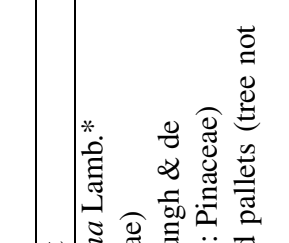

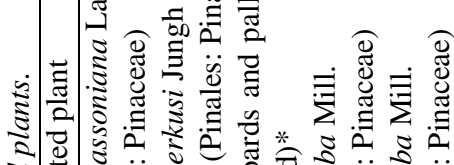

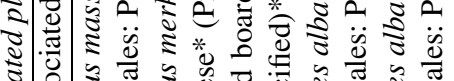

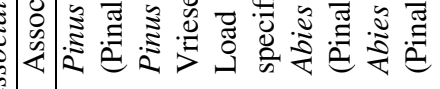
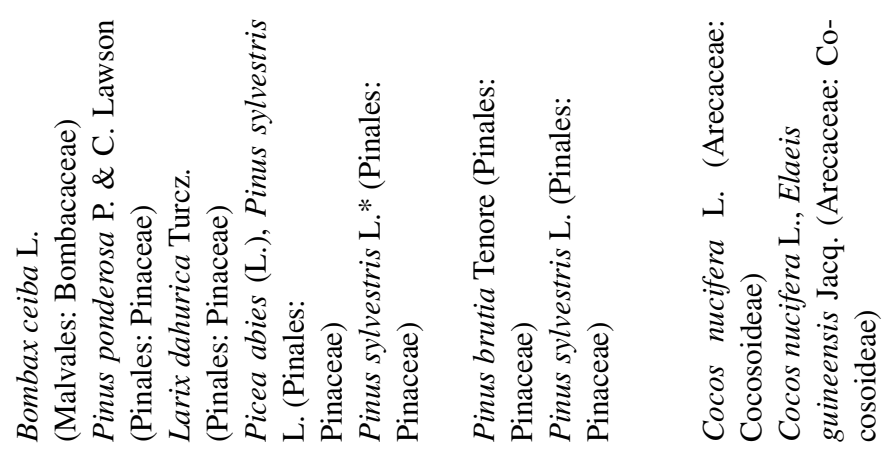

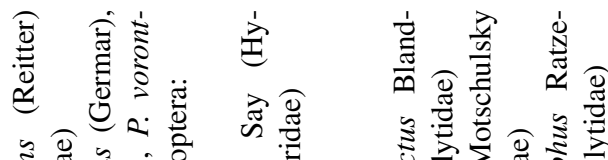

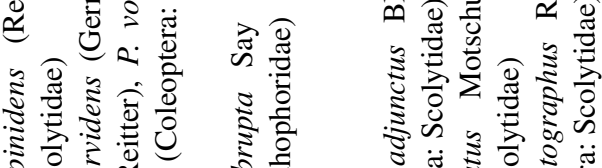

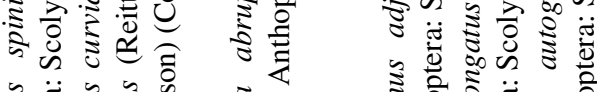
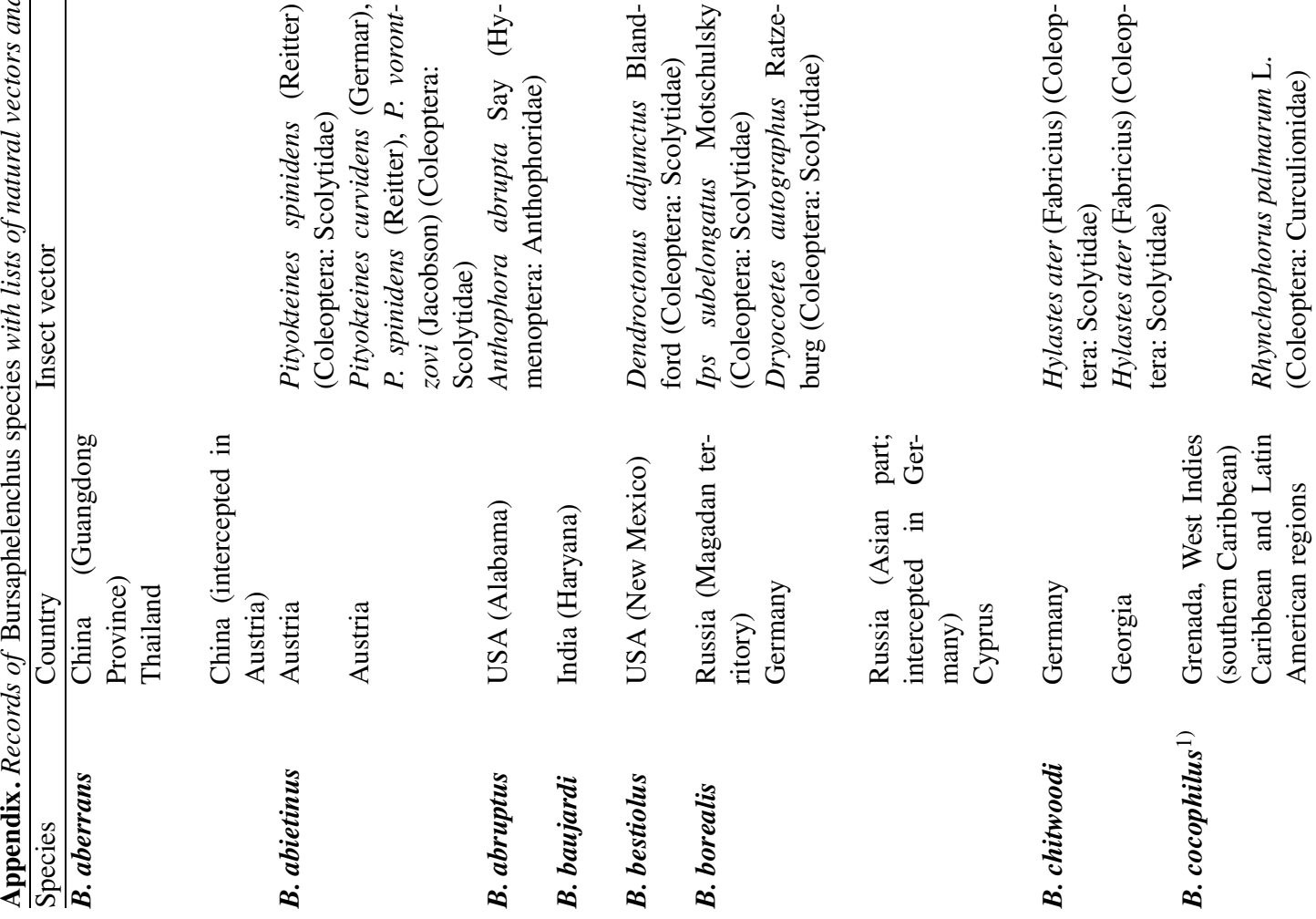

韦毫

莺.

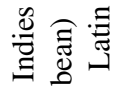

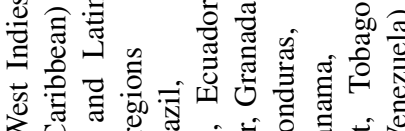

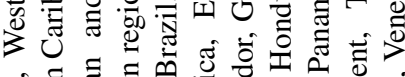

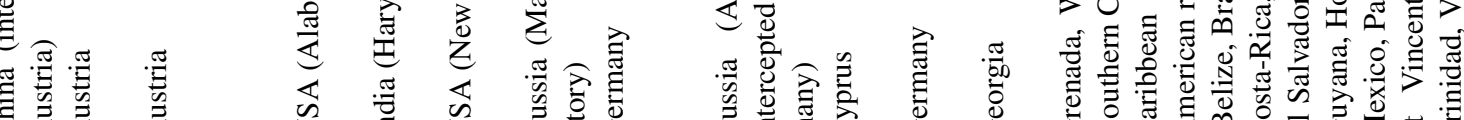




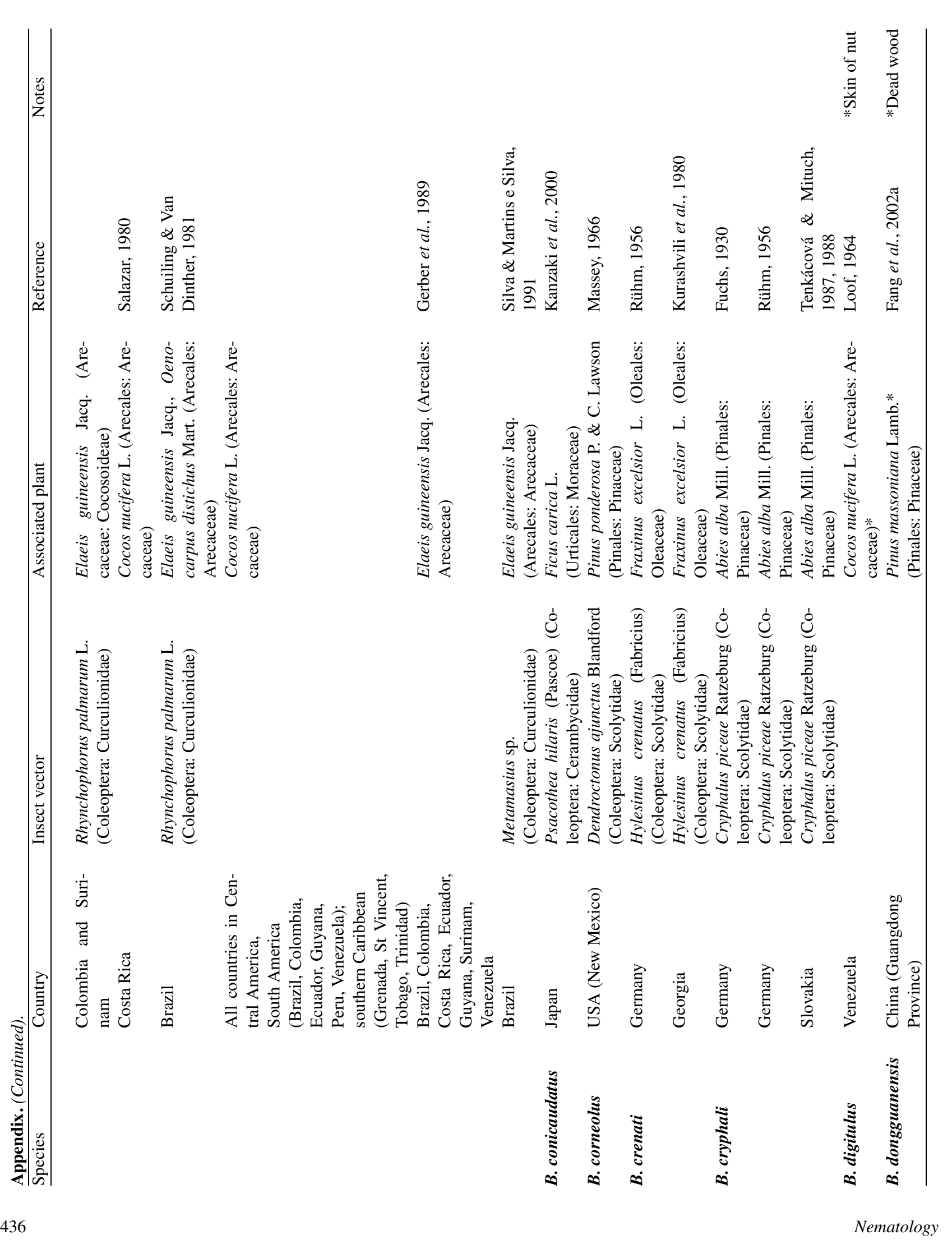




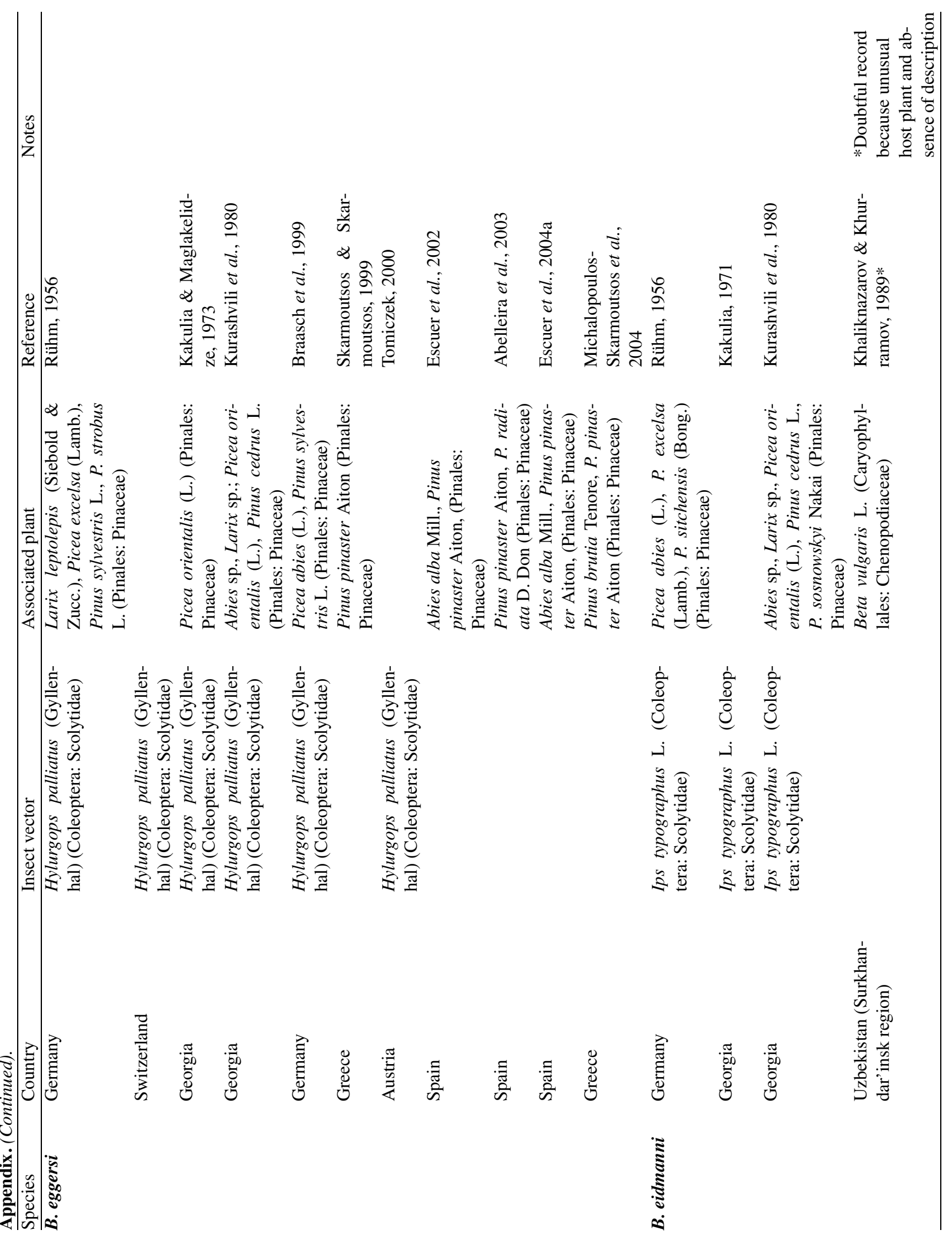

Vol. 7(3), 2005 


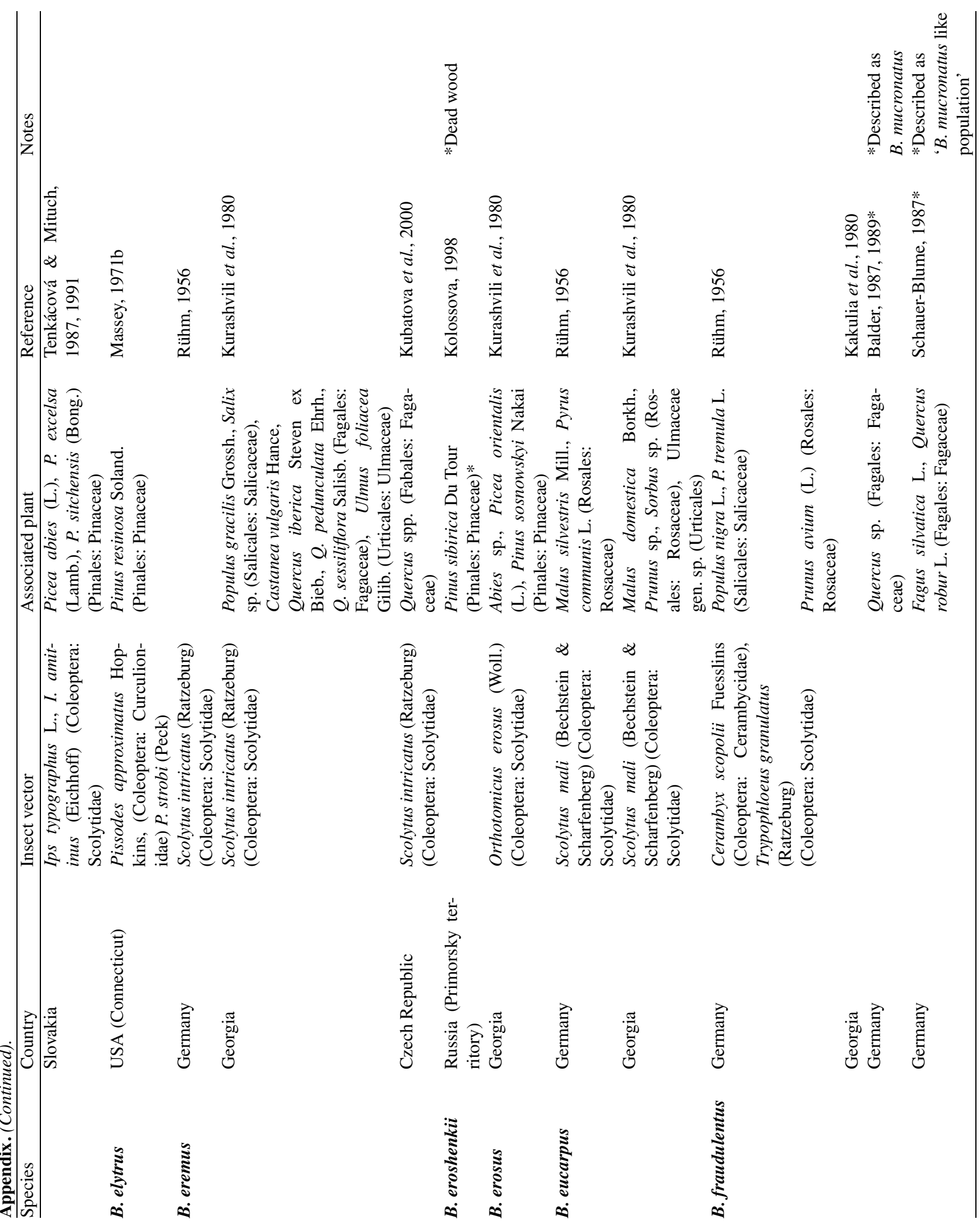




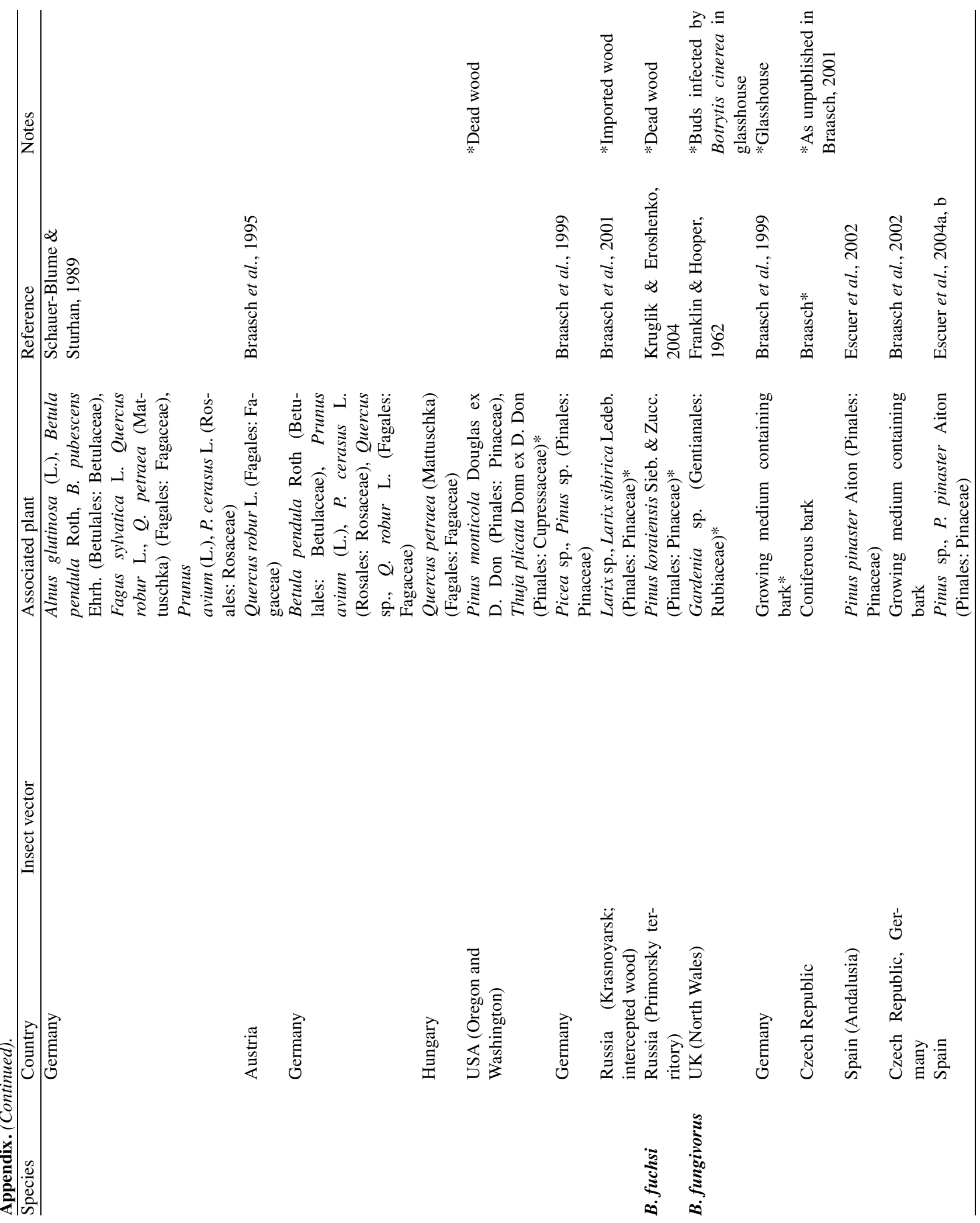

Vol. 7(3), 2005 


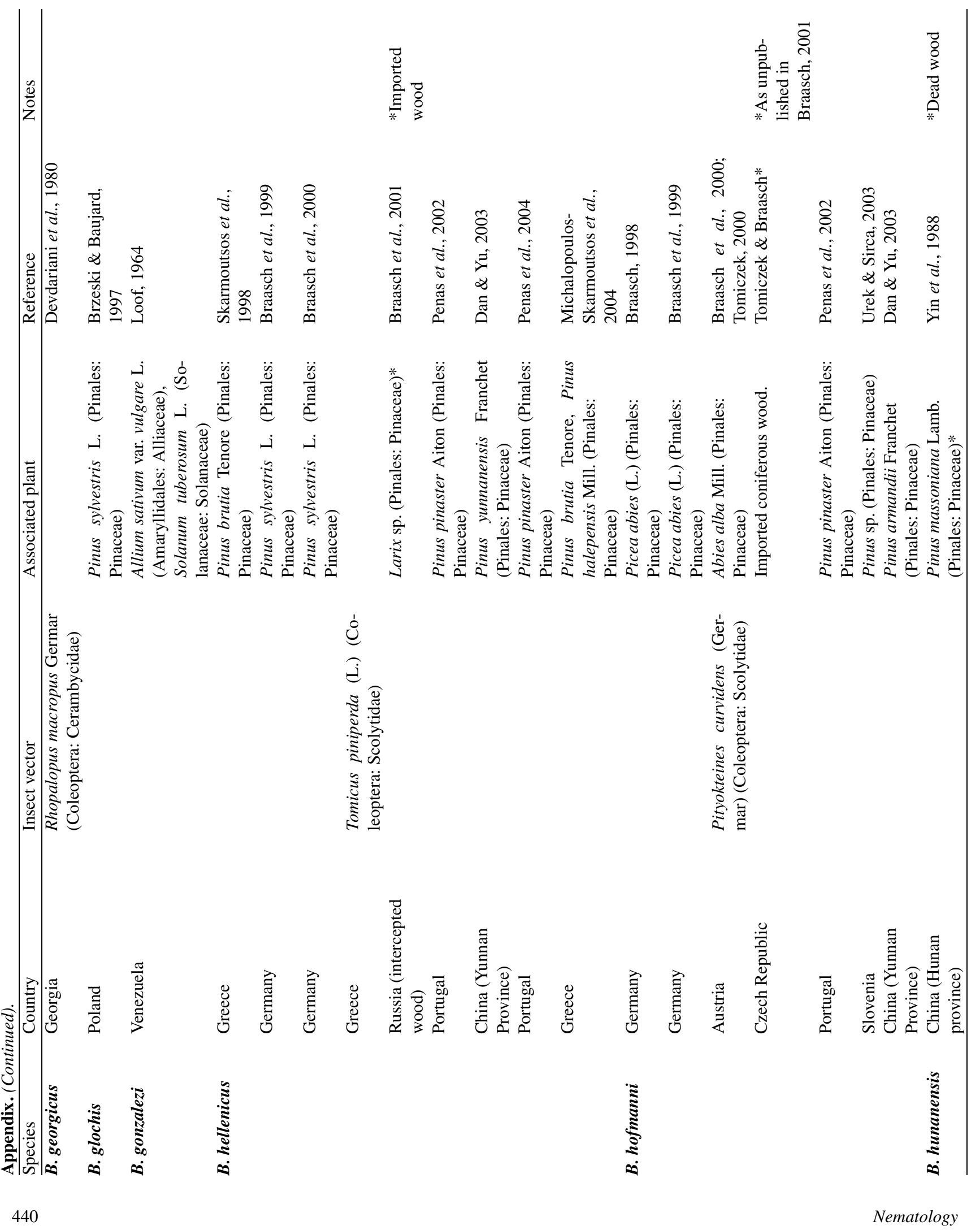


|

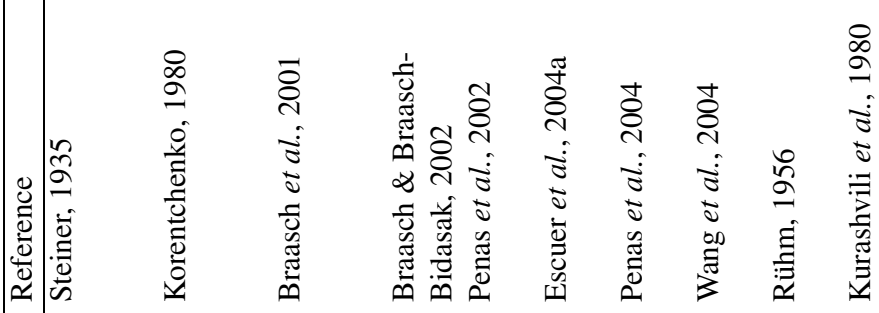

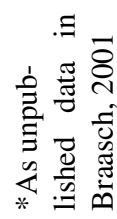

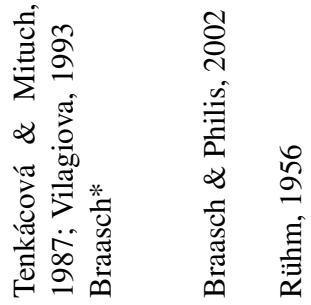

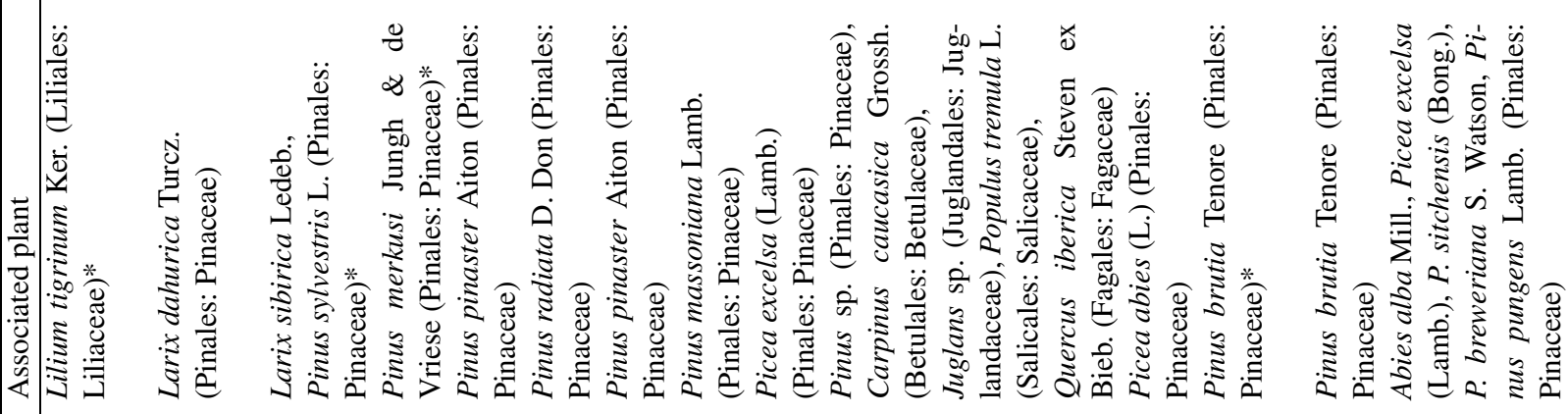
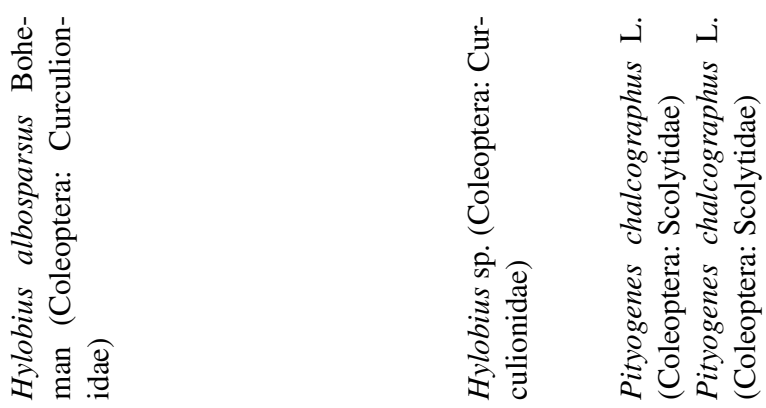

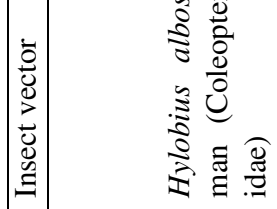

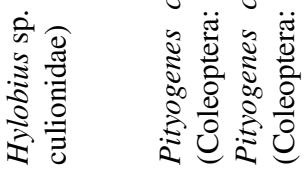

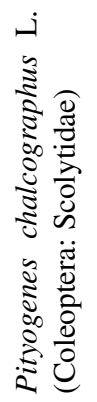

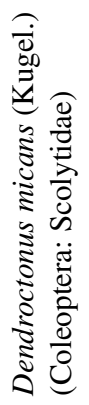

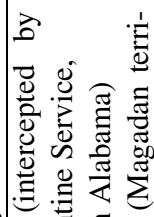

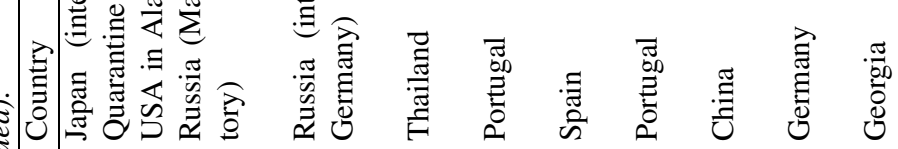

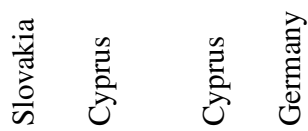

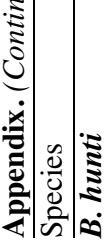

$\frac{1}{3}$
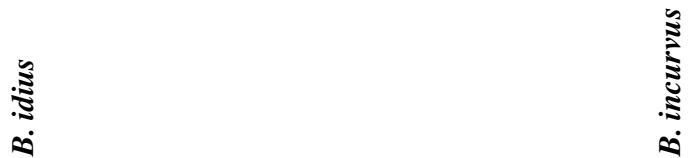

Vol. 7(3), 2005 


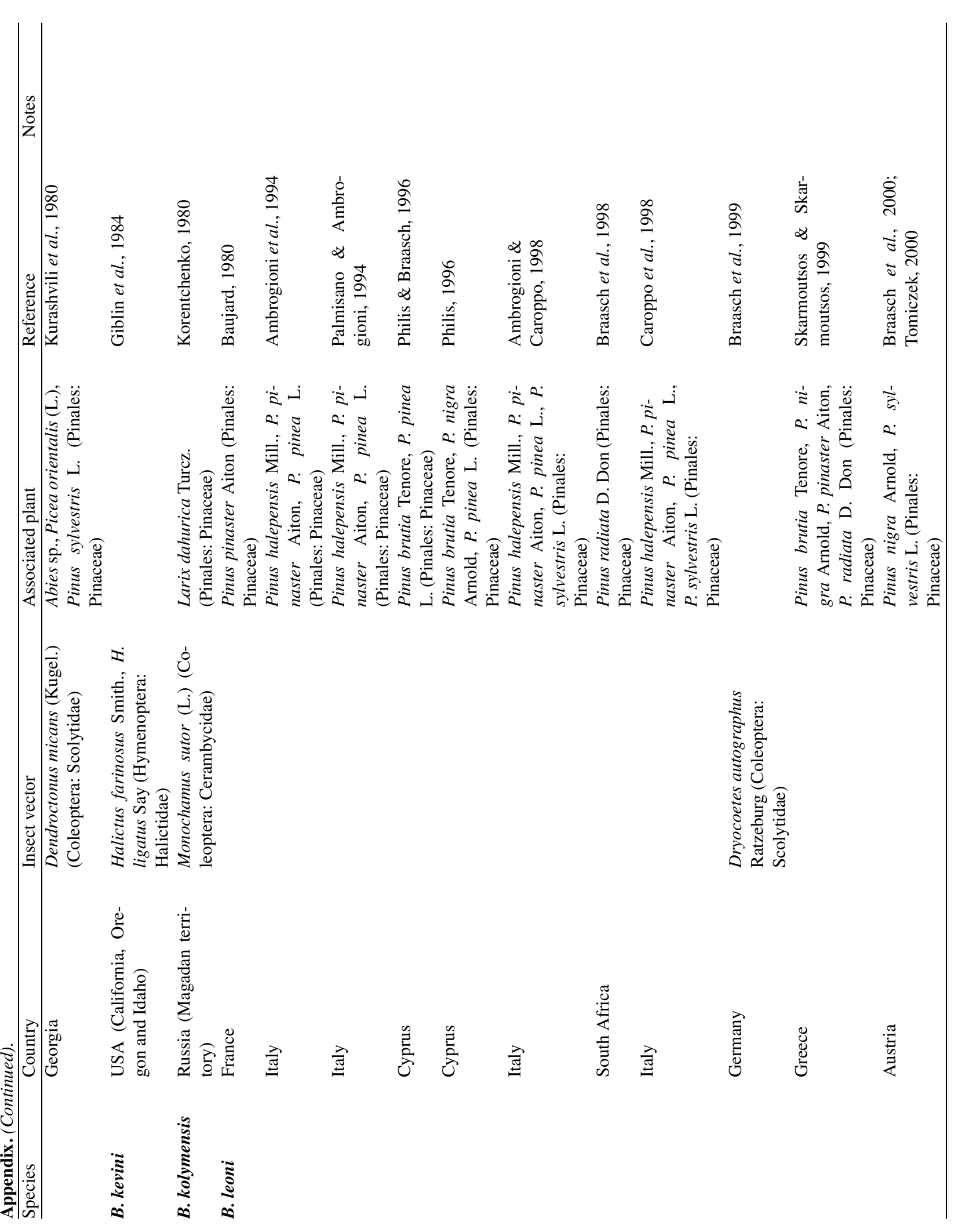




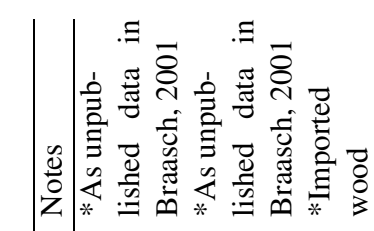

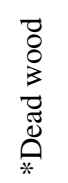

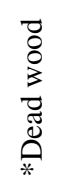

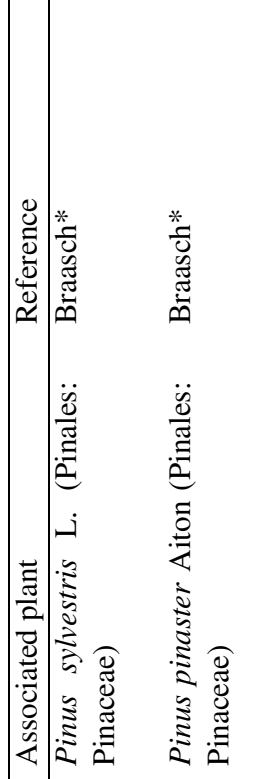

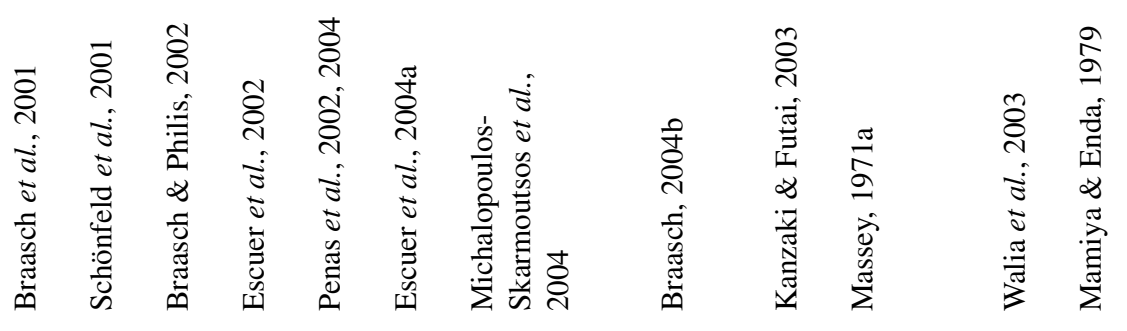

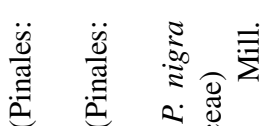

Q

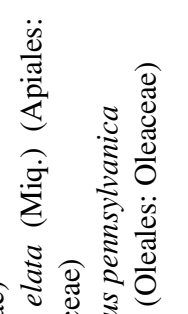

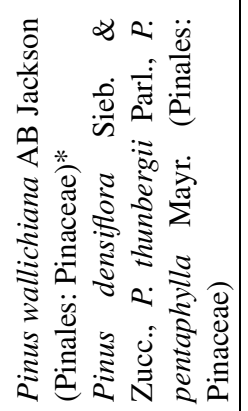

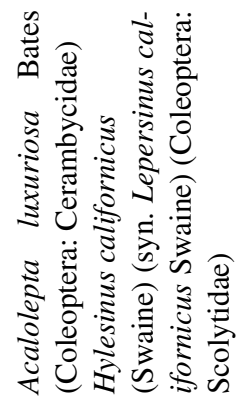

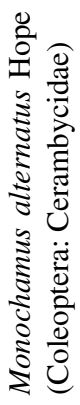

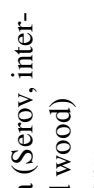

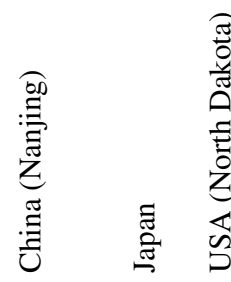

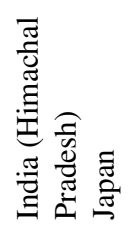

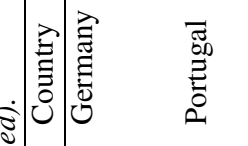
要

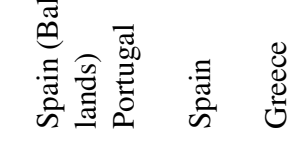

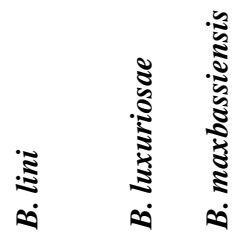

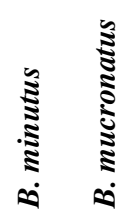

Vol. 7(3), 2005 


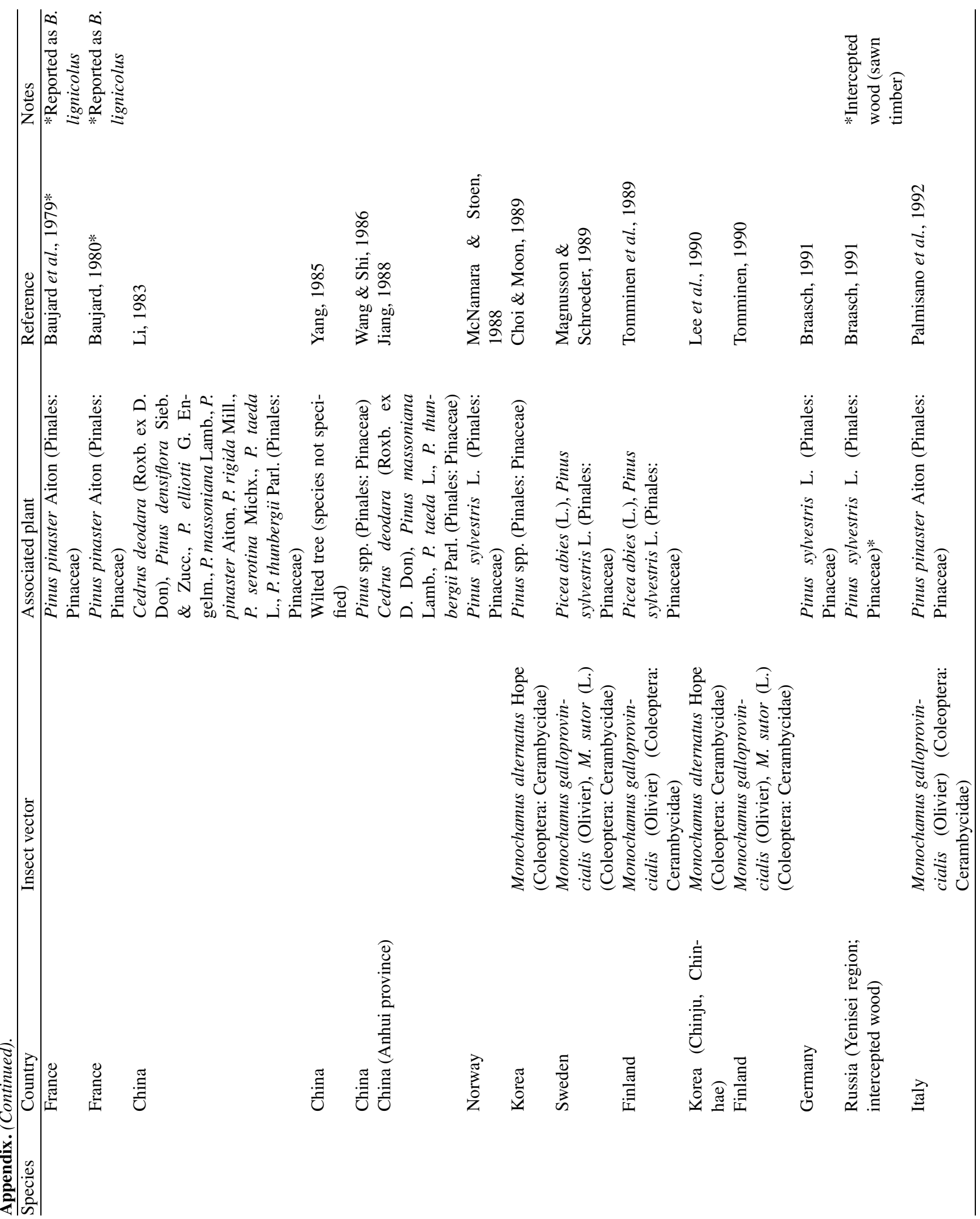




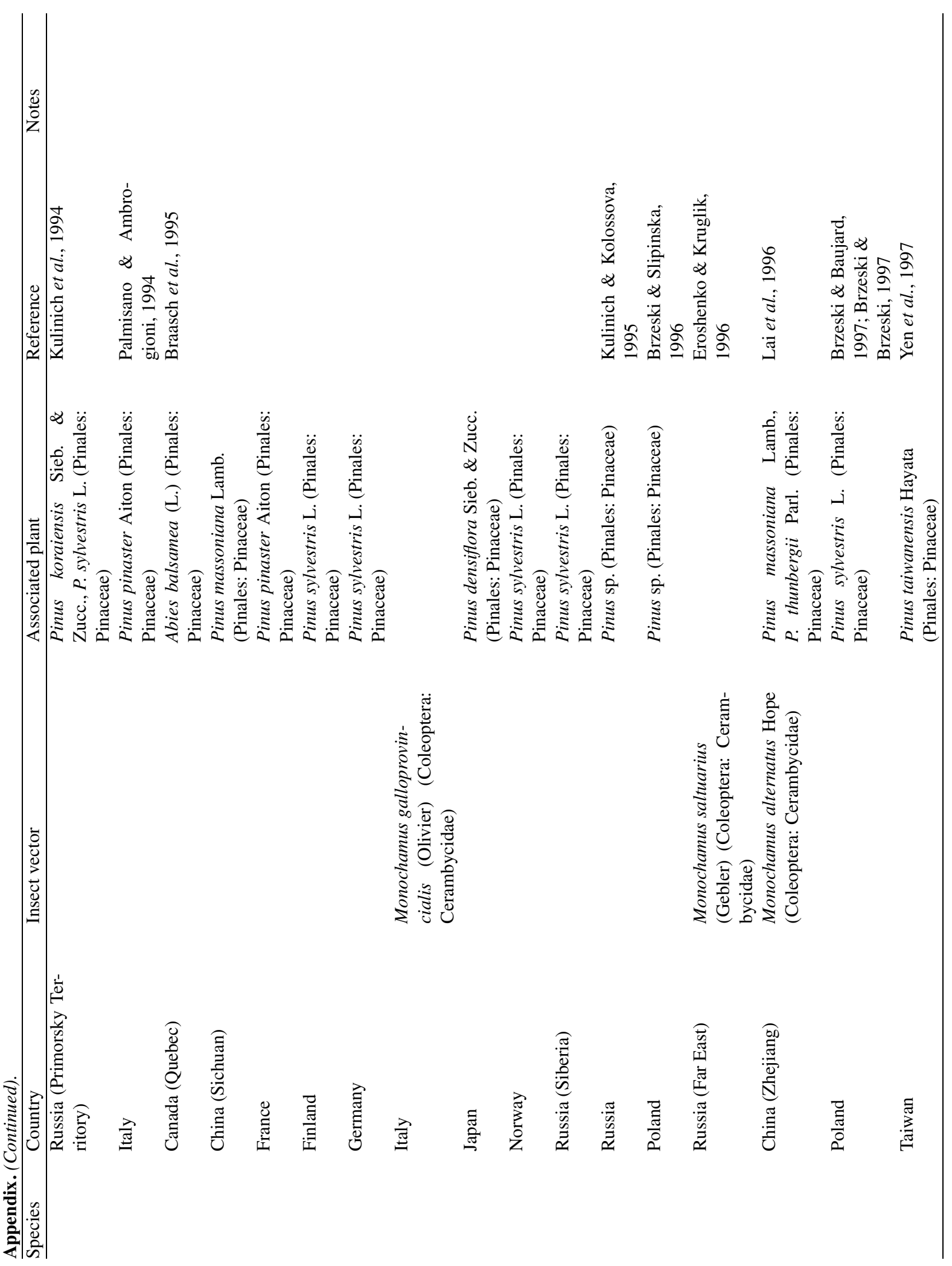




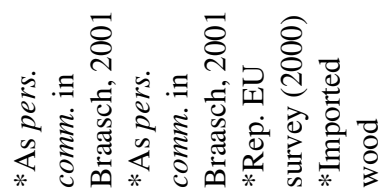

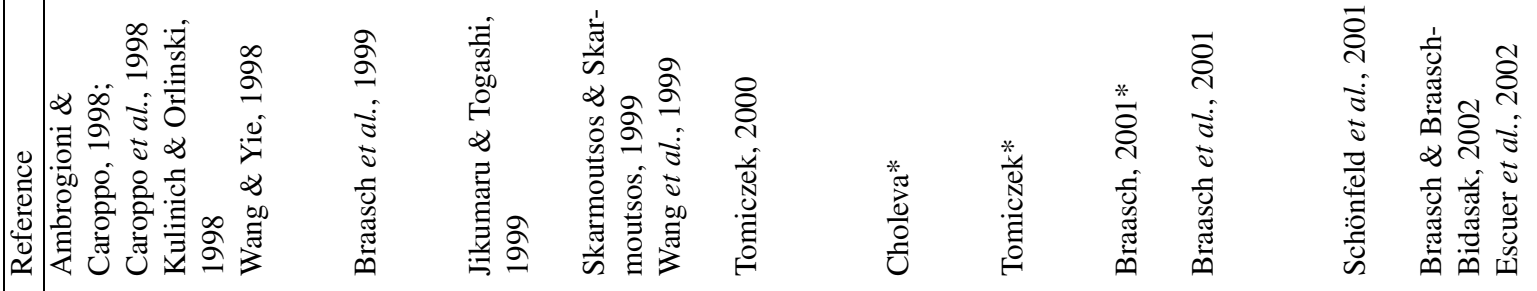

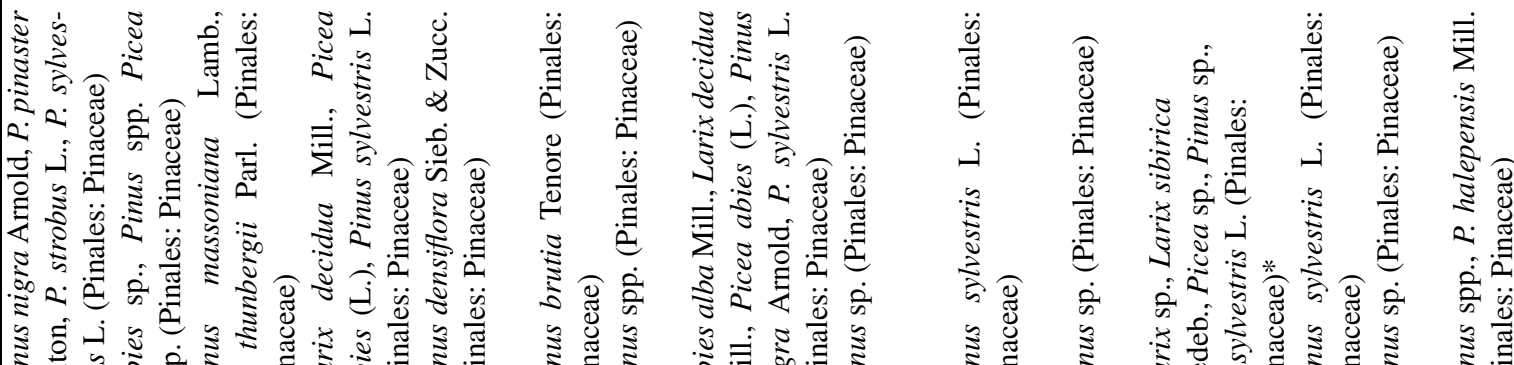

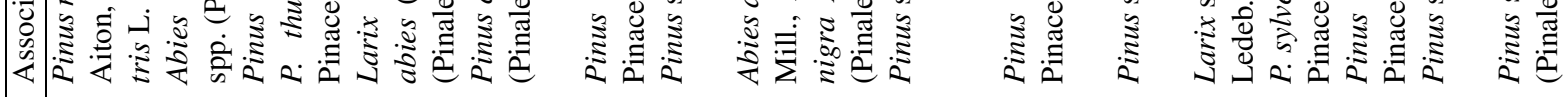

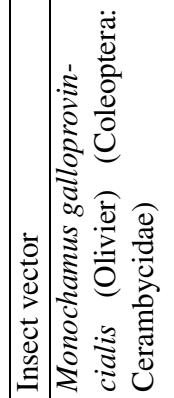

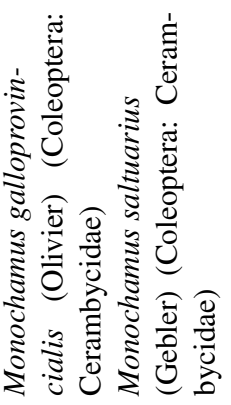

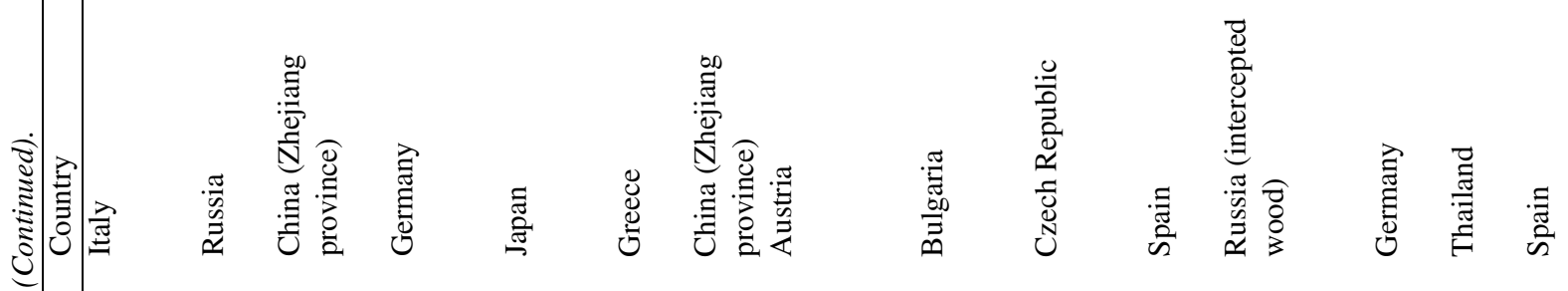




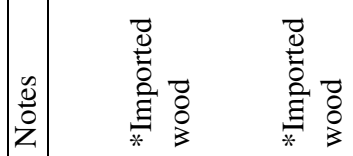

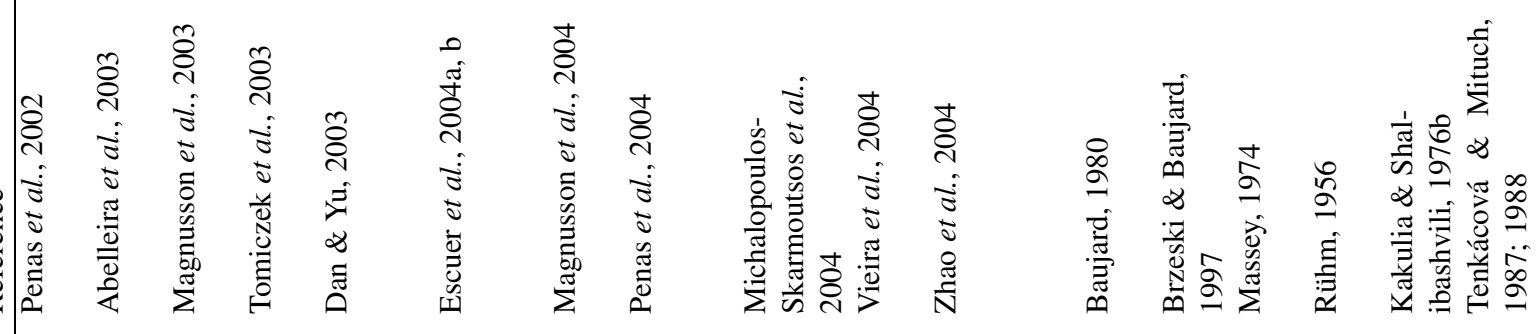

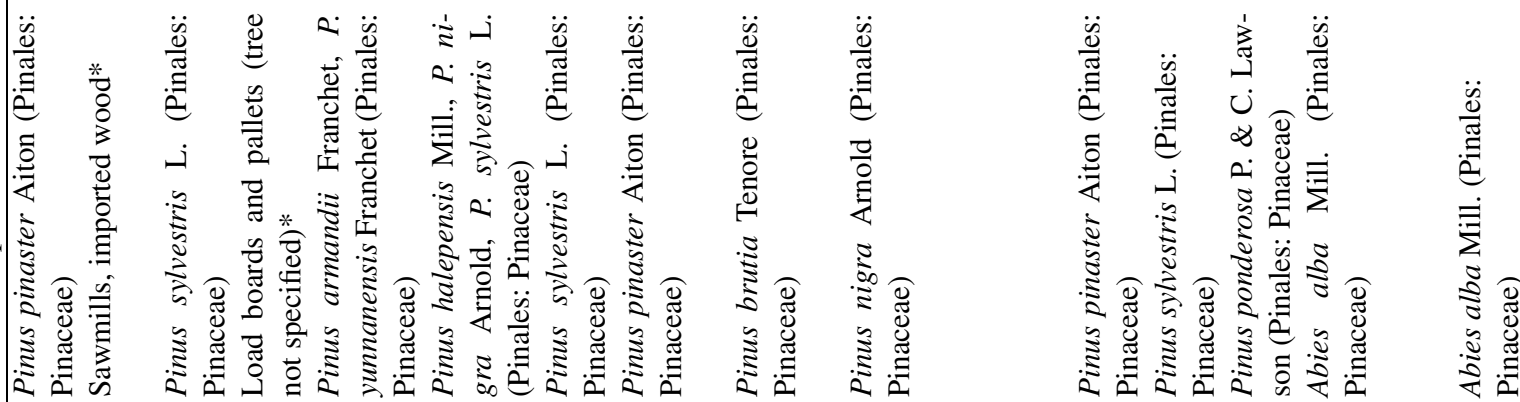

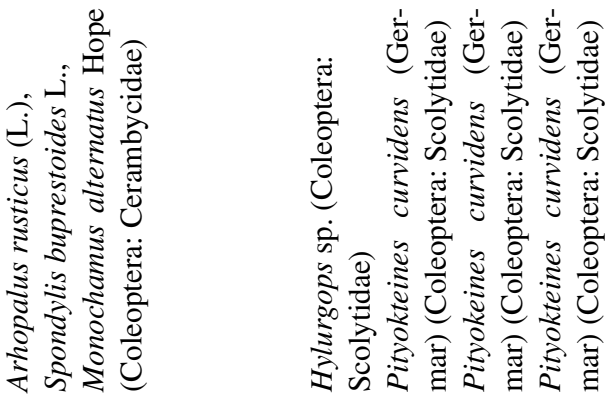

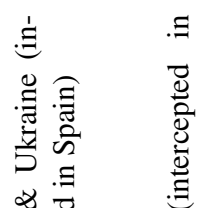

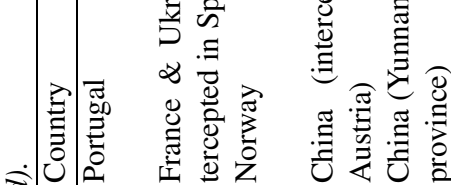

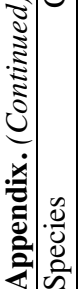

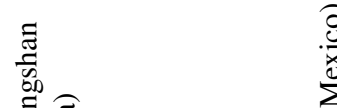

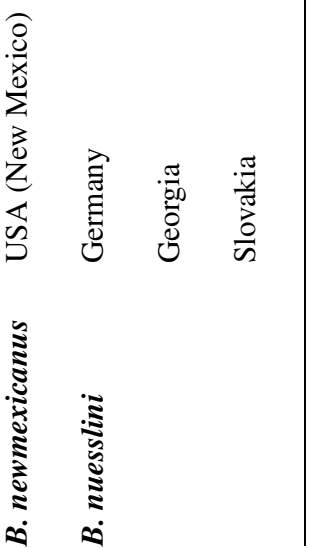

Vol. 7(3), 2005 


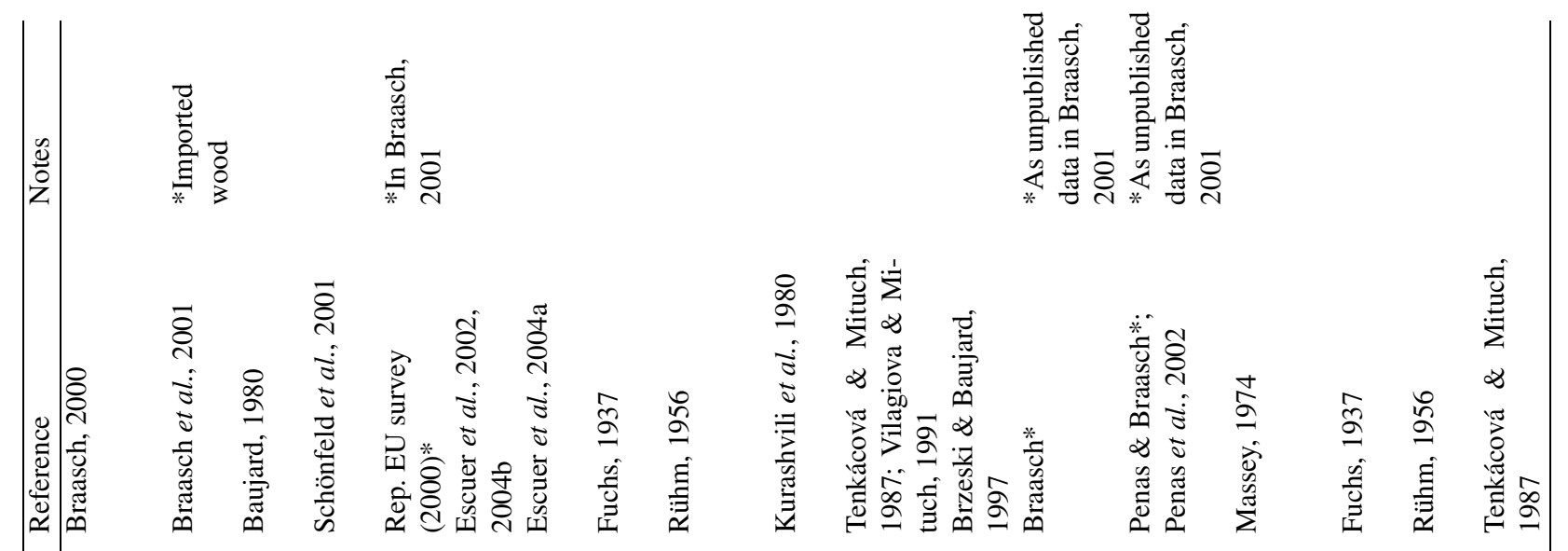

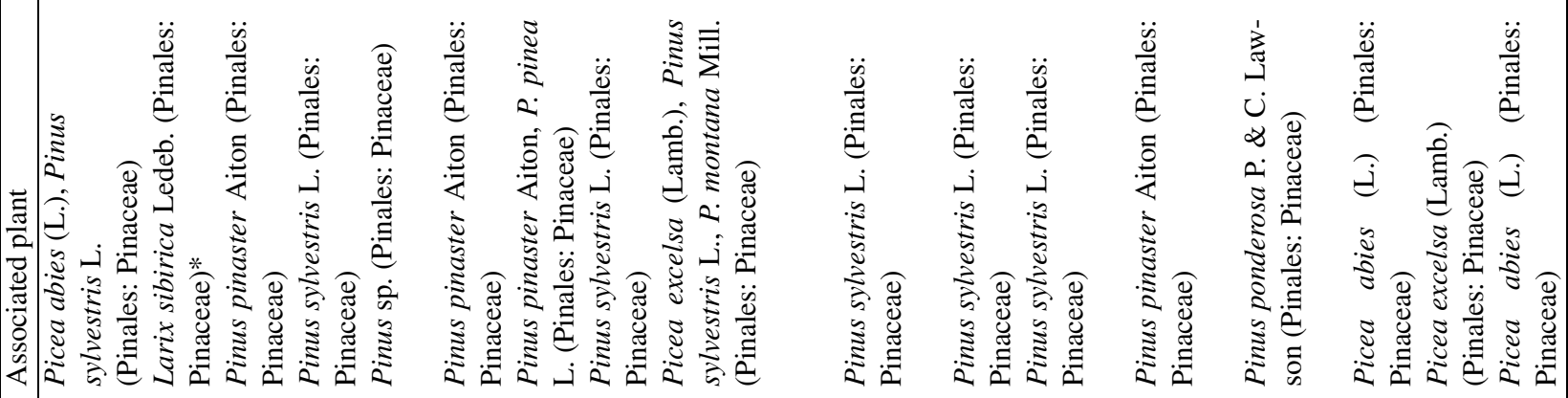

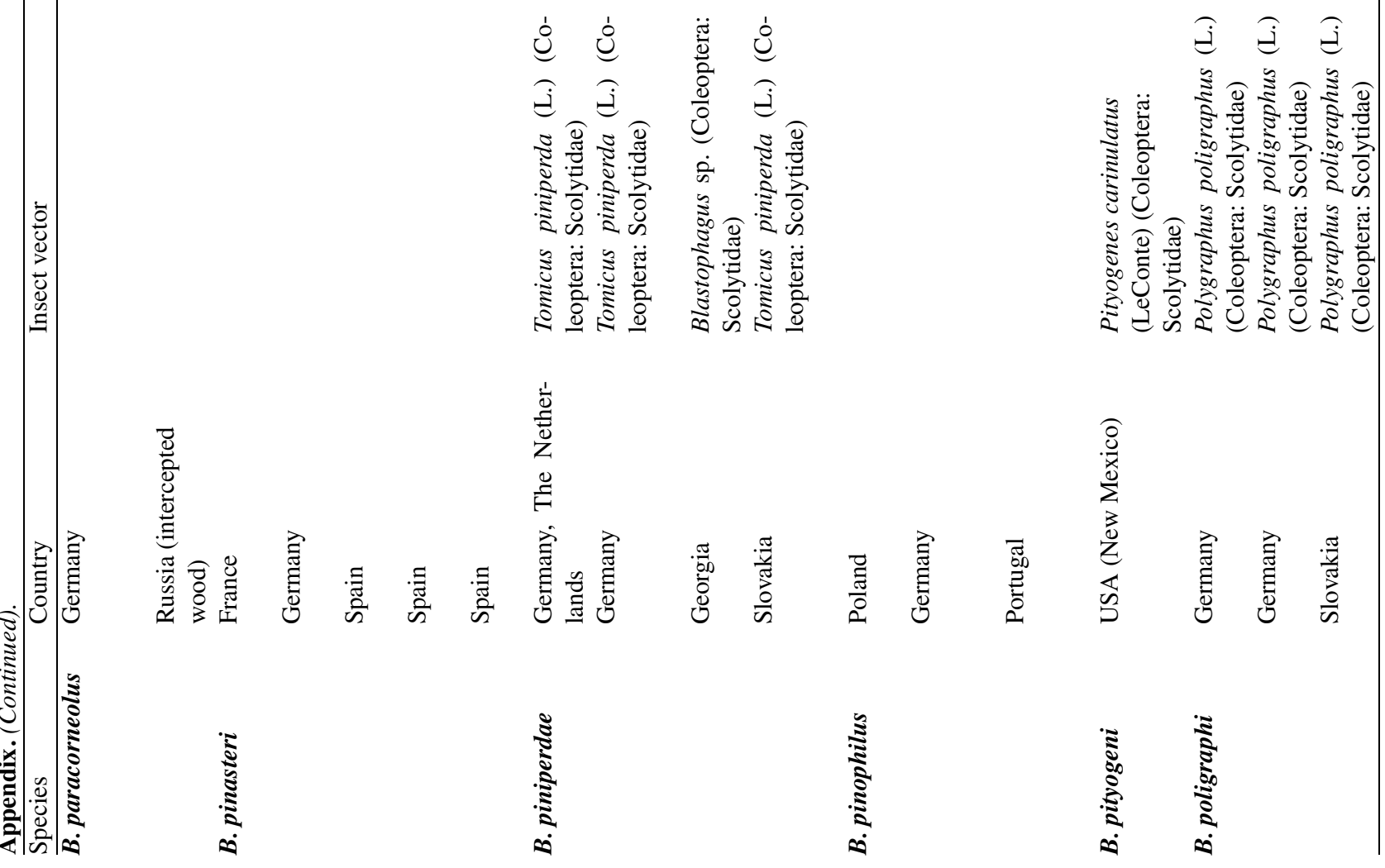




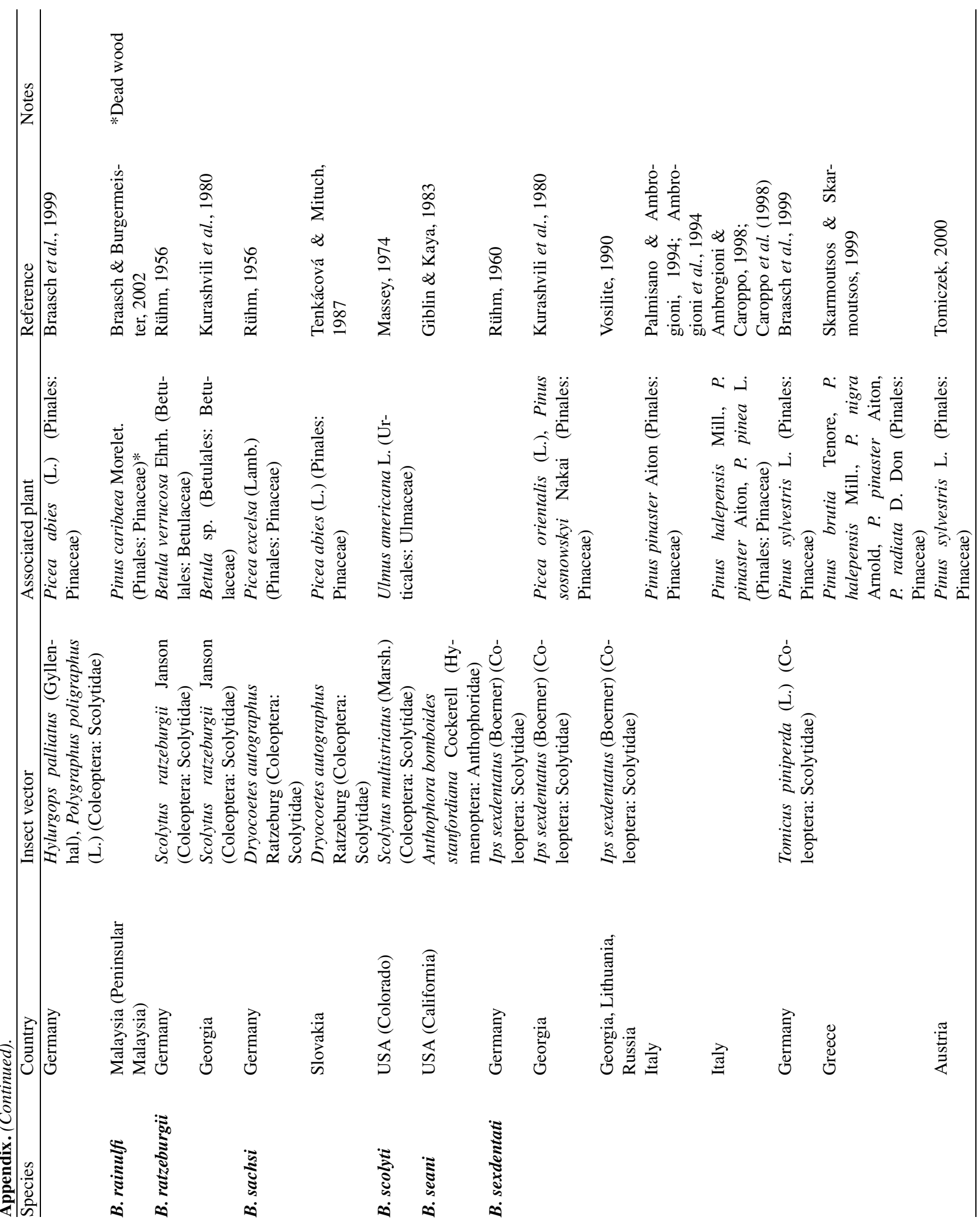

Vol. 7(3), 2005 


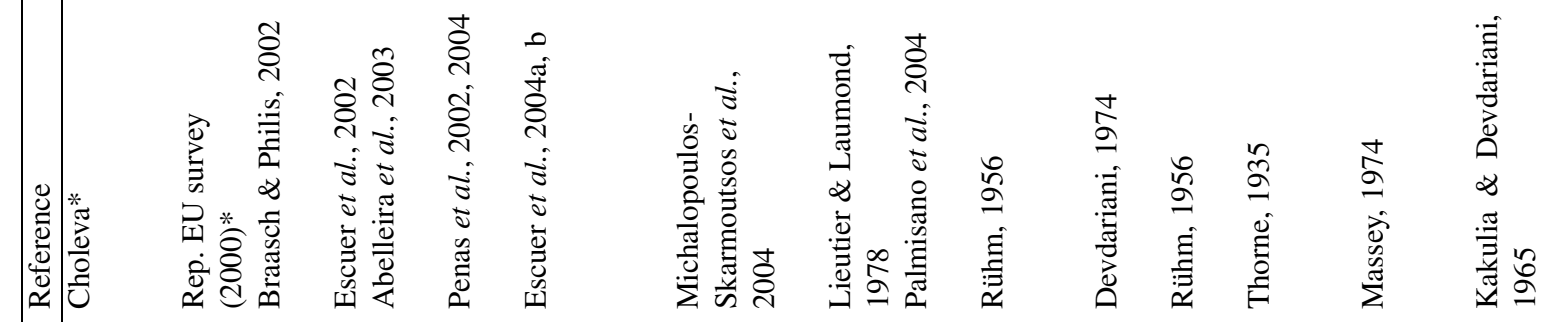

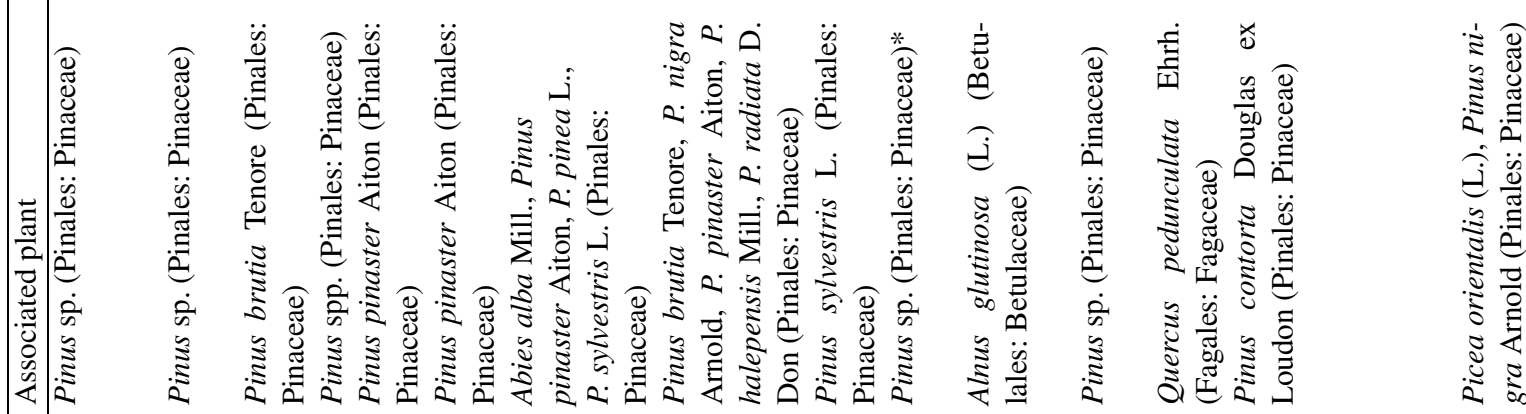

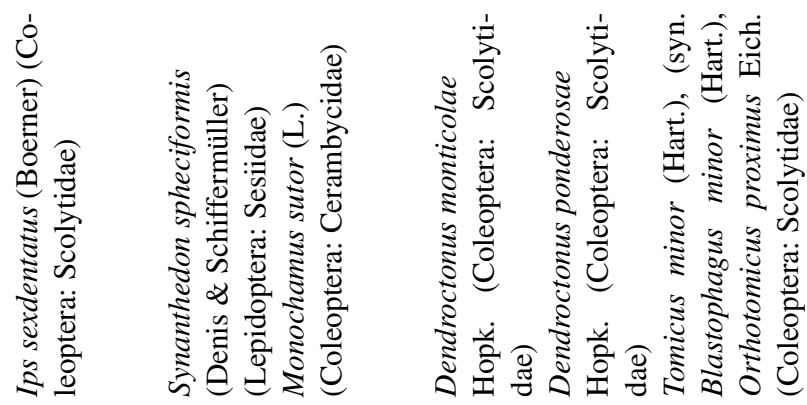

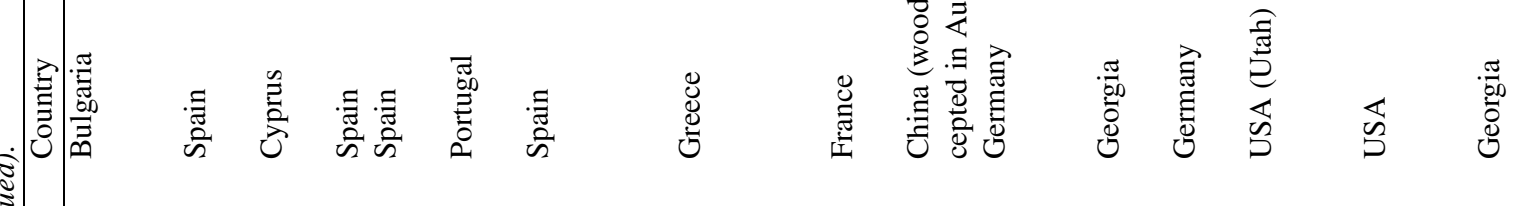
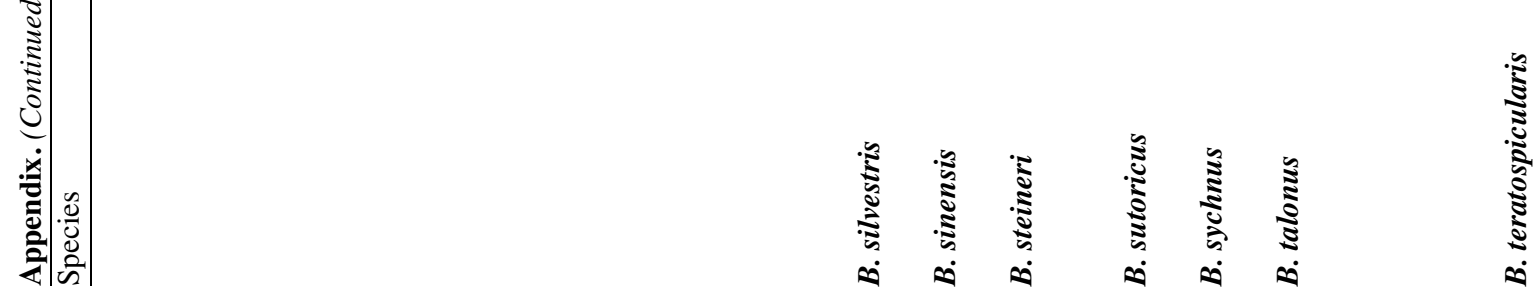

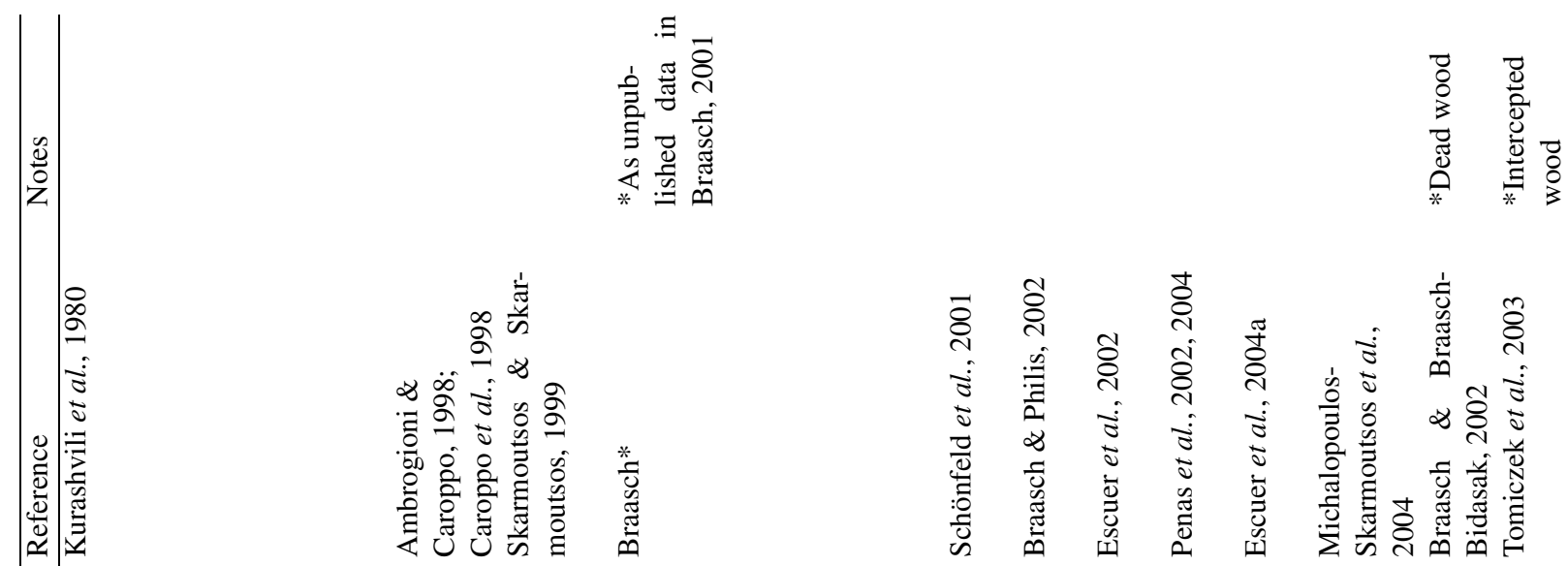

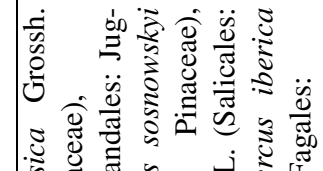

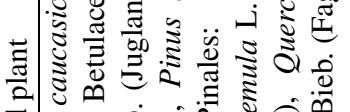

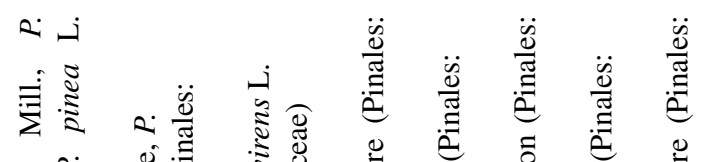

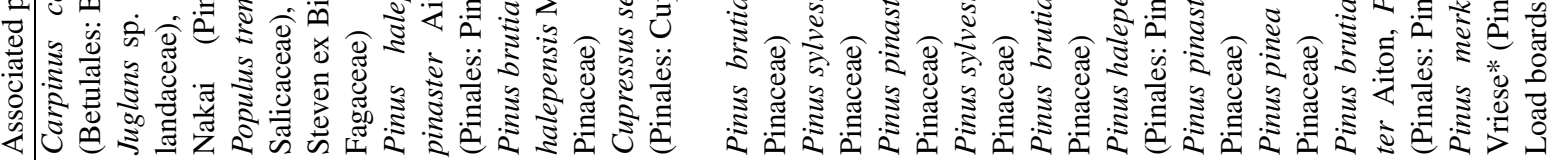

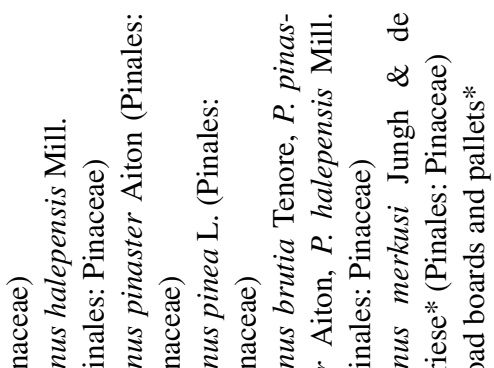

这泀

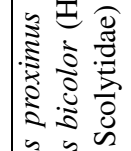

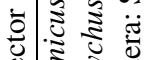

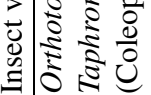

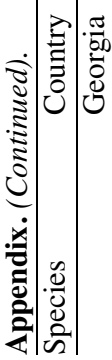

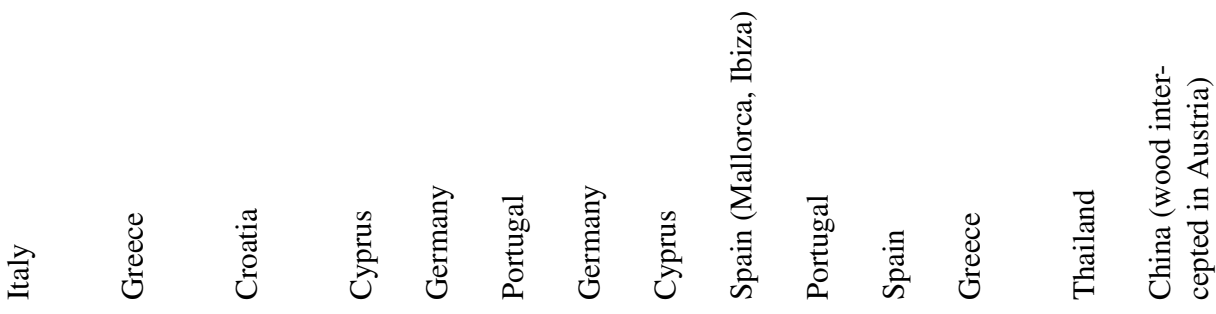




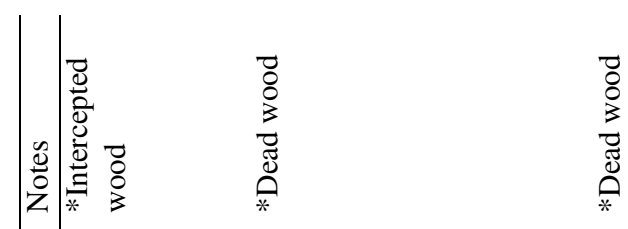

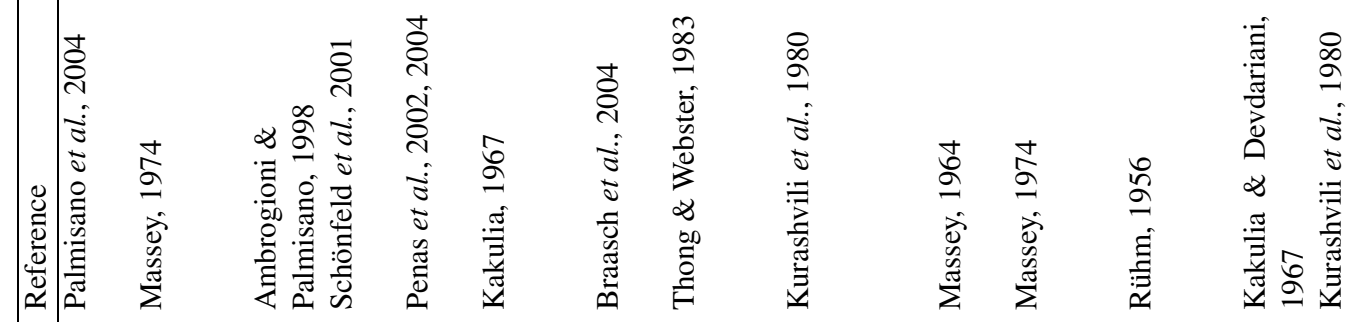

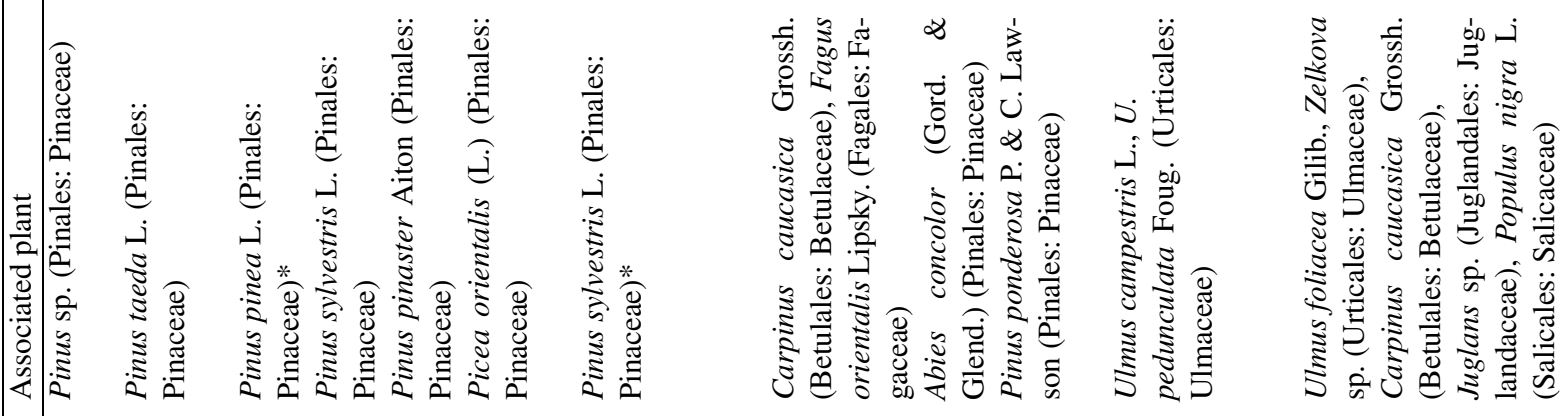

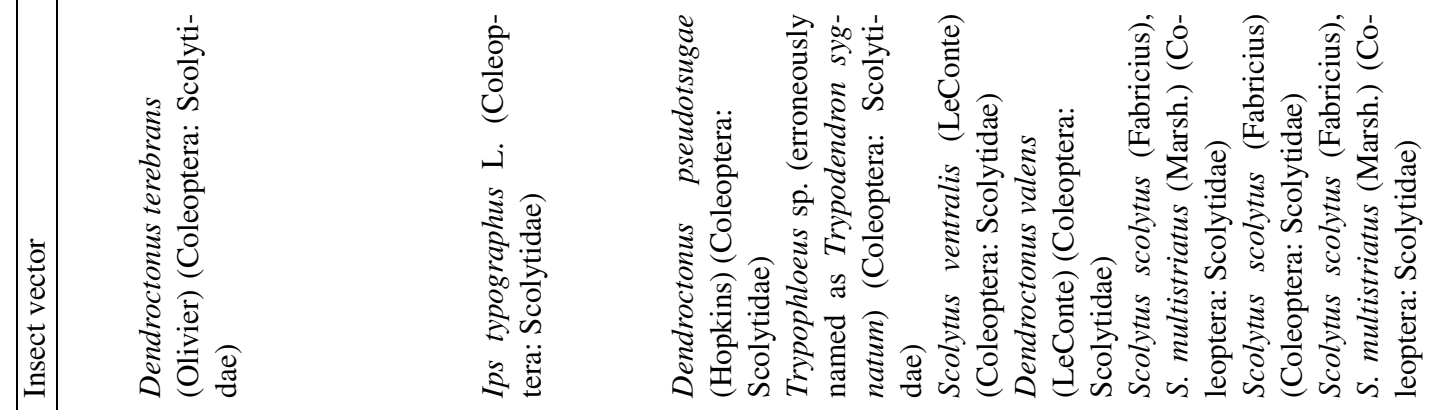

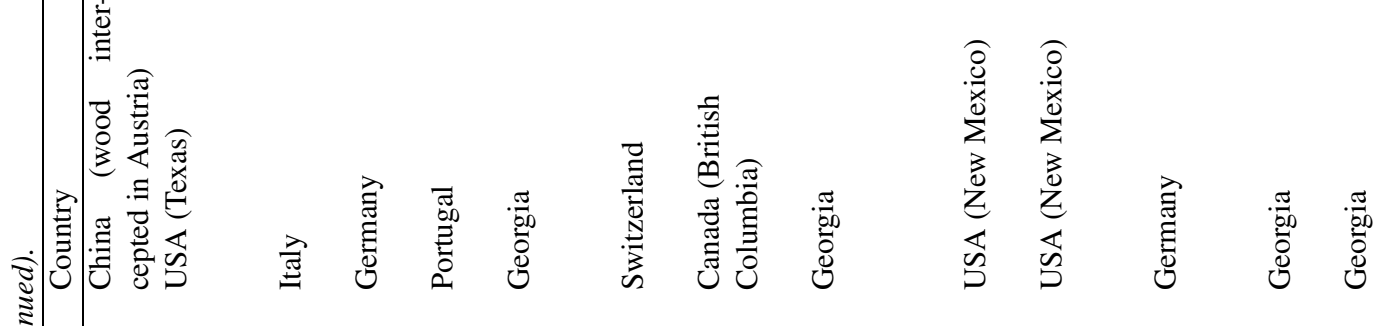

紧

111

裹部 


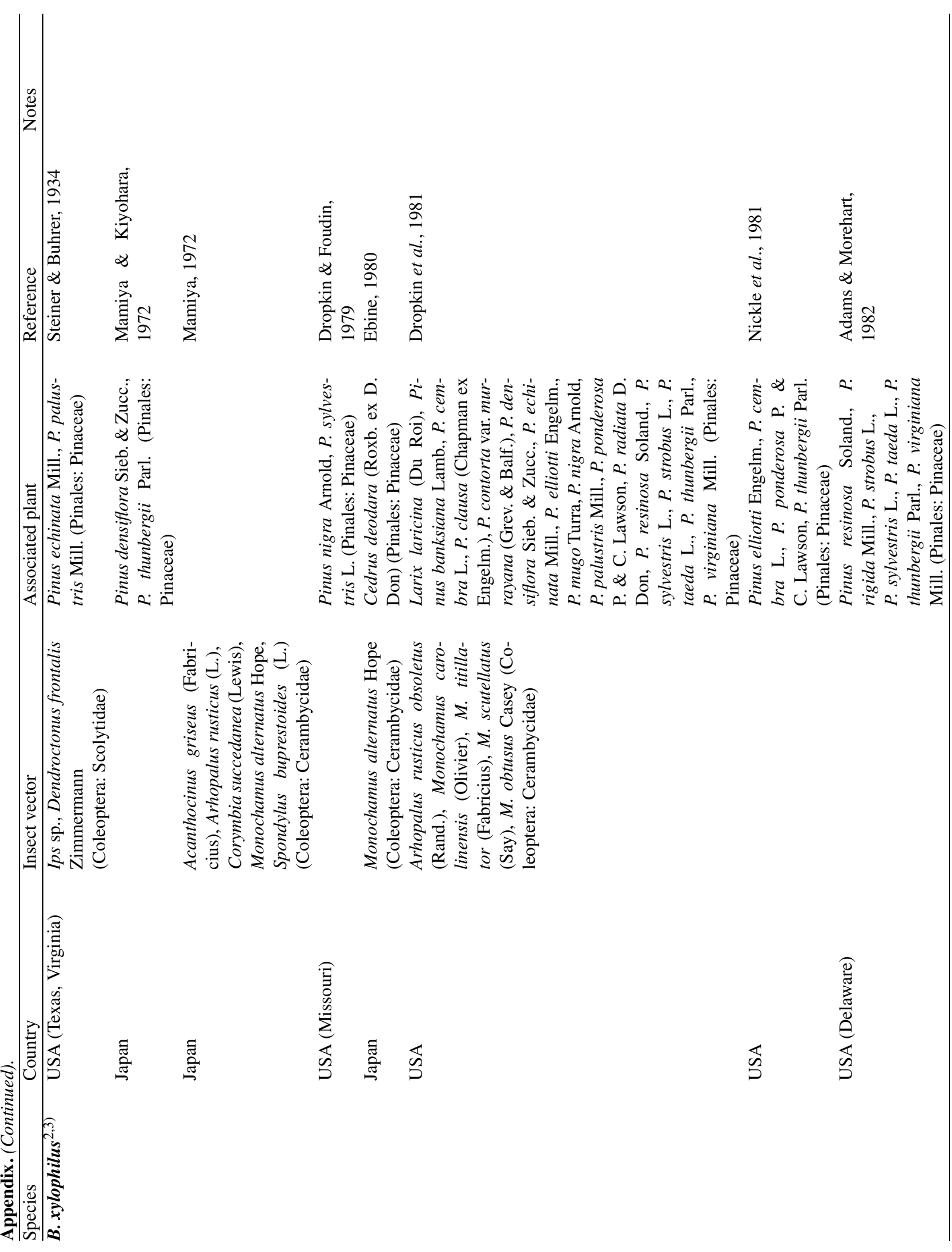




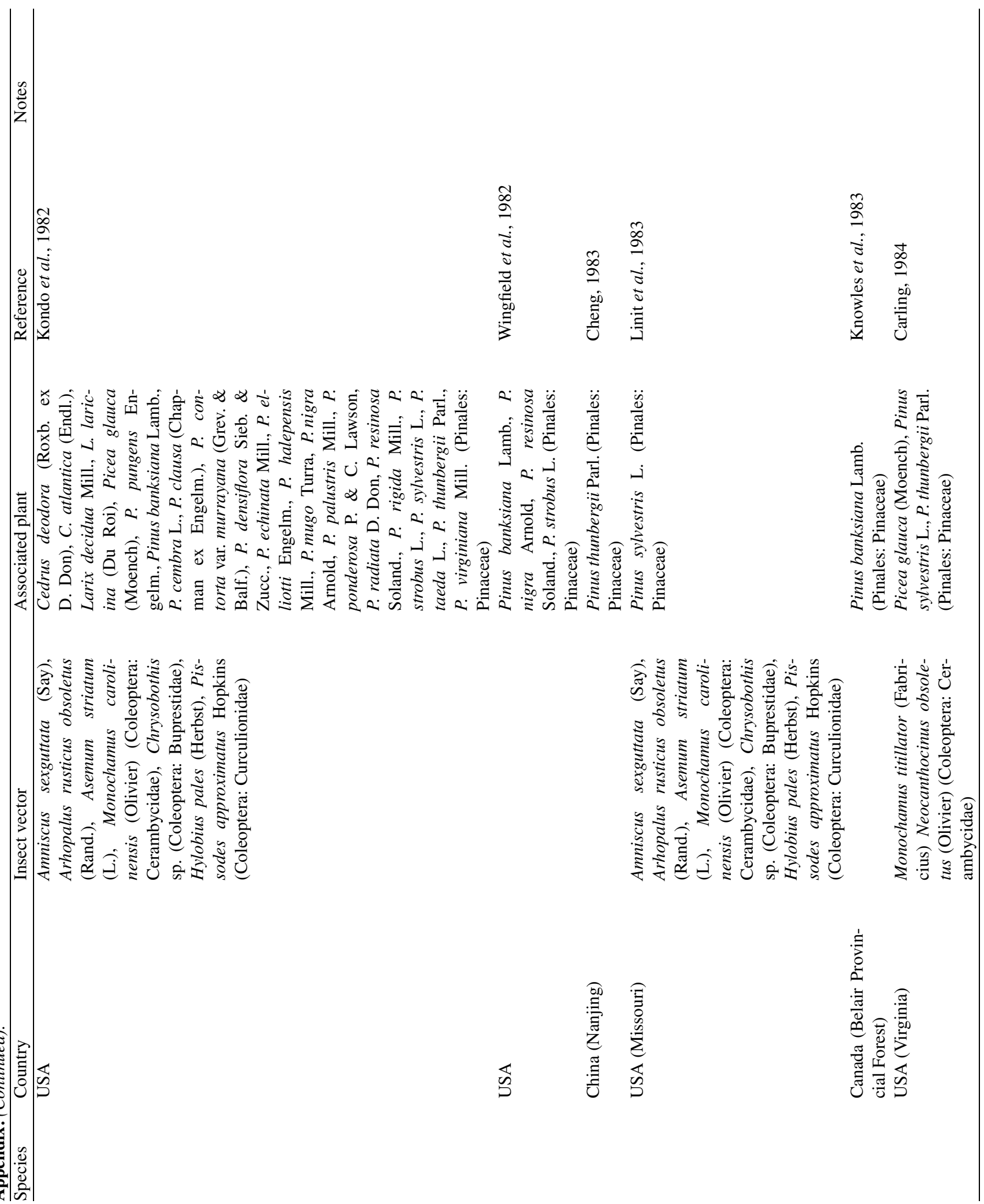




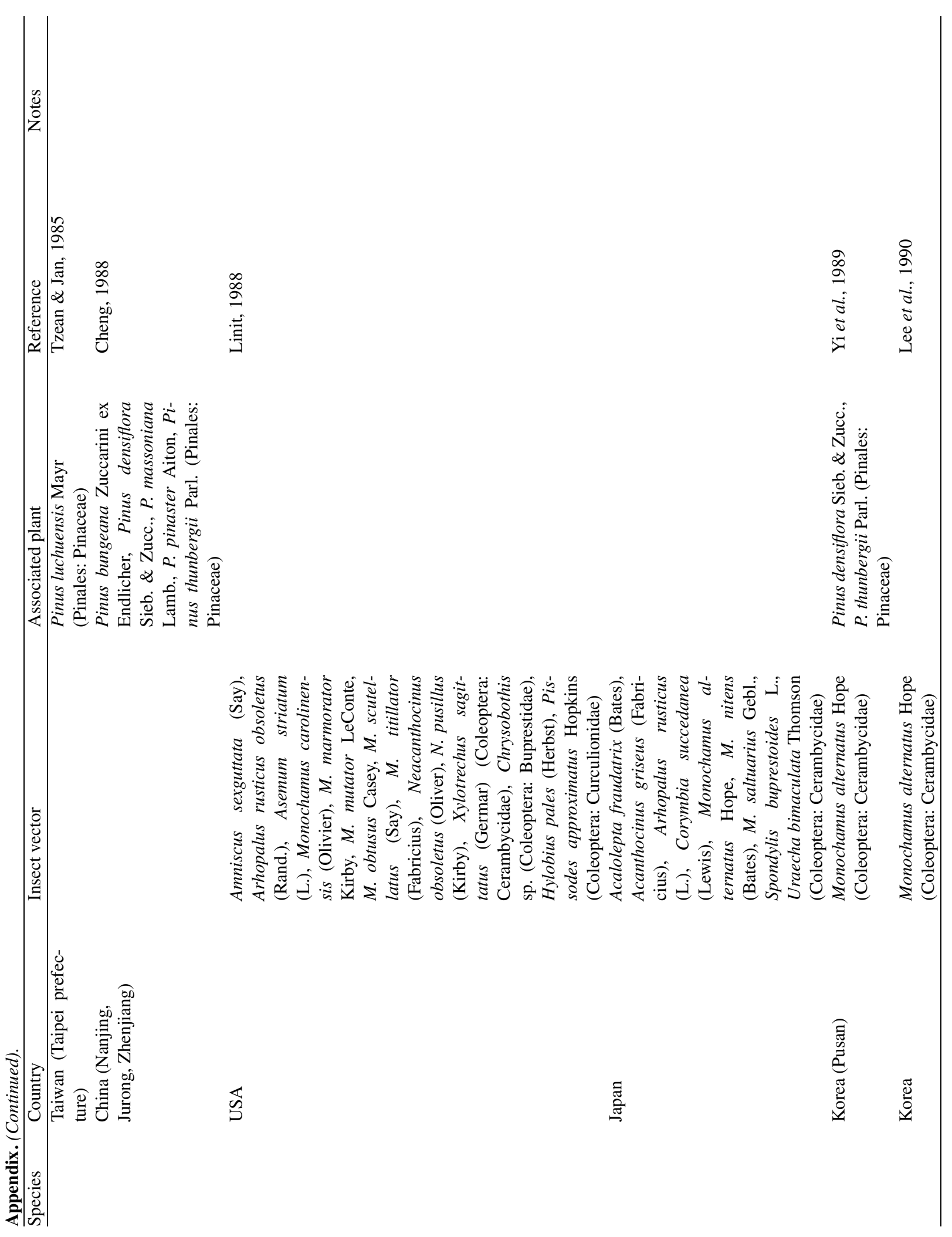

Vol. 7(3), 2005 

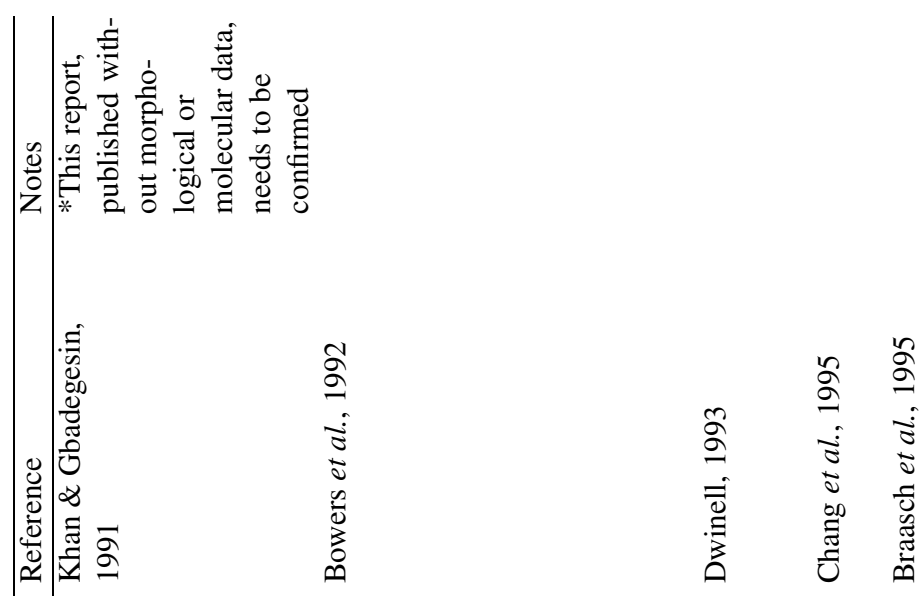

$\frac{n}{2}$

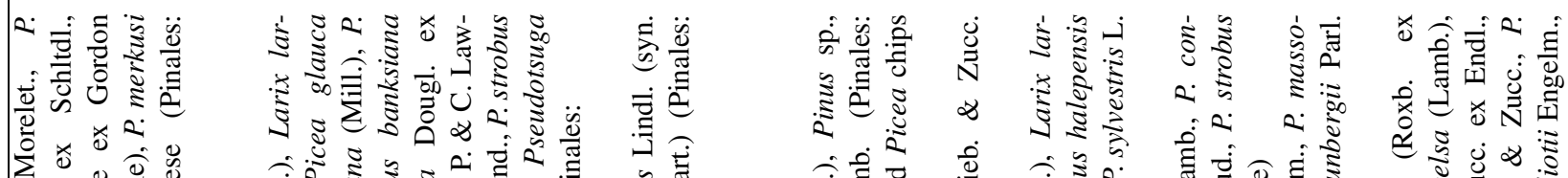

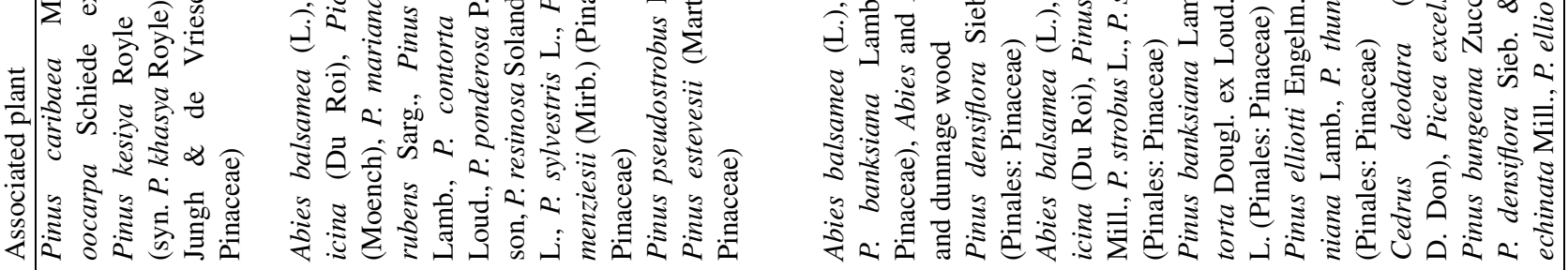
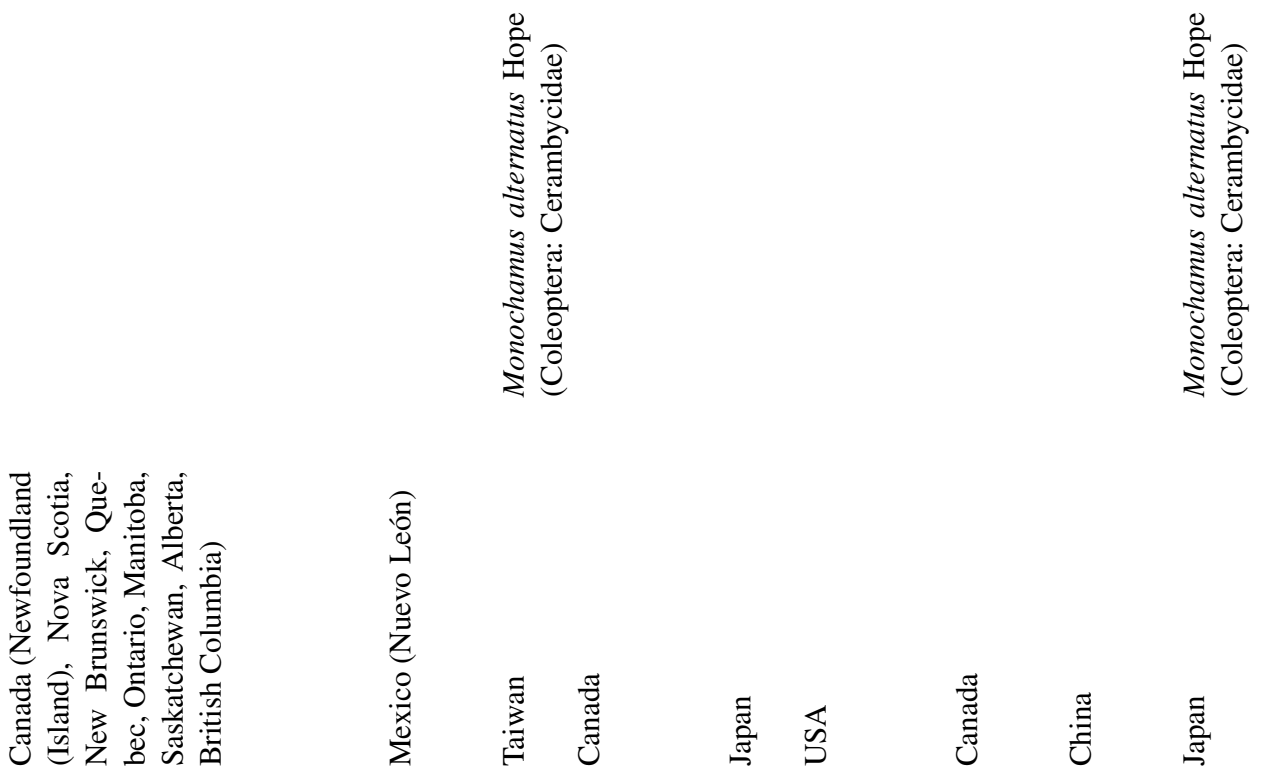

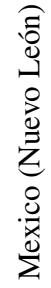

:

芯 芯

Uี 


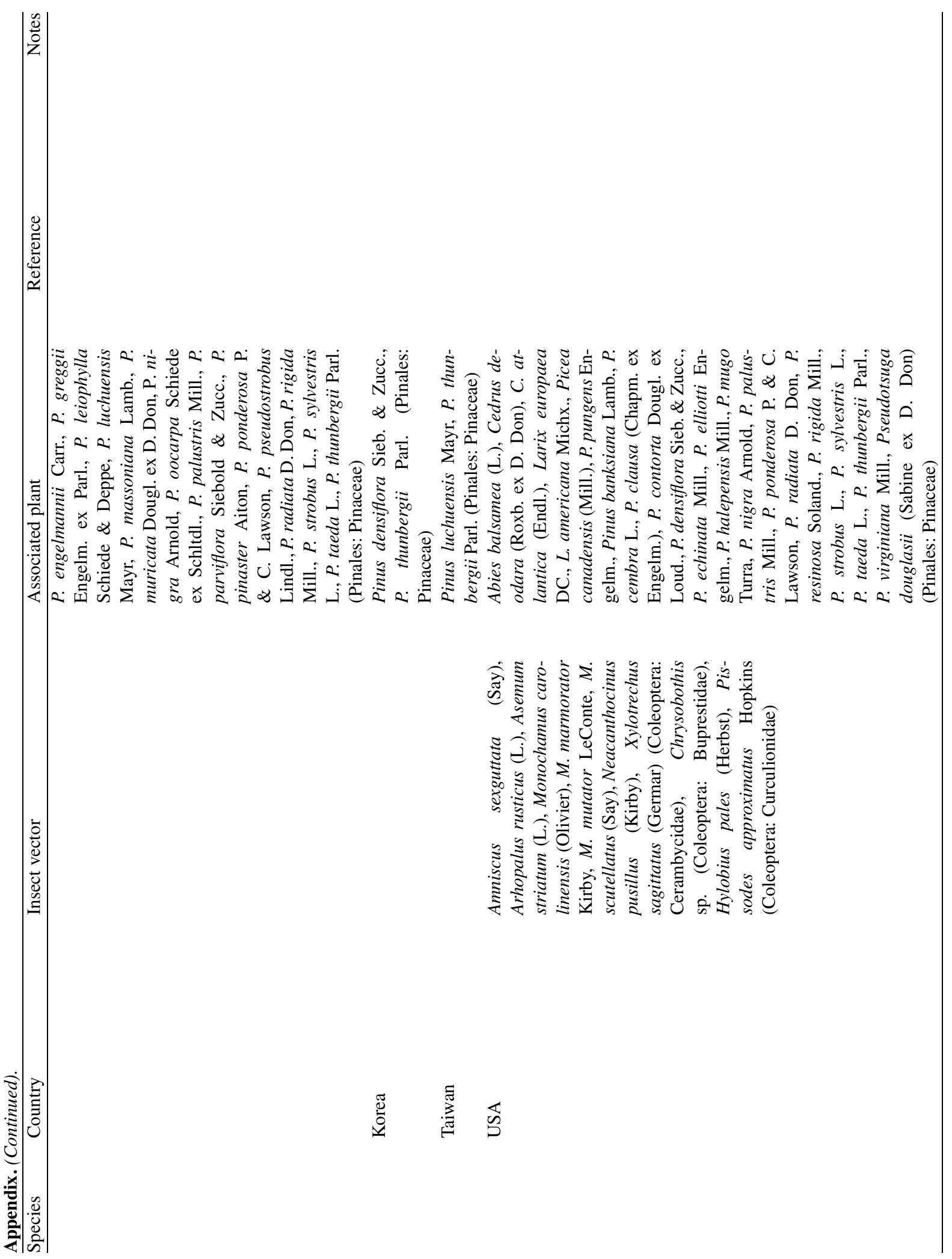




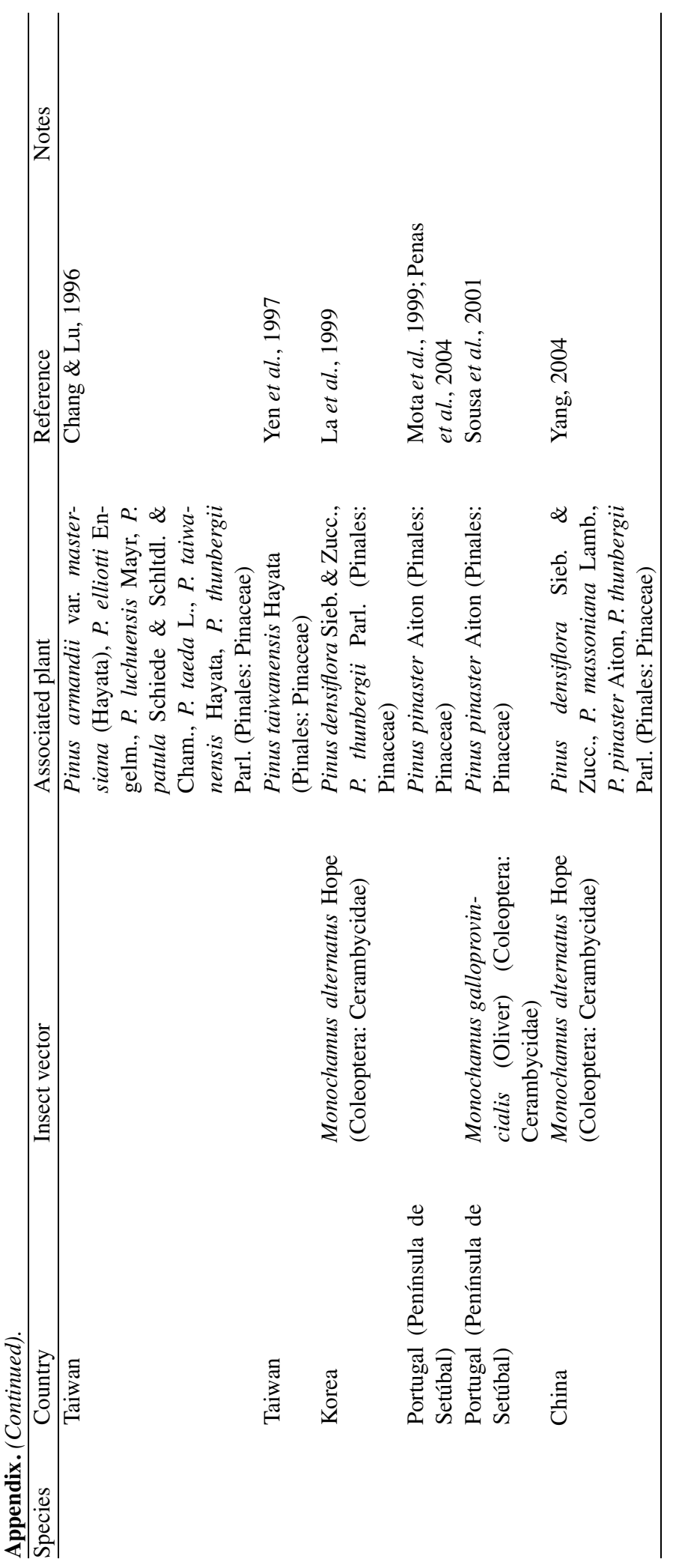

